$4 / 25-95$ \& (2)

ANL/APS/TB-24

\title{
Diamond Monochromators for APS Undulator-A Beamlines
}

by R. C. Blasdell, L. A. Assoufid, and D. M. Mills

September 1995

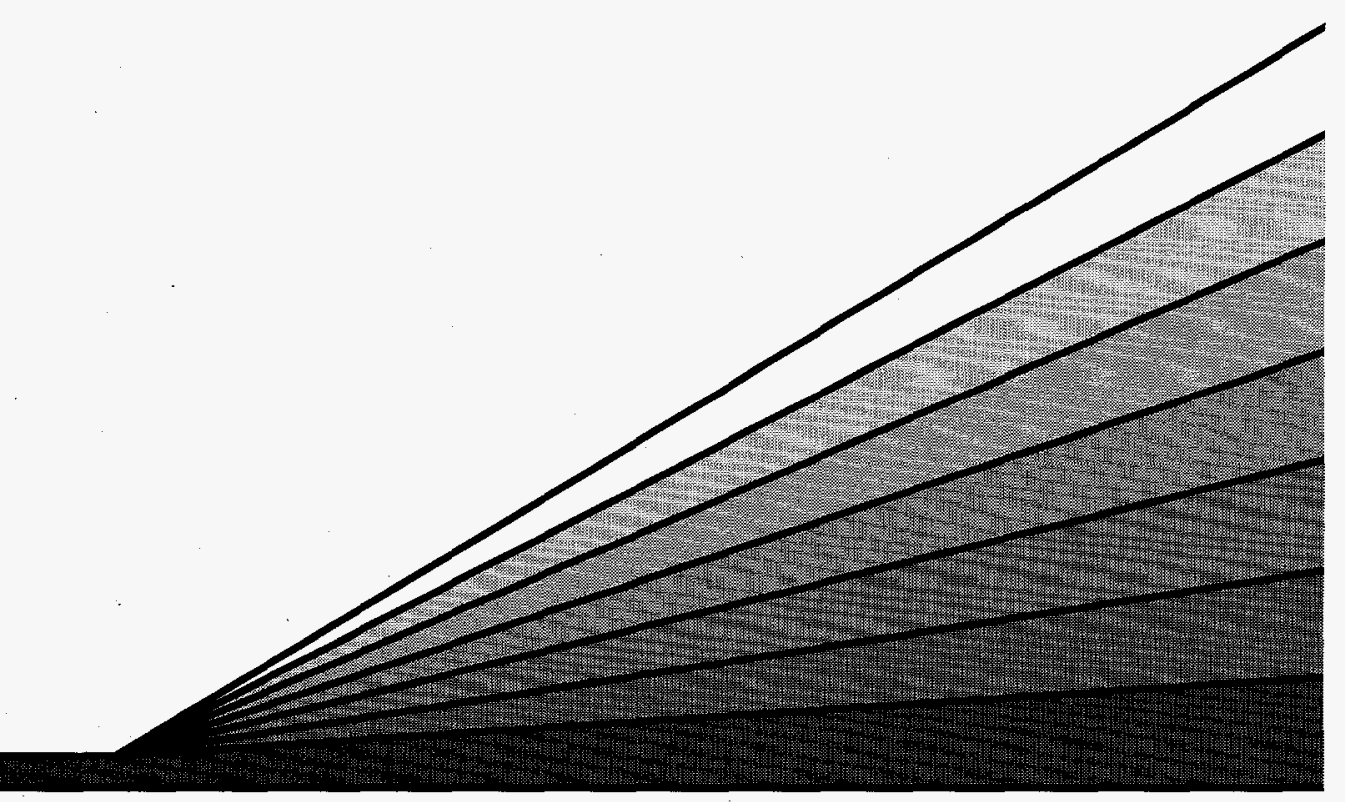


Argonne National Laboratory, with facilities in the states of Illinois and Idaho, is owned by the United States government, and operated by The University of Chicago under the provisions of a contract with the Department of Energy.

\section{DISCLAIMER}

This report was prepared as an account of work sponsored by an agency of the United States Government. Neither the United States Government nor any agency thereof, nor any of their employees, makes any warranty, express or implied, or assumes any legal liability or responsibility for the accuracy, completeness, or usefulness of any information, apparatus, product, or process disclosed, or represents that its use would not infringe privately owned rights. Reference herein to any specific commercial product, process, or service by trade name, trademark, manufacturer, or otherwise, does not necessarily constitute or imply its endorsement, recommendation, or favoring by the United States Government or any agency thereof. The views and opinions of authors expressed herein do not necessarily state or reflect those of the United States Government or any agency thereof.

Reproduced from the best available copy.

Available to DOE and DOE contractors from the

Office of Scientific and Technical Information

P.O. Box 62

Oak Ridge, TN 37831

Prices available from (615) 576-8401

Available to the public from the

National Technical Information Service

U.S. Department of Commerce

5285 Port Royal Road

Springfield, VA 22161

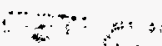




\section{DISCLAIMER}

Portions of this document may be illegible in electronic image products. Images are produced from the best available original document. 


\section{ARGONNE NATIONAL LABORATORY \\ 9700 South Cass Avenue \\ Argonne, Illinois 60439}

ANL/APS/TB-24

Diamond Monochromators for APS

Undulator-A Beamlines

R. C. Blasdell, L. A. Assoufid, and D. M. Mills

Experimental Facilities Division

Advanced Photon Source

September 1995

work sponsored by

U.S. DEPARTMENT OF ENERGY

Office of Energy Research 


\section{TABLE OF CONTENTS}

\section{Chapter}

1. INTRODUCTION

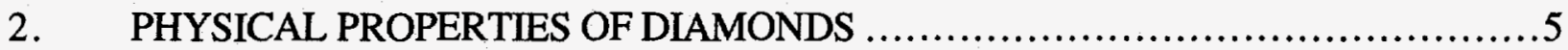

$2.1 \quad$ Varieties of Diamonds ............................................................

2.2 The Lattice Parameter ......................................................

2.3 Bulk Thermal and Mechanical Properties..................................6

$2.4 \quad$ Typical Surface and Lattice Plane Morphology $\ldots \ldots \ldots \ldots \ldots \ldots \ldots \ldots \ldots \ldots \ldots . \ldots \ldots$

2.5 The Liquid-GaIn/Diamond Interface.................................... 10

3. DIFFRACTION PROPERTIES OF DIAMOND ................................. 17

3.1 Reflection Widths and Integrated Reflectivities....................................17

3.2 Reflection Geometry, Cutoff Energies, and Tuning Range ..................27

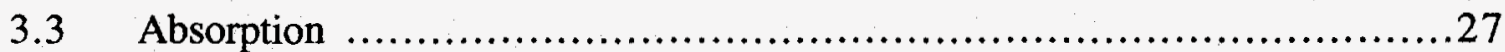

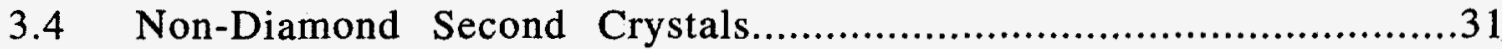

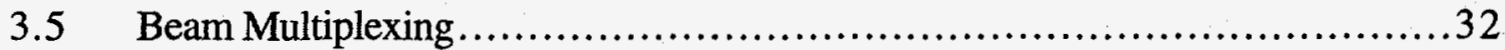

4. THERMAL DESIGN OF DIAMOND MONOCHROMATORS …..................36

$4.1 \quad$ General Design Constraints ..................................................

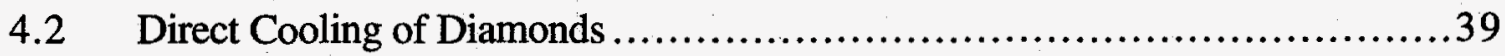

4.3 Operation at Cryogenic Temperatures .......................................39

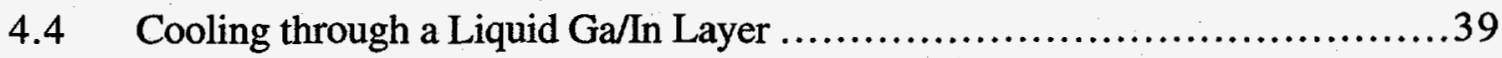

4.5 Finite Element Analysis of a Side-Cooled Diamond .........................41

4.6 Effect of the Vertical Slits .................................................43

5. SUMMARY AND APS RESEARCH PLANS …...............................48

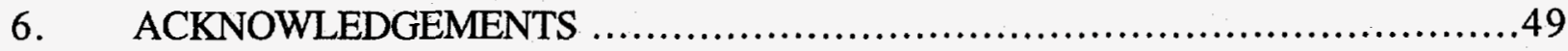

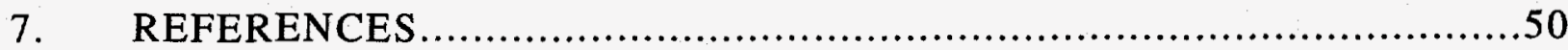

\section{Appendices:}

A. Thermal Properties of Diamond ................................................... 53

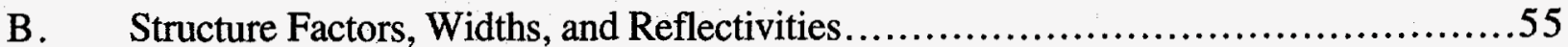

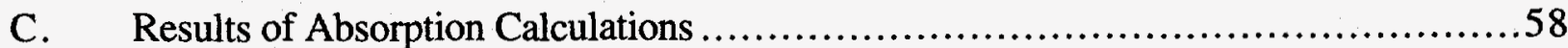


There has been considerable interest in the use of diamonds in high heat load monochromators (HHLMs) in the last several years. ${ }^{1-7}$ The superb thermal and mechanical properties of single crystal diamonds serve to minimize distortions caused by a given thermal load, while the low $\mathrm{x}$-ray absorption cross-section reduces both the total power deposited in the crystal as well as the peak (volumetric) power density. The primary obstacle for the widespread use of diamonds at present is a lack of ready availability of perfect single crystals of the desired size and orientation. Although it is possible to obtain near-perfect natural diamonds of the size and orientation required for use on an undulator beamline (the Darwin widths are a bit larger than desired and the crystals are just big enough to attach to a thermal heat sink), the selection process is generally one of trial and error. Near perfect synthetic diamonds can currently be obtained in the minimum necessary size (typically $4-5 \mathrm{~mm}$ on a side), albeit these are difficult to obtain and are in limited quantities.

A collaborative agreement has been made between the staff of the Advanced Photon Source (APS), the European Synchrotron Radiation Facility (ESRF), and the Super Photon Ring-8 GeV (SPring-8) to explore the use of diamonds as high heat load monochromators is on-going. One of the avenues of research is to push for improved perfection and size of synthetic diamonds. Sumitomo Electric Corporation of Japan has agreed to work with staff from SPring-8 to grow [100] oriented perfect single crystal diamonds of $10 \times 10 \times 1 \mathrm{~mm}^{3}$ size by $1996 / 1997$ (from which one could also cut pieces with the large face parallel to the (111) planes). They have taken the first step in producing an essentially perfect $4 \times 4 \times 1 \mathrm{~mm}^{3}$ type II diamond with less than $5 \mu \operatorname{rad}(1 \operatorname{arc}$ second) strain (measured over the entire surface). ${ }^{8}$ We believe progress in the production of synthetic diamonds, as well as improvement in ties with suppliers of natural diamonds, should make available a relatively large number of high quality diamonds of moderate size within the next several years.

Except at very low energies $(<3 \mathrm{keV})$, a diamond monochromator has a smaller energy bandpass than the equivalent silicon monochromator and so diamonds will probably not be every user's best friend. Nonetheless, one should be careful when making a comparison because it is still not known with certainty whether silicon-based designs will be able to endure the maximum heat loads of the APS and SPring-8 while providing beam on sample without a significant loss of spectral brilliance simply because x-ray beams of such combined spectral brilliance, power density, and total power do not exist yet. While people have been able to examine the throughput of HHLMs subject to high $\mathrm{x}$-ray power loads, little work has been possible to ascertain whether the beam will retain its original phase space volume. 9,10

Table 1.14-7,11 compares the essential results to date of the major high heat load experiments on diamond monochromators and the typical maximum heat loads that would be experienced by a diamond HHLM $30 \mathrm{~m}$ from an APS undulator A. The location of each experiment is given in column 2 , the reference and year of publication are given in columns 1 and 3 , the type and size of the diamond in columns 4 and 5 , and the reflection geometry and cooling and mounting schemes in columns 6 and 7. The absorbed (rather than incident - there can be a considerable difference for diamond) total power and absorbed peak power density are given in columns 8 and 9. The calculated rocking curve widths (including dispersion), low power, and high power rocking curve widths at the x-ray energy indicated in column 10 are given in columns 11-13. Two things are apparent from Table 1.1 -- first, no diamond monochromator has yet been subjected to the total power load expected at the APS and, second, clearly measurable distortions are observed at the highest power loads experienced -- about half that expected at the APS. (It is important to note that the principal problem for diamond HHLMs at the APS will be the total power deposited not the peak power density.) Not explicitly evident from Table 1.1 is the very 
Table 1.1 Survey of diamond HHLM experiments. (See text for description of column headings.)

\begin{tabular}{|c|c|c|c|c|c|c|c|c|c|c|c|c|}
\hline $\begin{array}{l}\text { Year } \\
\text { Publ. } \\
\end{array}$ & Beamline & Refs. & $\begin{array}{c}\text { Diamond } \\
\text { Type } \\
\end{array}$ & $\begin{array}{c}\text { Size } \\
\left(\mathrm{mm}^{3}\right) \\
\end{array}$ & $\begin{array}{l}\text { Geometry, } \\
\text { Reflection } \\
\end{array}$ & $\begin{array}{l}\text { Cooling, } \\
\text { Mounting } \\
\end{array}$ & $\begin{array}{l}P_{a b s} \\
(W) \\
\end{array}$ & $\begin{array}{c}\text { pabs } \\
\left(\mathrm{W} / \mathrm{mm}^{2}\right) \\
\end{array}$ & $\begin{array}{r}\mathrm{E} \\
(\mathrm{keV}) \\
\end{array}$ & $\begin{array}{r}\Delta \theta_{0} \\
(\mu \mathrm{rad}) \\
\end{array}$ & $\begin{array}{c}\Delta \theta \mathrm{P}=0 \\
(\mu \mathrm{rad}) \\
\end{array}$ & $\begin{array}{c}\Delta \theta \operatorname{Pmax} \\
(\mu \mathrm{rad}) \\
\end{array}$ \\
\hline 1993 & NSLS X25 & 5 & $\mathrm{~S},{ }^{12} \mathrm{C}-\mathrm{IIa}$ & $4 \times 4 \times 0.5$ & B $(4,0,0)$ & $\mathrm{RW}, \mathrm{GI}$ & 48 & $132^{*}$ & 22 & 16.0 & 19.4 & 27.5 \\
\hline 1993 & NSLS X25 & 6 & $\mathrm{~S},{ }^{12} \mathrm{C}-\mathrm{IIa}$ & $4 \times 4 \times 0.5$ & $\mathrm{~B}(4,0,0)$ & JW, CL & 40 & $166^{*}$ & 22 & - & 12.6 & $17.5^{\dagger}$ \\
\hline 1993 & ESRF ID6 & 7 & $\mathrm{~N},-$ & 0.25 thick & $\operatorname{AL}(1,1,1)$ & SW, CL? & 4.4 & $1.1^{*}$ & 8 & - & 40 & $54^{\dagger}$ \\
\hline 1993 & ESRF ID 10 & 11 & $\mathbf{N},-$ & 0.202 thick & $\mathrm{AL}(1,1,1)$ & SW, GI & $<26 ?$ & $<4$ ? & 9 & 22.1 & 35.6 & $34.1^{\dagger}$ \\
\hline 1994 & ESRF BL3 & 4 & $\mathrm{~S}, \mathrm{Ib}$ & $4 \times 8 \times 0.109$ & $\operatorname{SL}(2,2,0)$ & SW, GI & 8.7 & $109^{*}$ & 15 & 15.0 & 15.7 & $16.0^{\dagger}$ \\
\hline \multicolumn{2}{|c|}{ Expected, APS UA } & & - & 0.5 thick & $\mathrm{B}(1,1,1)$ & - & 115 & 14 & - & - & - & - \\
\hline$"$ & $"$ & & - & 0.1 thick & $\operatorname{AL}(1,1,1)$ & - & 50 & 7.5 & - & - & - & - \\
\hline
\end{tabular}

* Absorbed peak power density estimated from ratio of absorbed to incident total power.

${ }^{\dagger}$ Power level changed by masking the incident beam, so increased broadening in part due to increased field of view.

$\mathrm{B}=$ Bragg geometry

$\mathrm{AL}=$ Asymmetric Laue geometry

SL $=$ Symmetric Laue geometry

$\mathrm{RW}=$ Rear indirect water cooled

$$
\begin{aligned}
& \mathrm{JW}=\text { Jet direct } \text { water cooled } \\
& \mathrm{SW}=\text { Side indirect water cooled } \\
& \mathrm{CL}=\text { Clamped } \\
& \mathrm{GI}=\text { Floating on GaIn eutectic }
\end{aligned}
$$

$\mathrm{S}=$ Synthetic diamond

$\mathrm{N}=$ Natural diamond

${ }^{12} \mathrm{C}=$ Isotopicaly pure $\left(99.99 \%{ }^{12} \mathrm{C}\right)$ diamond. 
encouraging information that the incident power and peak power density in the 1994 ESRF experiments at BL3 were $280 \mathrm{~W}$ and $3.4 \mathrm{~kW} / \mathrm{mm}^{2}$, respectively. 4

The APS hands-on experience with the use of diamonds as high heat load monochromators has so far been rather limited. A water-jet-cooled diamond monochromator was tested on the APS/CHESS prototype undulator installed on CESR, the Cornell Electron-Position Storage Ring in the fall of 1993. A $6 \times 6 \times 0.3 \mathrm{~mm}^{3}$, [100] oriented, type Ib Sumitomo (Sumicrystal ${ }^{\circledR}$ ) diamond was sealed to a jet-cooling apparatus with RTV silicone, a material known from past experiences to maintain resiliency and strength even when subjected to high doses of $\mathrm{x}$-radiation. A symmetric Si (531) crystal was used as a near-dispersionless second crystal. With a $0.7 \mathrm{~mm} \mathrm{x}$ $1.0 \mathrm{~mm}$ beam incident on the diamond, double-crystal rocking curves of less than 2.5 arc seconds were recorded at $15 \mathrm{keV}$ (nearly independent of incident power from 0 to 15 watts), larger than the expected theoretical value of 0.8 arc seconds. When the beam size was increased to $2 \mathrm{~mm} \times 3 \mathrm{~mm}$ and the stored beam current ramped to $100 \mathrm{~mA}$, the RTV seal gave way under the pressure of the $0.1 \mathrm{MPa}$ (15 psi) water jet. This was probably due to heating of the mount adjacent to the RTV seal by the transmitted x-ray beam resulting in a weakening of the RTV seal. Because of the limited time available for testing during the undulator run, these tests could not be pursued further.

In November of 1994, we had the opportunity to gain more experience when the APS staff participated in an experiment with the ESRF and SPring-8 to explore the performance of cryogenically cooled diamonds on the BL3 (focused wiggler) line at the ESRF. (The details of this experiment are discussed in Section 4.3 of this document.) In addition to the testing of diamonds on synchrotron sources, we have recently commissioned an in-house topography station that can be used to characterize diamond crystals as well as other potential single crystal optical components for users of the APS. One of the first such topographs taken with this instrument is shown in Figure 1.1

Simple theoretical calculations 1,3,12 (and experimental results) suggest that it should be possible to produce a diamond monochromator that can withstand the maximum expected heat load of APS Undulator (operating @ $7 \mathrm{GeV}, 100 \mathrm{~mA}$ storage ring current) and provide approximately half the theoretical bandpass of a Si monochromator while preserving the brilliance of the beam (more details on the thermal calculations can be found in Chapter 4). Clearly diamonds look promising and already several CATs are seriously contemplating the use of a diamond monochromator as a first optical element on an APS undulator beamline. However, the needs of the twenty-odd insertion device beamlines planned for the initial startup of the APS vary considerably - for some diamond may be a good or expedient choice while for others it may not be. Likewise, beam multiplexing (so far accomplished with one Laue geometry crystal - others have yet to be installed) may be advantageous for a few diamond advocates while others will need a double Bragg geometry monochromator. Recognizing this diversity and the early stage of research on diamond monochromators, we do not advance a preferred design (or designs) for a monochromator at this time but instead attempt to provide a reference document that will allow designers not familiar with diamonds to more easily examine the possible advantages and disadvantages of diamond monochromators for their beamline(s). The APS is actively exploring possible diamond monochromator designs and is open to collaboration with CATs on the development of prototype monochromators as well as general issues related to diamond quality and availability.

The first several sections of this document tabulate the general physical characteristics of diamond and diamond monochromators. This is followed by simple analytical and finite element analysis models of diamond monochromators and an overview of the APS R\&D plans for diamond high heat load monochromators. 


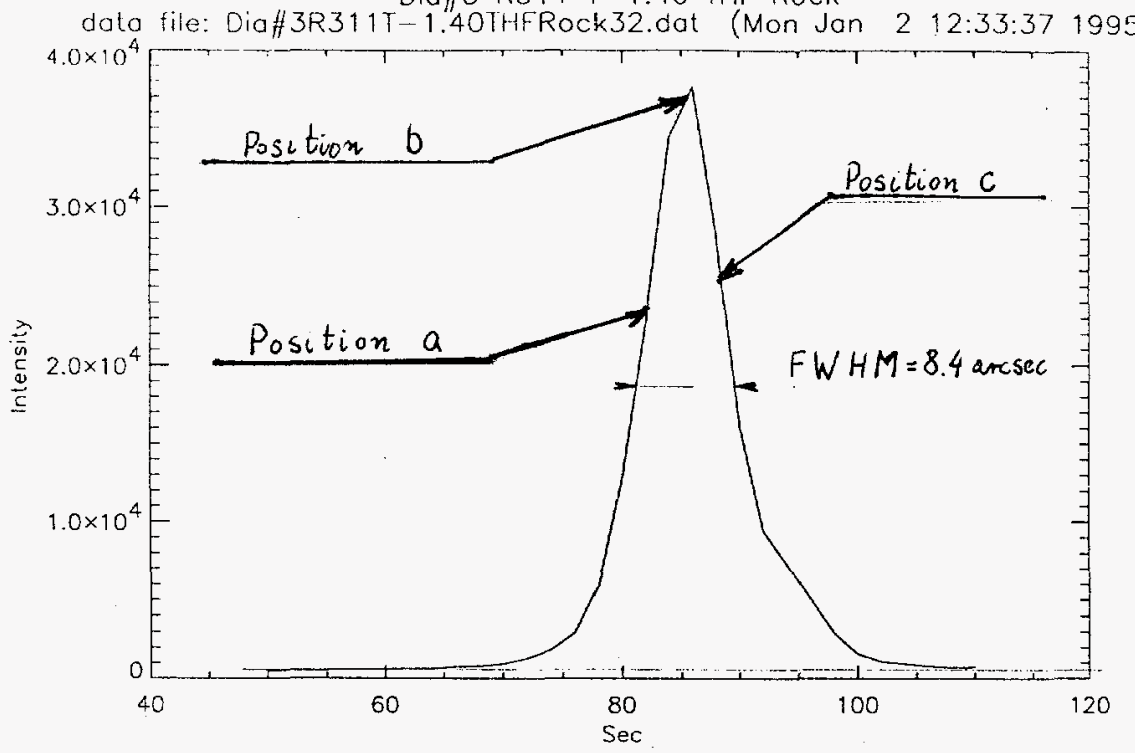

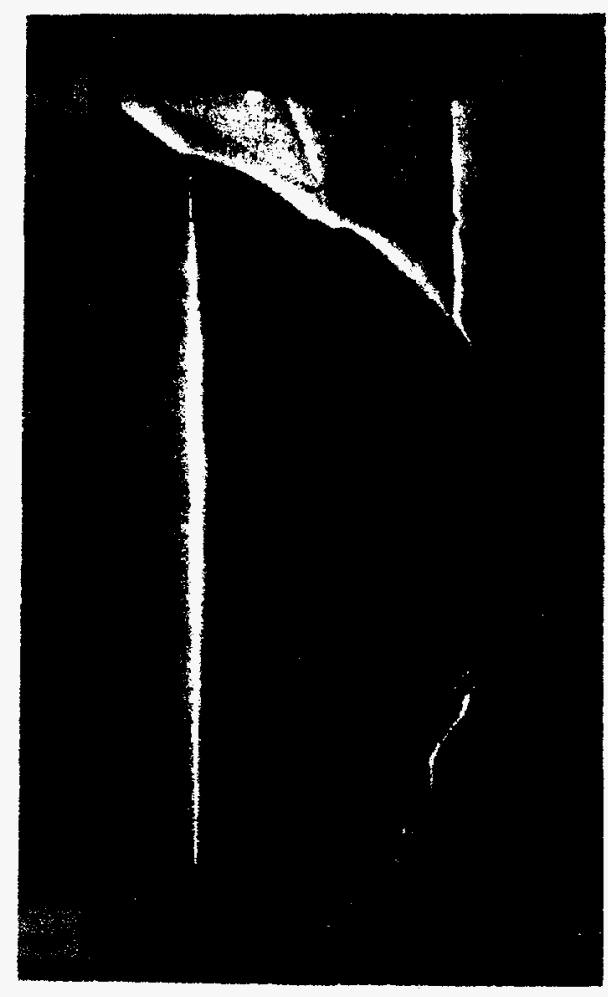

(a)

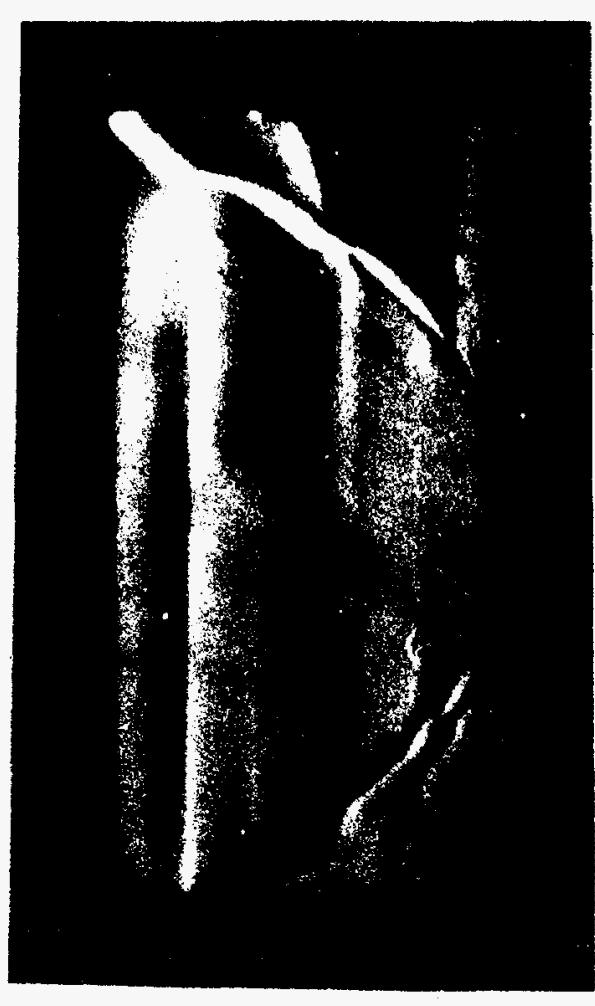

(b)

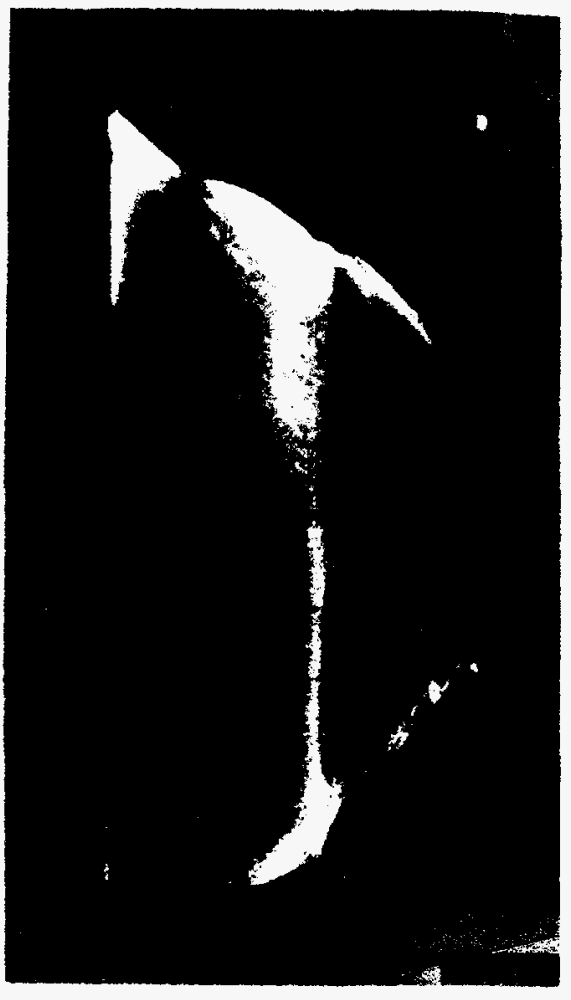

(c)

Figure 1.1 Double crystal topograph of a [111] oriented synthetic diamond from Sumitomo. The diamond (311) reflection was used in the topograph taken with $8 \mathrm{keV}$ radiadtion. An asymmetrically cut silicon (333) crystal served as the collimating monochromator. The size of the diamond was $3 \mathrm{~mm} \times 7 \mathrm{~mm}$. (Diamond courtesy of R. Hewitt, EXXON Corp., topograph taken by Felix Krasnicki, APS). 


\subsection{Varieties of Diamonds}

Diamonds come in a great variety of shapes and sizes, and in general may include substantial amounts of impurities (see, for example, References 13 and 14 for an extended discussion and additional references). Natural diamonds are produced in volcanic vent tubes and may include any impurities characteristic of the magma and surrounding rock; synthetic diamonds are grown at high temperatures and pressures from a solid solution of (typically) graphite and a metal catalyst in the presence of a diamond seed crystal and may, in principle, include any impurities characteristic to the catalyst, gaskets, anvils, air present during assembly, etc. Natural diamonds are generally classified as boart (ground-up, diamond-like material), industrial (crystals of poor quality or purity), and gemstones. Synthetic diamonds are generally classified as polycrystalline diamond (PCD), single crystal diamond (SCD), or diamond-like material (DLM). Uncut single crystals are termed rough. Diamond single crystals are historically classified into types based on their IR and UV optical spectra. The differences in these spectra reflect the differences in the type and concentration of impurities. 13 The types and impurity content are summarized in Table 2.1 .

Table 2.1 Classsifications of Single Crystal Diamond

\begin{tabular}{ccc}
\hline \hline Type & Impurity & Color \\
\hline \hline Ia & $\sim 0.1 \% \mathrm{~N}_{2}$, in aggregates & pale yellow \\
Ib & $<500 \mathrm{ppm} \mathrm{N}_{2}$, substitutional & pale yellow \\
Ila & "none" & clear \\
Ib & Trace B, substitutional & blue white \\
\hline \hline
\end{tabular}

Not included in this older classification scheme is an allowance for growing diamonds with variable ${ }^{13} \mathrm{C}$ content, which can dramatically change the thermal properties. (The natural atomic fraction of ${ }^{13} \mathrm{C}$ is $1.07 \%$.) Type IIa diamonds are those most often considered for use as $\mathrm{X}$-ray monochromators.

Because of the wide range of impurities, diamonds are often quoted as having a rather broad range of values of their physical properties (see for example the appendix of Reference 13, which also appears - essentially verbatim - in the Dubbledee Harris Diamond Corp. publication "Properties of Diamonds"). One should bear in mind that these numbers are meant to reflect the range of values one encounters in good and poor quality gemstones. High quality gemstones (particularly synthetic crystals with a uniform and well characterized impurity content) may have well determined and well measured physical properties.

\subsection{The Lattice Parameter}

As discussed above, natural diamonds show a wide range of impurity content (primarily nitrogen in high X-ray-quality diamonds), and synthetic diamonds can in principle be produced with a range in the value of the ${ }^{13} \mathrm{C}$ to ${ }^{12} \mathrm{C}$ ratio (isotopic purity has been found to improve the 
thermal properties of diamond by as much as 60\%.) As the variations in these quantities and the temperature affect the lattice parameter, $a_{o}$, it is convenient to give here an approximate expression for this dependence:

$$
a_{o} \approx 3.56715 \AA-5.3 \times 10^{-4} \AA \cdot X_{13} c+3.14 \AA \cdot X_{N_{2}}+3.6 \times 10^{-6} \AA \cdot K^{-1} \cdot(T-298 \mathrm{~K}),
$$

where $X_{13}$ (is the atomic fraction of ${ }^{13} \mathrm{C}$ and $\mathbf{X}_{\mathrm{N} 2}$ is the atomic fraction of $\mathrm{N}_{2}$. Here we have simply added the room temperature thermal expansion coefficient 14 and the experimentally measured nitrogen impurity dependence of Kaiser and Bond 15 to the (presumably more accurate)

${ }^{13} \mathrm{C}$ concentration dependent lattice parameter measurements of Holloway et al.. 16 For natural ${ }^{13} \mathrm{C}$ abundance, $\mathrm{T}=298 \mathrm{~K}$, and zero nitrogen, $a_{o}=3.56714 \pm 0.00005 \AA$.

The diamond lattice parameter is smaller than that of silicon or germanium. The consequences of this upon the energy cutoff and monochromator tuning range are discussed in Section 3.2.

\subsection{Bulk Thermal and Mechanical Properties}

The principle thermal and mechanical constants of interest in the design of a monochromator crystal and mount are the thermal conductivity $\boldsymbol{k}$, thermal expansion coefficient $\alpha$, lattice constant $\boldsymbol{a}_{0}$, and the elastic constants, $\mathrm{c}_{\mathrm{ij}}$. We summarize these quantities here for ease of discussion.

Diamond has the best thermal conductivity, from cryogenic temperatures to at least several hundred degrees Kelvin, of any existing material. Because diamond is an electrical insulator (or, at best, type IIb diamond, a semiconductor), the heat is carried principally by the phonons not the electrons. The high thermal conductivity is due to the strength of the diamond covalent bond, which results in a high Debye temperature $\left(2000^{\circ} \mathrm{K}\right)$ and therefore a reduced number of populated phonon modes near and below room temperature. This reduces the phonon-phonon scattering contribution to the thermal resistance. The thermal conductivity is of course very sensitive to phonon impurity scattering and so the nitrogen, boron, and ${ }^{13} \mathrm{C}$ (or ${ }^{12} \mathrm{C}$ concentration for samples enriched in ${ }^{13} \mathrm{C}$ ) can significantly reduce the thermal conductivity. Figure 2.1 shows the average experimental thermal conductivity of type I, type IIa, and type IIb natural isotopic abundance diamond (lines) suggested by ref. 17, as well as some more recent values including one for isotopically pure ${ }^{12} \mathrm{C}$-diamond from ref. 18 . The values of ref. 17 "...are for high-purity, highperfection, water-white diamond and are thought to be accurate to within $10 \%$ of the true values at temperatures above $100 \mathrm{~K}$." The various data are tabulated in Appendix A for convenience.

Three estimates of the thermal expansion coefficient of diamond,

$$
\alpha(T) \equiv \frac{1}{L_{T=0 K}} \frac{\partial L(T)}{\partial T}
$$

are given in Fig. 2.2. The recommended values of ref. 17 (circles in Fig. 2.2 and Table A.2) agree well with the more recent suggested fourth-order polynomial fit,

$$
\alpha \cong \alpha_{0}+\alpha_{1} T+\alpha_{2} T^{2}+\alpha_{3} T^{3}+\alpha_{4} T^{4}
$$




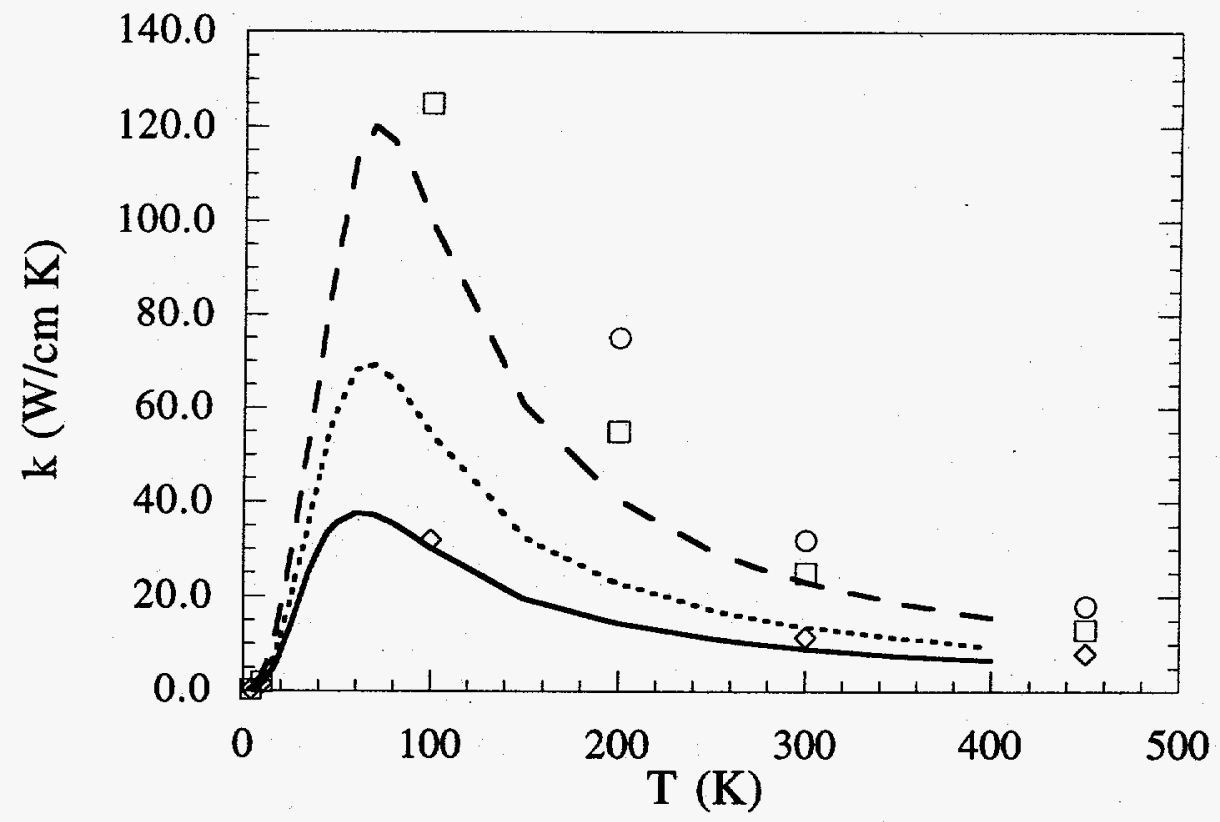

Figure. 2.1. Recommended experimental average of the thermal conductivity (k) of type I (solid), type IIa (dashed), type $\mathrm{Ilb}$ (dotted), natural isotopic abundance diamond as a function of temperature from ref. 17 from 1970. Also shown are recent (1994) experimental values for type Ia (mean value, diamonds), type $\mathrm{IIa}$ (best value, squares), and isotopically pure ${ }^{12} \mathrm{C}$ (circles) diamonds from ref. 18. The values are tabulated in Appendix A. 
of ref. 19 (solid line Fig. 2.2), but disagree with the second order polynomial fit one obtains by differentiating the third order polynomial expression for $\Delta \mathrm{L} / \mathrm{L}_{293} \mathrm{~K}$ in ref. 17 . The coefficients of both fits are given in Table 2.2 .

Table 2.2. Coefficients for polynomial expansions of the linear thermal expansion coefficient of diamond (see eqn. (2.3)).

\begin{tabular}{ccc}
\hline \hline Coefficient & Ref. [17] & Ref. [19] \\
\hline \hline$\alpha_{0}$ & $-5.912 \times 10^{-7}$ & 0.00 \\
$\alpha_{1}\left(\mathrm{~K}^{-1}\right)$ & $+6.641 \times 10^{-9}$ & $+5.05 \times 10^{-10}$ \\
$\alpha_{2}\left(\mathrm{~K}^{-2}\right)$ & $-1.663 \times 10^{-12}$ & $-5.04 \times 10^{-12}$ \\
$\alpha_{3}\left(\mathrm{~K}^{-3}\right)$ & - & $+7.79 \times 10^{-14}$ \\
$\alpha_{4}\left(\mathrm{~K}^{-4}\right)$ & - & $-1.01 \times 10^{-16}$ \\
\hline \hline
\end{tabular}

In order to calculate in detail the deflection of a diamond plate due to mounting strains or direct coolant pressure, it is necessary to know the elastic constants. For rough estimation, only a knowledge of an average Young's modulus is necessary. The experimental elastic moduli and temperature coefficients 20 are given in Table 2.3.

Table 2.3. Elastic moduli and temperature coefficients for diamond.

\begin{tabular}{ccc}
\hline \hline Modulus & $\begin{array}{c}\text { Value } \\
\left(10^{11} \mathrm{~N} / \mathrm{m}^{2}\right)\end{array}$ & $\begin{array}{c}\frac{1}{c} \frac{\partial c}{\partial T} \\
\left(10^{-5} \mathrm{~K}^{-1}\right)\end{array}$ \\
& & $-1.37 \pm 0.2$ \\
& $10.79 \pm 0.05$ & $-5.70 \pm 1.5$ \\
$\mathrm{c}_{11}$ & $1.24 \pm 0.05$ & $-1.25 \pm 0.1$ \\
$\mathrm{c}_{12}$ & $5.78 \pm 0.02$ & $\mathrm{c}_{44}$ \\
\hline \hline
\end{tabular}

Young's modulus along the (111) direction is

$$
E_{11}=\frac{1}{S_{11}}=\frac{\left(c_{11}-c_{12}\right)\left(c_{11}+2 c_{12}\right)}{c_{11}+c_{12}} \cong(10.5 \pm 0.1) \times 10^{11} N^{-2}
$$

and Poisson's ratio is found to vary between 0.1 and 0.29 with an average value of $\bar{v} \approx 0.2 .14$

\subsection{Typical Surface and Lattice Plane Morphology}

Many aspects of the performance of a diamond HHLM are affected by the state of the physical surface of the diamond (to be distinguished from the state of the bulk atomic, or lattice, planes): the thermal boundary resistance depends on the contact surface area; the thermal contact of 


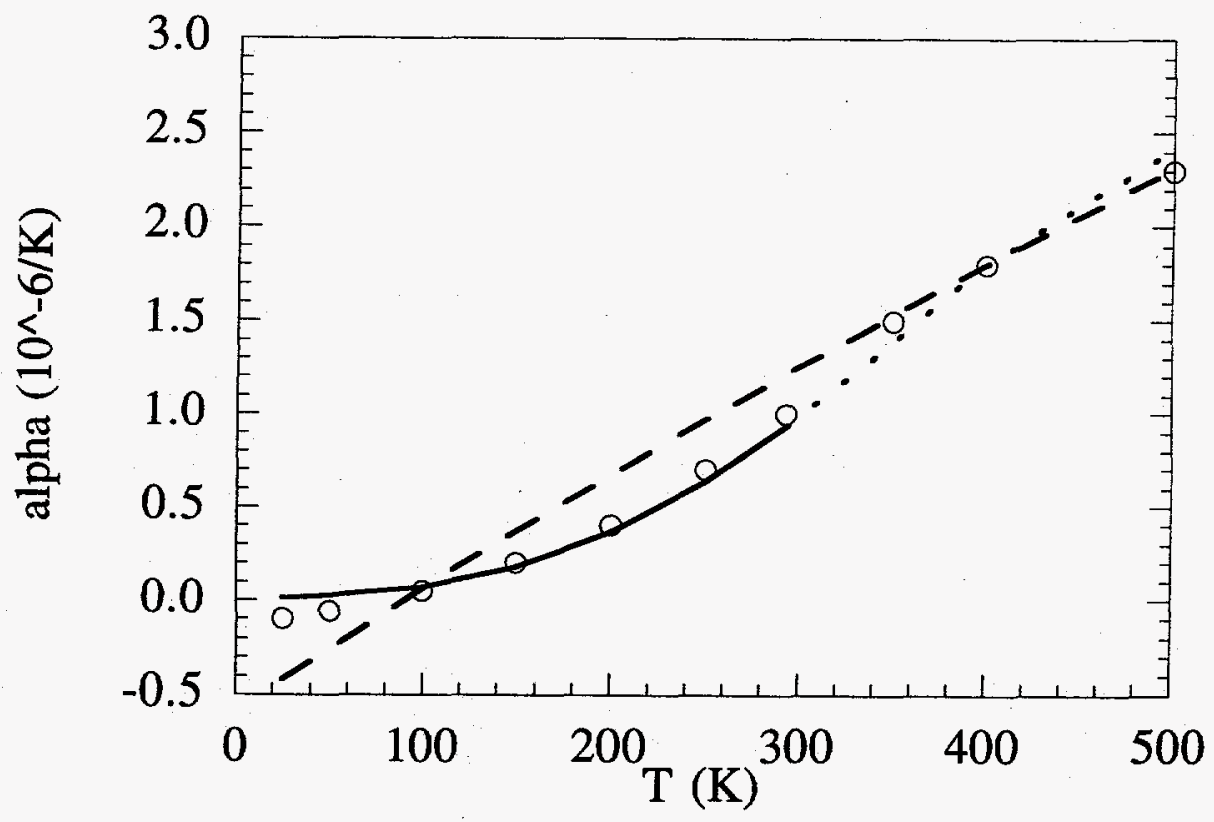

Figure. 2.2. Thermal expansion coefficient, $\alpha$, of diamond as a function of temperature, $T$. Recommended values of ref. 17 (circles) agree well with the more recent suggested 4th-order polynomial fit of ref. 19 (solid line) but disagree with the 2 nd order polynomial fit (dashed) one obtains by differentiating ref. 17 's $3 \mathrm{rd}$ order polynomial expression for $\Delta \mathrm{L} / \mathrm{L}_{293} \mathrm{~K}$. The extrapolation of the 4 th order fit of ref. 19 (dotted) is in reasonable agreement with the data to $500^{\circ}$ $\mathrm{K}$. 
clamped plates depends on the surface roughness; and the deflection of a thin diamond crystal plate is often dominated by strain induced when a cylindrically or spherically cut surface is clamped to a flat cooling block.

The state of the bulk atomic lattice planes also has a direct impact on the diffraction performance of a HHLM as lattice distortions can decrease the reflectivity, increase the energy bandpass, and decrease the brilliance of the $\mathrm{x}$-ray beam. It is convenient for the following discussions to decompose the lattice distortions into d-spacing gradients parallel and perpendicular to the lattice plane of interest (as occurs in nonuniform crystal growth), short- and long-range bowing of the lattice plane (characterized by an overall figure or an rms slope error), and mosaic structure (characterized by an rms mosaic angle spread), which we reserve to denote (in the original sense) comparatively perfect sub-crystals separated by rapid changes in the lattice as at a grain boundary or line defect. Synthetic diamonds generally have a true mosaic spread (as defined above) compared to float-zone silicon crystals, which can have essentially no grain boundaries and very low dislocation densities.

As a preliminary survey of such problems, surface and lattice plane measurements were performed on several diamonds currently in possession of the APS staff. The surface roughness measurements were performed with a WYKO TOPO-3D surface profilometer. Measurements were taken at several regions on the front and back surface of the diamond. The profilometer has a $5 x$ objective that samples a $2.05 \mathrm{~mm} \times 2.05 \mathrm{~mm}$ area with a pixel size of $8 \mu$, and a $40 \mathrm{x}$ objective that samples a $0.256 \mathrm{~mm} \times 0.256 \mathrm{~mm}$ area with a pixel size of $1 \mu$. Lattice plane bowing was examined by measuring the deviation of the center of the diamond (400) double-crystal rocking curve (Si (531) first crystal) as an x-ray beam was rastered across the surface of the diamond. 21 Figure 2.3 shows a typical diamond surface as seen by the WYKO profilometer with the $5 \mathrm{x}$ and $40 \mathrm{x}$ objectives. The surface and lattice plane bowing information is summarized in Table 2.4.

\subsection{The Liquid-GaIn/Diamond Interface}

Achieving a strain- and vibration-free mounting of the first crystal that is also mechanically rigid and provides a good thermal mounting can be a daunting task. Because of the high thermal conductivity of diamond, indirect cooling may be practical. Therefore one solution that has been pursued is to use the surface tension of a thin liquid gallium-indium (GaIn) eutectic to hold the crystal in thermal contact to a cooled copper substrate. (A eutectic of gallium and indium was used to ensure that the liquid metal would remain liquid at room temperatures, which is near the freezing point of pure liquid gallium, and thereby reduce strain in the diamond from differential thermal expansion of the diamond and substrate.) This solution is currently in use on several beamlines at the ESRF. In order to explore the viability of this mounting scheme for the APS, one needs to know several properties of the liquid GaIn - diamond interface at the temperatures that the first crystal is likely to experience. Unfortunately, very little on this subject can be found in the literature.

The first quantity of interest is the thermal boundary heat transfer conductance, $\boldsymbol{h}_{\boldsymbol{b}}$, which characterizes the thermal conductance at the $\mathrm{GaIn} /$ diamond and $\mathrm{GaIn} /$ heatsink interfaces. For an assumed uniform, heat flux, the temperature drop across the interface, $\Delta T$, the heat flux q", and $\boldsymbol{h}_{\boldsymbol{b}}$ are related by the equation

$$
\mathrm{q}^{\prime \prime}=\mathrm{P} / \mathrm{A}=\boldsymbol{h}_{b} \Delta \boldsymbol{T}
$$




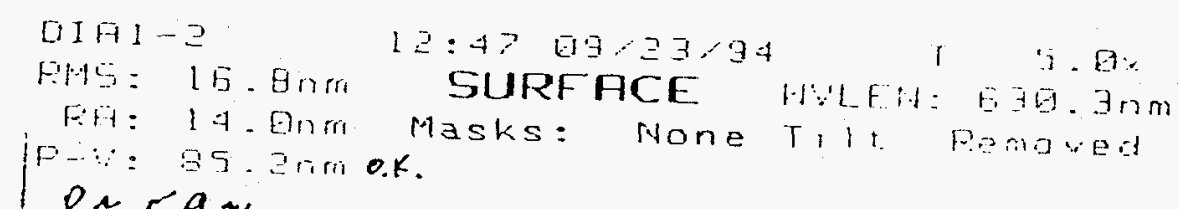

$R \simeq 5.9 \%$
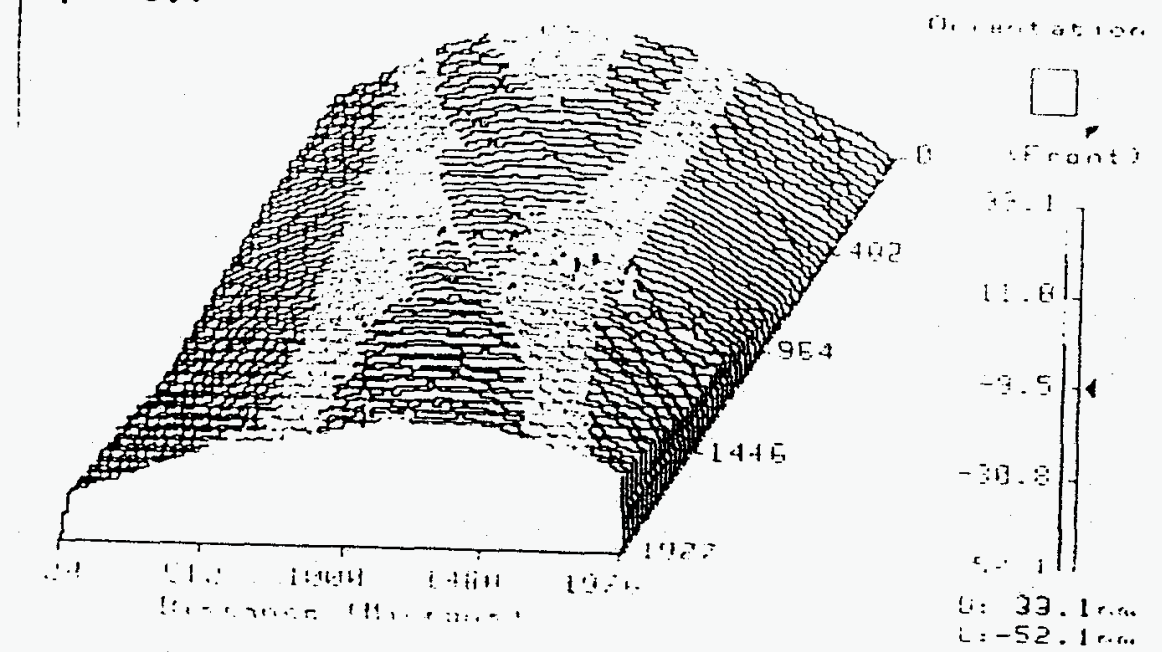

WYKO

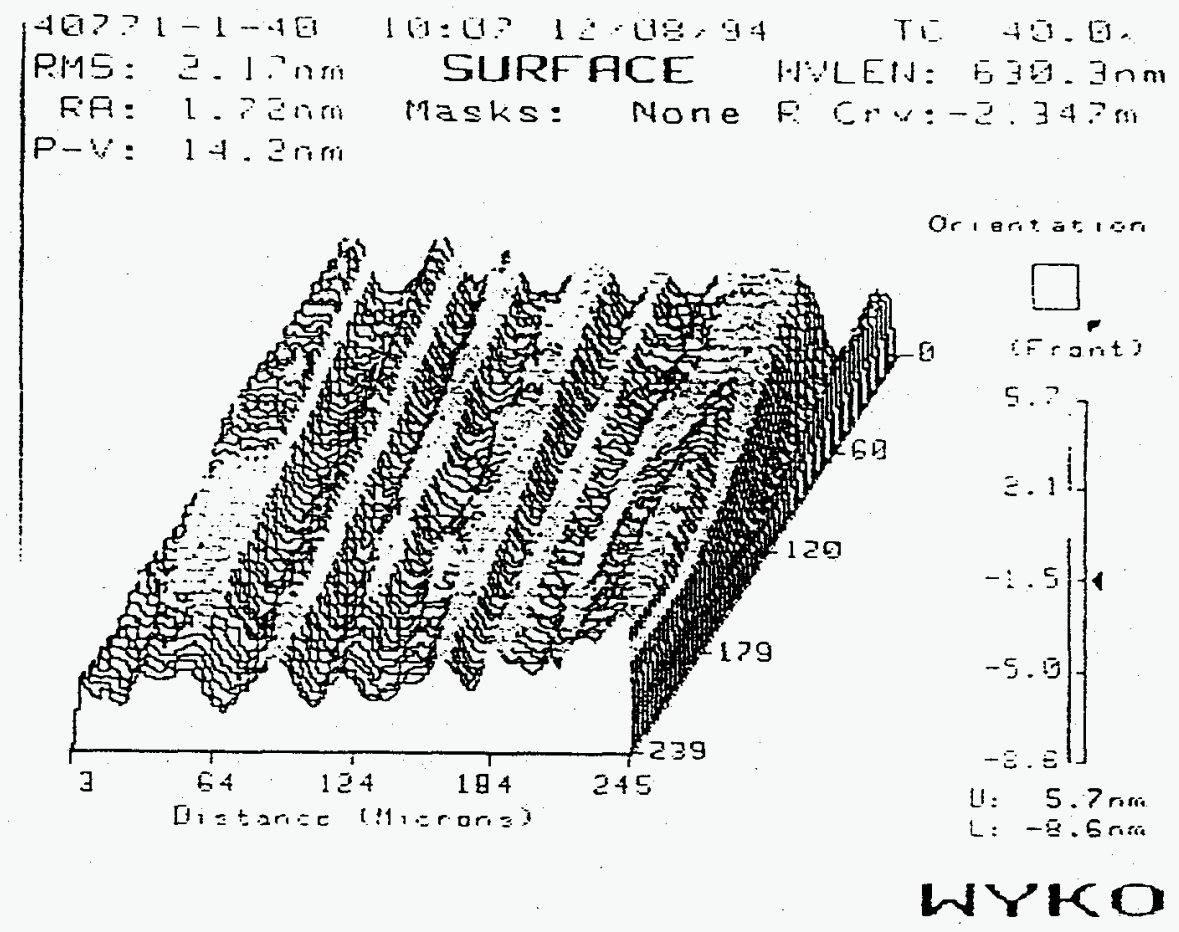

Figure 2.3. Surface of two diamonds as measured by a WYKO model TOPO-3D profilometer with (top) $5 \mathrm{x}$ and (bottom) 40x objectives. The top crystal is a type Ila (100) oriented seed from Sumitomo (courtesy T. Ishikawa, Spring-8), the bottom a type Ib (111) oriented plate from Sumitomo (courtesy of R. Hewitt EXXON Corp). 
Table 2.4. Surface and lattice plane characteristics of several diamonds.

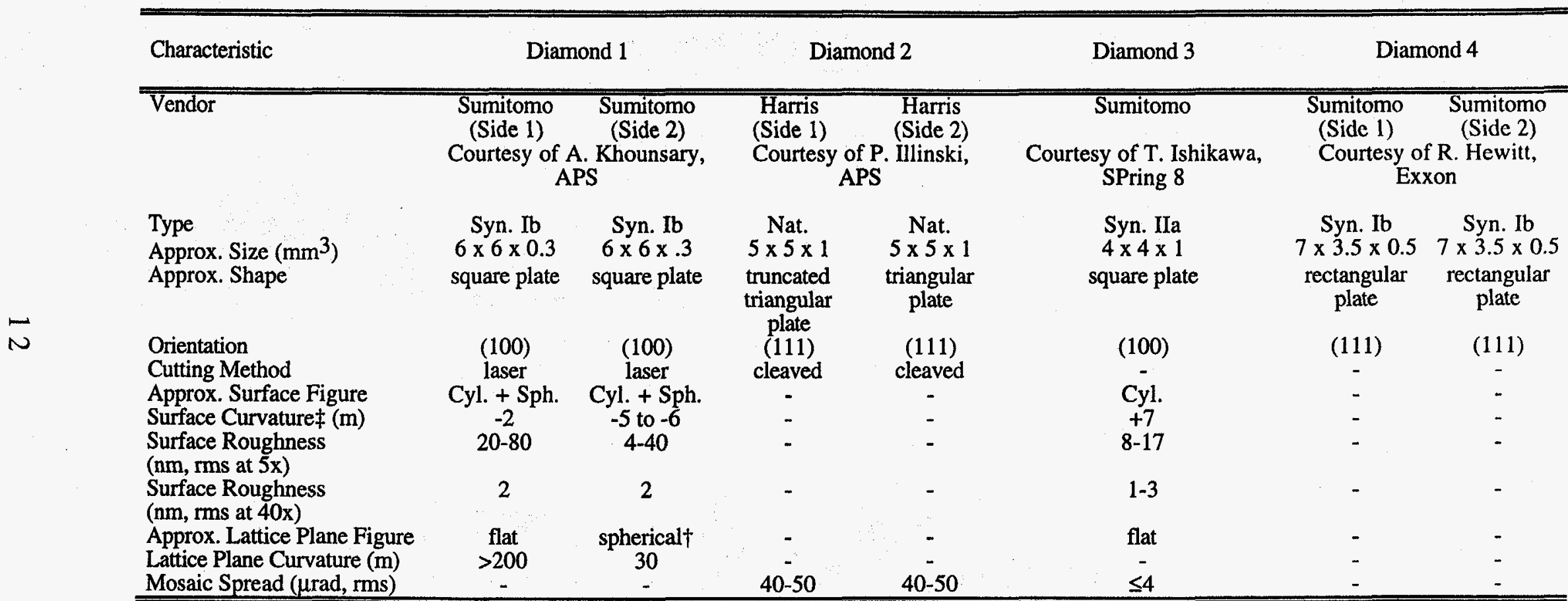

† Lattice plane figure due to mounting of crystal.

$\ddagger$ Positive radii are convex, negative radii are concave. 
Here $\boldsymbol{P}$ is the total power transmitted across the interface of cross sectional area $\boldsymbol{A}$.

To our knowledge, there are no published experimental data on the boundary heat transfer conductance between GaIn and diamond (or for that matter GaIn and copper). In a recent publication, 5 a value for $\boldsymbol{h}_{b}$ of $0.04 \mathrm{~W} / \mathrm{mm}^{2}-\mathrm{K}$ was assumed. This value, the extrapolated zero velocity intercept of Fig. 3 of ref. 22 is not a heat transfer conductance of a static pure $\mathrm{Ga} /$ silicon interface (as suggested) but rather includes the effects of the bulk thermal conduction to the center of the assumed array of $5 \mathrm{~mm} \times 5 \mathrm{~mm}$ square cooling channels.

Although taken out of context when applied to a static, GaIn/diamond, planar-geometry interface, indirect experimental evidence indicates that this number may be close to the true value. 23 As has been pointed out by Hart, 24 a value of $h_{b}$ of $0.04 \mathrm{~W} / \mathrm{mm}^{2}-\mathrm{K}$ would lead to sizeable temperature gradients $\left(\approx 100^{\circ} \mathrm{C}\right.$ ) under the maximum heat load of APS undulator A. We have thus begun an effort to measure this important quantity.

In order to obtain preliminary measurements in a timely fashion, the prototype split bar measuring device of Fig. 2.4 was constructed. Two $25.4 \mathrm{~mm}$ diameter copper rods were machined down to a $6 \mathrm{~mm}$ diameter over a $70 \mathrm{~mm}$ length, and the ends were machined to slip fit into a $25.4 \mathrm{~mm}$ O.D. stainless steel alignment tube $(1.0 \mathrm{~mm}$-thick wall). The mating ends of the copper rods were machined flat. Three $0.9 \mathrm{~mm}$ diameter holes were drilled $20 \mathrm{~mm}$ apart in the conduction rods to accommodate the stainless steel clad thermocouple probes. A $250 \mathrm{~W}$ heater strap was wound around the top of the device during operation. A variable transformer was used to adjust the electrical power. It is desirable to place such devices in vacuum, but, in order to obtain preliminary results quickly, the device was wrapped with an insulating glass-fiber blanket. This blanket and the stainless alignment tube reduce convective and radiative heat losses.

The heat transfer coefficient is measured (see left side of Fig. 2.4) by producing a linear heat flow through the gap between the rods. The heat flux is calculated from the measured temperature drop across the known distance between each thermocouple in the top and bottom rods. By assuming a linear (or other model) heat drop in the rods, one can estimate the temperature drop across the gap. Subtracting temperature drops due to previously measured interfaces and bulk conductances, one can obtain an estimate of the temperature drop across the interface of interest. Dividing the heat flux by this number yields the boundary heat transfer conductance, $\boldsymbol{h}_{\boldsymbol{b}}$.

Initially pure liquid gallium was coated on the ends of the copper conduction rods. In order to get the gallium to wet the copper, it was necessary to sand and heat the surface. The device was assembled with liquid gallium filling the $0.080 \mathrm{~mm}$ gap between the rods, and the heat transfer coefficient was measured (see Table 2.5). Next, diamonds were put in the device and measured. Again it was important to clean and heat the surface while scrubbing the gallium in with the wooden end of a cotton swab. To ensure that the thermocouples gave the same reading at a given temperature, they were all immersed in ice water and then boiling water after the experiment was completed. The results of the measurements are given in Table 2.5 . In all cases, the inferred temperature drops are only a couple of degrees or less and may be significantly affected by the assumed temperature independence of the copper thermal conductivity as well as other systematic errors. The quoted numbers should therefore be taken as preliminary, order-of-magnitude estimates. Preparations are now underway to perform a more precise measurement under a vacuum environment. 


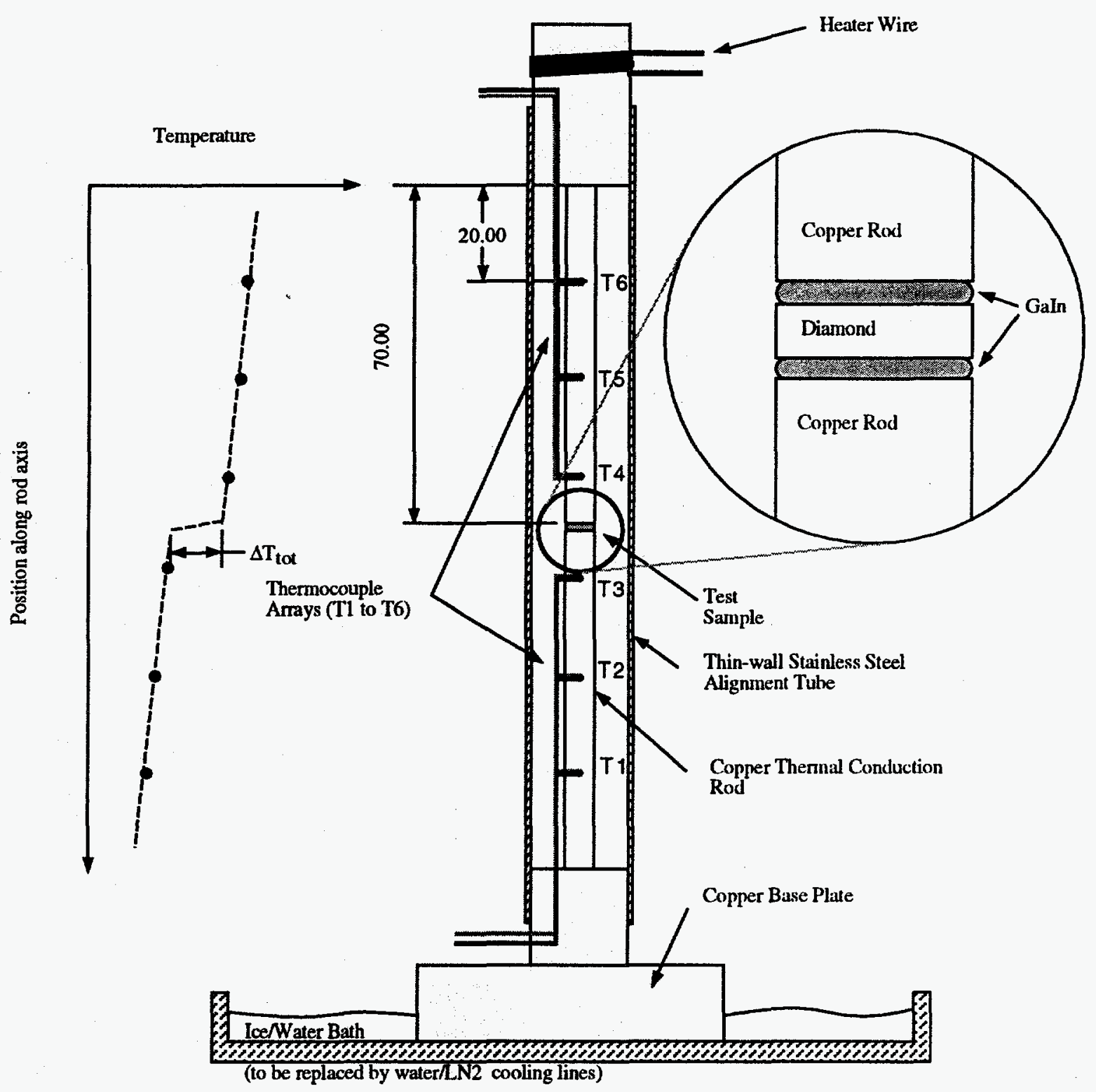

Figure. 2.4. Split bar device used to measure the liquid GaIn/diamond boundary heat transfer conductance, $\boldsymbol{h}_{\boldsymbol{b}}$. A large temperature gradient $\left(150-200^{\circ} \mathrm{C}\right)$ is placed across the two bars and the temperature drop across the gap is inferred from the temperature drop along each bar. The (assumed linear) heat flux across the gap divided by the inferred temperature drop across the interface yields an estimate of the heat transfer coefficient, $\boldsymbol{h}_{\boldsymbol{b}}$. 
Table 2.5. Results of boundary heat transfer conductance measurements. $T_{6}$ and $T_{1}$ are temperature readings by the thermocouples $T_{6}$ and $T_{1}$ (see Fig. 2.4), $\mathrm{Q}^{\prime}$ is the heat flux at the interface, $\Delta \mathrm{T}_{\text {tot }}$ is the temperature drop across the entire joint, $\mathrm{T}_{\mathrm{joint}}$ is the approximate temperature at the center of the joint (taken equal to $\left.\left(\mathrm{T}_{6}+\mathrm{T}_{1}\right) / 2\right), \Delta \mathrm{T}_{\mathrm{b}}$ and $\mathrm{h}_{\mathrm{b}}$ are, respectively, the temperature drop and the heat conductance at the interfaces $\mathrm{Cu}-\mathrm{Cu}$ or diamond-Cu with a Ga layer as a heat transfer medium (here $\Delta \mathrm{T}_{\mathrm{b}}$ is equal to $\Delta \mathrm{T}_{\text {tot }}$ minus the contributions of diamond, when present).

\begin{tabular}{|c|l|c|c|c|c||c|c|c|}
\hline \hline $\begin{array}{c}\text { Expt. } \\
\mathbf{N}^{\circ}\end{array}$ & \multicolumn{1}{|c|}{ Total Heat Path } & $\begin{array}{c}\mathbf{Q}^{\prime \prime} \\
\left(\mathbf{W} / \mathbf{m m}^{2}\right)\end{array}$ & $\begin{array}{c}\mathbf{T}_{\mathbf{6}}-\mathbf{T}_{\mathbf{1}} \\
\left({ }^{\circ} \mathbf{C}\right)\end{array}$ & $\begin{array}{c}\mathbf{T}_{\mathbf{j o i n t}} \\
\left.{ }^{\circ} \mathbf{C}\right)\end{array}$ & $\begin{array}{c}\Delta \mathbf{T}_{\text {tot }} \\
\left({ }^{\circ} \mathbf{C}\right)\end{array}$ & $\begin{array}{c}\text { Measured } \\
\text { Interface }\end{array}$ & $\begin{array}{c}\Delta \mathbf{T}_{\mathbf{b}} \\
\left({ }^{\circ} \mathbf{C}\right)\end{array}$ & $\begin{array}{c}\mathbf{h}_{\mathbf{b}} \\
\left(\mathbf{W} / \mathbf{m m}^{2}-{ }^{\circ} \mathbf{C}\right)\end{array}$ \\
\hline \hline 1 & $\begin{array}{l}\text { Cu-Ga-Cu } \\
\text { (OFHC copper) }\end{array}$ & 0.49 & $186.4-61.1$ & 124 & 1.4 & $\mathrm{Cu}-\mathrm{Ga}-\mathrm{Cu}$ & 1.4 & $0.35^{*}$ \\
\hline 2 & $\begin{array}{l}\text { Cu-Ga-Diam-Ga-Cu } \\
\text { (Diamond Ilb, 0.3-mm thick) }\end{array}$ & 0.5 & $187.1-58.9$ & 123 & 3.3 & Diam-Ga-Cu & 1.6 & 0.31 \\
\hline 3 & $\begin{array}{l}\text { Cu-Ga-Diam-Ga-Cu } \\
\text { (Diamond IIa, 0.5 mm-thick) }\end{array}$ & 0.95 & $198.2-88$ & 143 & 4.5 & Diam-Ga-Cu & 1.9 & 0.50 \\
\hline
\end{tabular}

* Note that there is a gap, $0.08 \mathrm{~mm}$ wide, between the tips of the OFHC Cu rods (see text), and this gap is filled with liquid gallium. Therefore this number includes the contribution of conduction through the gallium thickness. 
If liquid metals for thermal contact are to be used, the corrosion rates of diamond and copper in liquid $\mathrm{Ga}$ or GaIn eutectic could be important parameters. Again, little quantitative information is available, and so we have begun a series of measurements. The results of the initial measurements indicate that diamond is not quickly desolved by liquid $\mathrm{Ga}$ even at $250^{\circ} \mathrm{C}$. Optical measurements of a diamond surface after 2 and 6 hour exposures to pure liquid $\mathrm{Ga}$ at $250 \pm 20^{\circ} \mathrm{C}$ seemed to indicate pitting of the diamond surface at a rate of approximately $50 \mathrm{~nm} / \mathrm{hr}$ in localized spots, but cleaning of the surface followed by a third optical measurement found the pits to have disappeared. 25 At present, the situation has not been sorted out and simply requires systematic study. 


\section{DIFFRACTION PROPERTIES OF DIAMOND}

In order to better understand the possibilities and limits of proposed diamond HHLM designs, it is useful to recall and examine some of the basic absorption and diffraction properties of diamonds compared to silicon for typical APS Undulator beams.

\subsection{Reflection Widths and Integrated Reflectivities}

\subsubsection{The Bragg Geometry}

The angular range over which the reflection curve is near unity is called the Darwin width and, for zero absorption, is given by:

$$
\omega_{D}=2 r_{e} F(h k l) \lambda^{2} / \pi \mathrm{V} \sin (2 \Theta),
$$

where $r_{e}$ is the classical electron radius, $F(h k l)$ the structure factor for the $\mathrm{hkl}$ reflection, $\lambda$ the wavelength, $V$ the volume of the unit cell, and $\Theta$ the Bragg angle. Figure 3.1 shows the Darwin width of several low-order symmetric reflections of diamond, silicon, and germanium along with the vertical opening angle of APS insertion devices and bend magnet sources for comparison. Fig. 3.2 shows the corresponding Darwin energy width

$$
\Delta \mathrm{E}_{\mathrm{D}}=\omega_{\mathrm{D}} \mathrm{E} \cot (\Theta)
$$

as a function of energy.

The width of the reflectivity curve can also be expressed in terms of temperature variation, i.e., $\Delta \mathrm{TD}=\omega_{\mathrm{D}} /(\alpha \tan \Theta)$, where $\alpha$ is the coefficient of thermal expansion. This is an indication of the temperature difference that can be tolerated across the face of the crystal transverse to the beam direction and still diffract from the second (similar) crystal of a double-crystal monochromator. When the expression for the Darwin width is substituted in the expression above, it can be seen that this width, when expressed in terms of temperature, is independent of $\mathrm{x}$-ray energy for a given reflection:

$$
\begin{aligned}
\Delta \mathrm{TD}_{\mathrm{D}} & =[-1 / \alpha]\left[4 \mathrm{r}_{\mathrm{e}} \mathrm{F}(\mathrm{hkl}) \mathrm{d}^{2} / \pi \mathrm{V}\right] \\
& =[-1 / \alpha]\left[4 \mathrm{re}_{\mathrm{e}} \mathrm{F}(\mathrm{hkl}) / \pi \mathrm{a}_{\mathrm{o}}\left(\mathrm{h}^{2}+\mathrm{k}^{2}+\mathrm{l}^{2}\right)\right] .
\end{aligned}
$$

Table 3.1 shows the energy and temperature Darwin widths for the low order $\mathrm{Si}, \mathrm{Ge}$, and diamond reflections. The linear thermal expansion coefficients used were $1.0 \times 10^{-6}{ }^{\circ} \mathrm{C}^{-1}$ (@293 ${ }^{\circ} \mathrm{K}$ ) for diamond and $2.6 \times 10^{-6}{ }^{\circ} \mathrm{C}^{-1}$ (@293K) for silicon. 17 


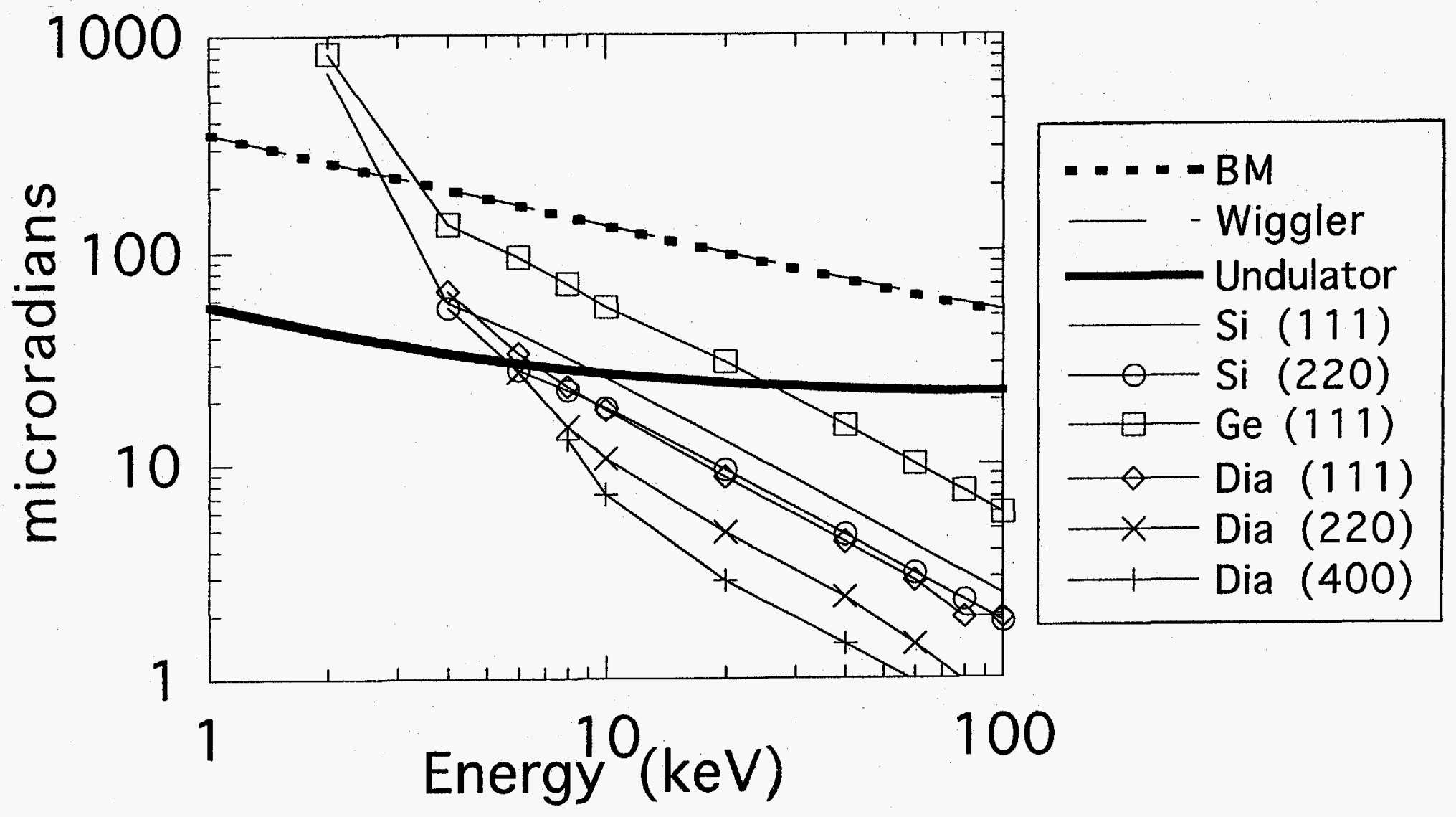

Figure 3.1 The Darwin widths of several diamond, silicon, and germanium reflections are plotted as a function of energy. Also plotted is the FWHM opening angles of the bending magnet, wiggler and undulator beams. 


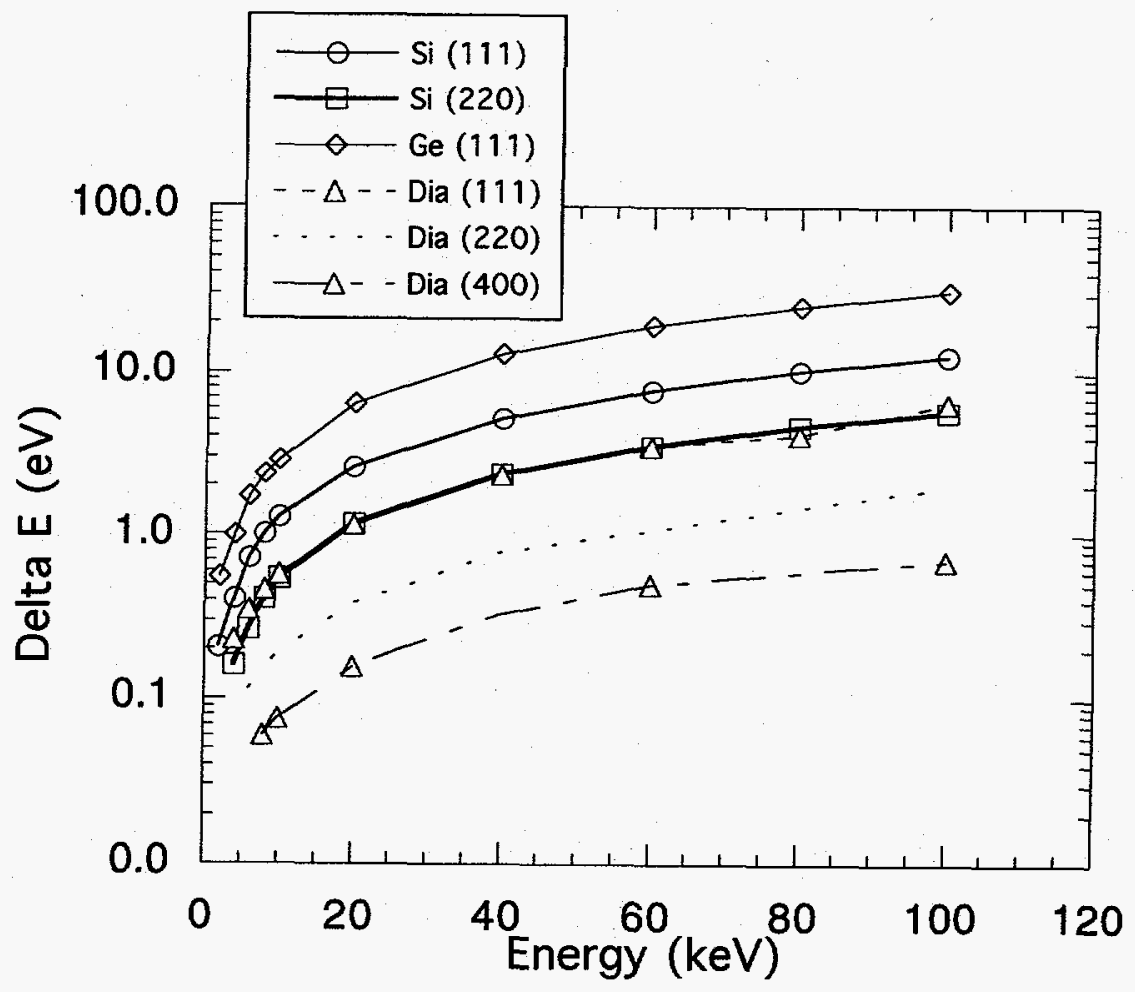

Figure 3.2. Energy widths of several diamond, germanium, and silicon reflections as a function of energy. 
Table 3.1. Bragg geometry reflection widths and integrated reflectivities of several diamond and silicon reflections at $10 \mathrm{keV}$.

\begin{tabular}{|c|c|c|c|c|c|}
\hline Reflection & $\begin{array}{l}\Delta \mathrm{T}_{\mathrm{D}} \\
\left({ }^{\circ} \mathrm{C}\right) \\
\end{array}$ & $\begin{array}{l}\Delta \mathrm{E}_{\mathrm{D}} / \mathrm{E} \\
\left(\times 10^{-6}\right) \\
\end{array}$ & $\begin{array}{c}\int \mathrm{R}(\mathrm{E}) \mathrm{dE} \\
(\mathrm{eV}) \\
\end{array}$ & $\begin{array}{c}\int \mathrm{R}^{2}(\mathrm{E}) \mathrm{dE} \\
(\mathrm{eV}) \\
\end{array}$ & Ratio \\
\hline Diam (111) & 59 & 62 & 0.809 & 0.635 & 0.51 \\
\hline Diam (220) & 20 & 19 & 0.24 & 0.199 & 0.16 \\
\hline Diam (400) & 8 & 7 & 0.093 & 0.077 & 0.063 \\
\hline $\operatorname{Si~(111)~}$ & 59 & 133 & 1.629 & 1.236 & 1.00 \\
\hline $\mathrm{Si}(220)$ & 25 & 56 & 0.685 & 0.531 & 0.43 \\
\hline $\mathrm{Si}(400)$ & 11 & 25 & 0.278 & 0.212 & 0.17 \\
\hline
\end{tabular}

Ignoring mosaic spread and strain, the throughput of a single-crystal monochromator should (to a very good approximation) be proportional to the integral of the dynamical diffraction reflectivity curve $R(E)$, which includes the non-negligible effects of absorption:

$$
1 \text { Crystal Throughput } \propto \int \mathrm{R}(\mathrm{E}) \mathrm{dE} \text {. }
$$

Likewise the throughput of a double-crystal monochromator (with the same first and second crystals) should be proportional to the integral of the square of the reflectivity curve:

$$
2 \text { Crystal Throughput } \propto \int R^{2}(E) d E .
$$

Table 3.1 shows the Bragg geometry integrated reflectivity and integrated square reflectivity at 10 $\mathrm{keV}$. The last column gives the ratio of the integrals of the square reflectivity of each entry relative to that for $\mathrm{Si}$ (111). Note that the energy integrated reflectivity of the diamond (111) reflection is a factor of 2 less than the $\mathrm{Si}$ (111) reflection and produces a significant loss of usable flux on sample as compared with silicon. The losses for the higher $\mathrm{Q}$ diamond reflections are, for most, unacceptable, and therefore the remainder of this document focuses primarily on monochromators using the diamond (111) reflection even though, as mentioned earlier, [100] oriented diamond plates are the most readily available.

The integral of the reflectivity curve and of the square of the reflectivity curve for the diamond (111) and silicon (111) reflection are shown in Figure 3.3. The ratio of the integral of the diamond (111) reflectivity curve to the integral of the silicon (111) reflectivity curve and the ratio of the integral of the square of the diamond (111) reflectivity curve to the integral of the square of the silicon (111) reflectivity curve are shown in Figure 3.4. The structure factor information used in the above calculations is summarized in Appendix B. 


\section{Integrated Reflectivities of Diamond and Silicon}

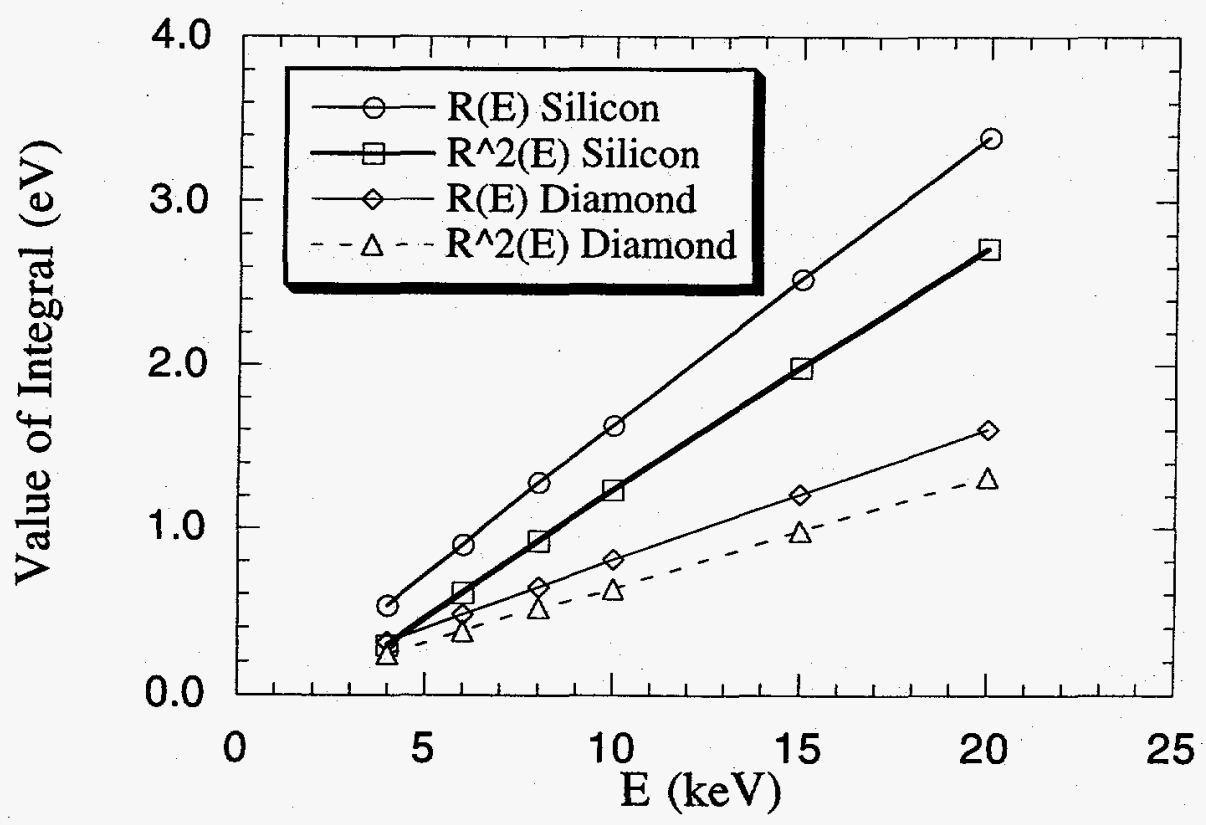

Figure 3.3. Integrated, Bragg geometry, one crystal $[\boldsymbol{R}(\boldsymbol{E})]$ and two-crystal $\left[\boldsymbol{R}^{2}(\boldsymbol{E})\right]$ energy reflectivity curves for diamond (111) and silicon (111). 


\section{Ratio of Diamond Integrated Reflectivity Relative to that of Silicon}

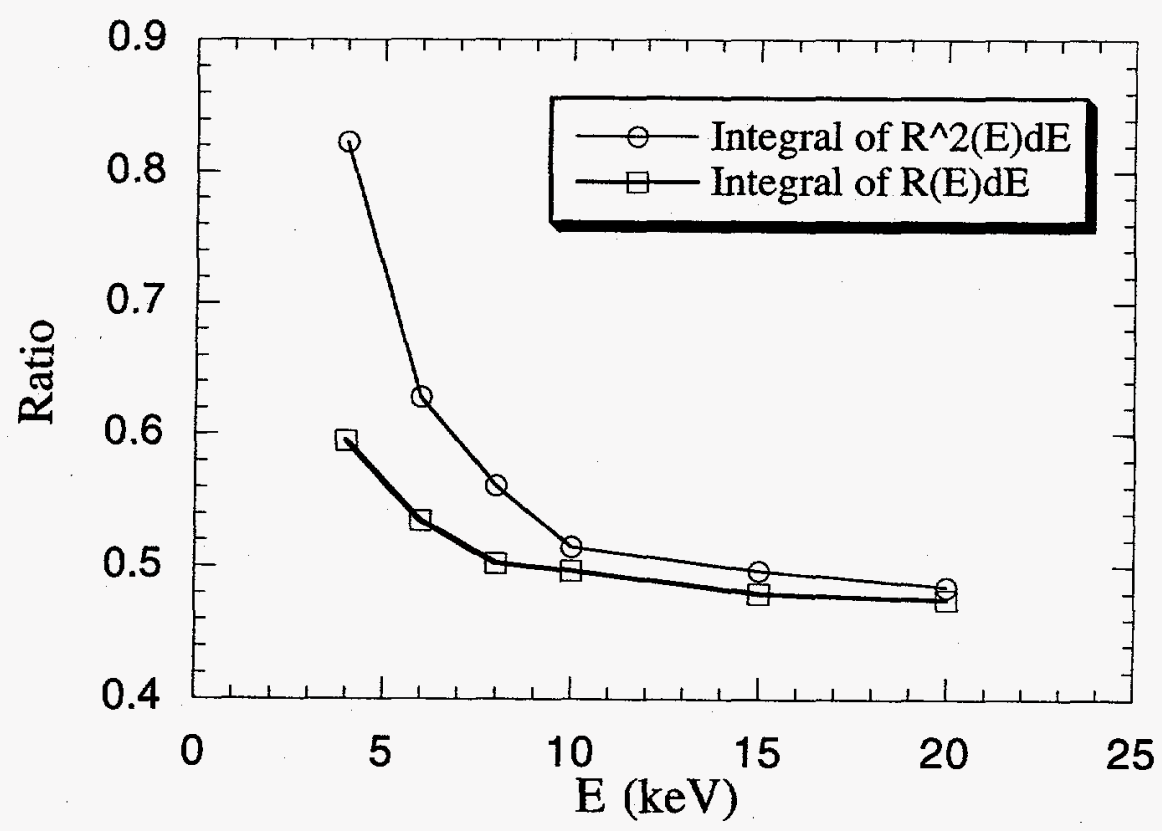

Figure 3.4 Ratios of single and double crystal diamond (111) reflectivity to silicon (111) reflectivity. 


\subsubsection{The Laue Geometry}

Diamond plates whose large face is parallel to the (400) planes can be used in a Laue or transmission geometry to diffract from the (111) planes. The geometry of this arrangement is shown in Figure 3.5 with the angle between the (100) planes and (111) planes equal to $54.74^{\circ}$. This means that the reflection from the (111) planes will be asymmetric and that Eqn. (3.1) for the Darwin width must be modified with the inclusion of the asymmetry parameter, $b$, given by 26,27 :

$$
\mathrm{b}=\mathbf{n} \cdot \mathbf{s}_{\mathrm{O}} / \mathbf{n} \cdot \mathbf{s}_{\mathrm{H}},
$$

where $\mathbf{n}$ is the unit normal of the incident surface, and $\mathbf{s}_{\mathrm{O}}$ and $\mathbf{s}_{\mathrm{H}}$ are unit vectors in the incident and scattered beam directions. The Darwin width for an asymmetric reflections is given by:

$$
\omega_{\mathrm{D}} \text { asy }=\omega_{\mathrm{D}} / \sqrt{\mathrm{b}}
$$

A corollary to this is that the size of the beam also changes when asymmetric crystals are used.

$$
\Delta \mathrm{y}^{\mathrm{asy}}=\{\sqrt{\mathrm{b}}\} \Delta \mathrm{y}
$$

where $\Delta \mathrm{Y}$ is the size of the incident beam. Depending on the arrangement of the crystal with respect to the incident beam, the asymmetry can be used to increase the input acceptance or to narrow the physical size of the outgoing beam (if only a single Laue reflection is used) as has been done at the Troika beamline at the ESRF. The primary disadvantage of the Laue geometry is that, except for very thin crystals, the diffracted beam power is shared equally between the two exit beams, the so-called diffracted and forward diffracted beams. This loss could be made up through increased acceptance when the asymmetry parameter, $b$, could be made smaller than 0.25 . As can be seen from Figure 3.6, only over a very small energy range can $b$ be made less than 0.25 .

Figure 3.6 shows the asymmetry parameter versus energy for the diamond (111) reflection and the various asymmetry angles that naturally occur with a (100) or (110) oriented diamond in Laue and Bragg geometry. At small grazing incidence or exit angles, the crystal surface has to be extremely flat to retain good reflectivity. Because of this fact (and matching of first and second crystals if a two-crystal device is to be used), the monochromator design becomes very problematic for $b$ values with

$$
|b|<\frac{1}{10} \text {, or } 10<|b|
$$

Figure 3.7 summarizes the effects of the various geometries on the beam size, divergence, and transmission. 


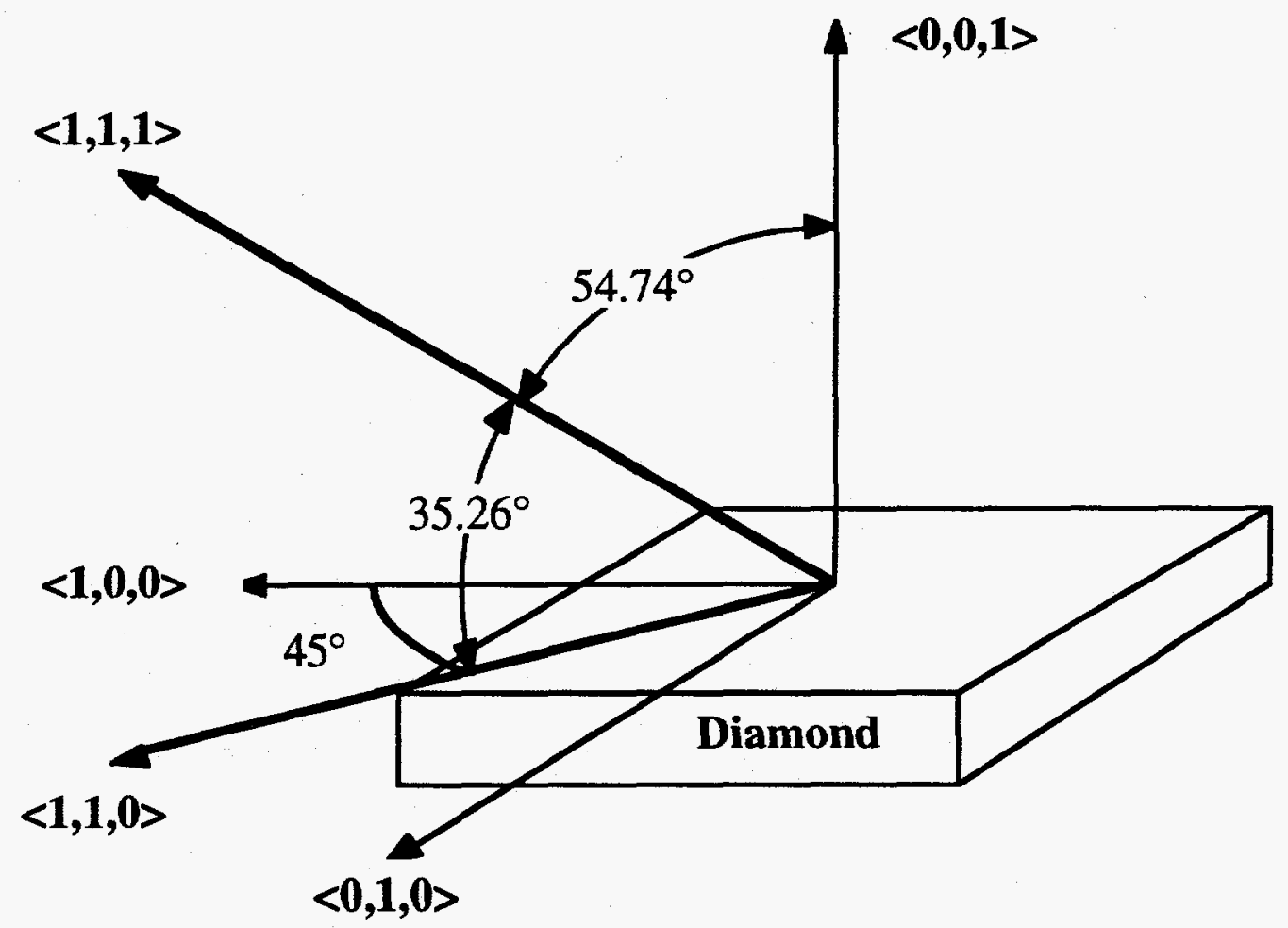

Figure 3.5. Orientation of $<111>$ and $<110>$ conventional cubic cell reciprocal lattice vectors in a $<001>$ oriented diamond plate such as is commonly obtained from synthetic diamonds. The inclination angle of the (111) planes to the (001) surface is $54.74^{\circ}$. 

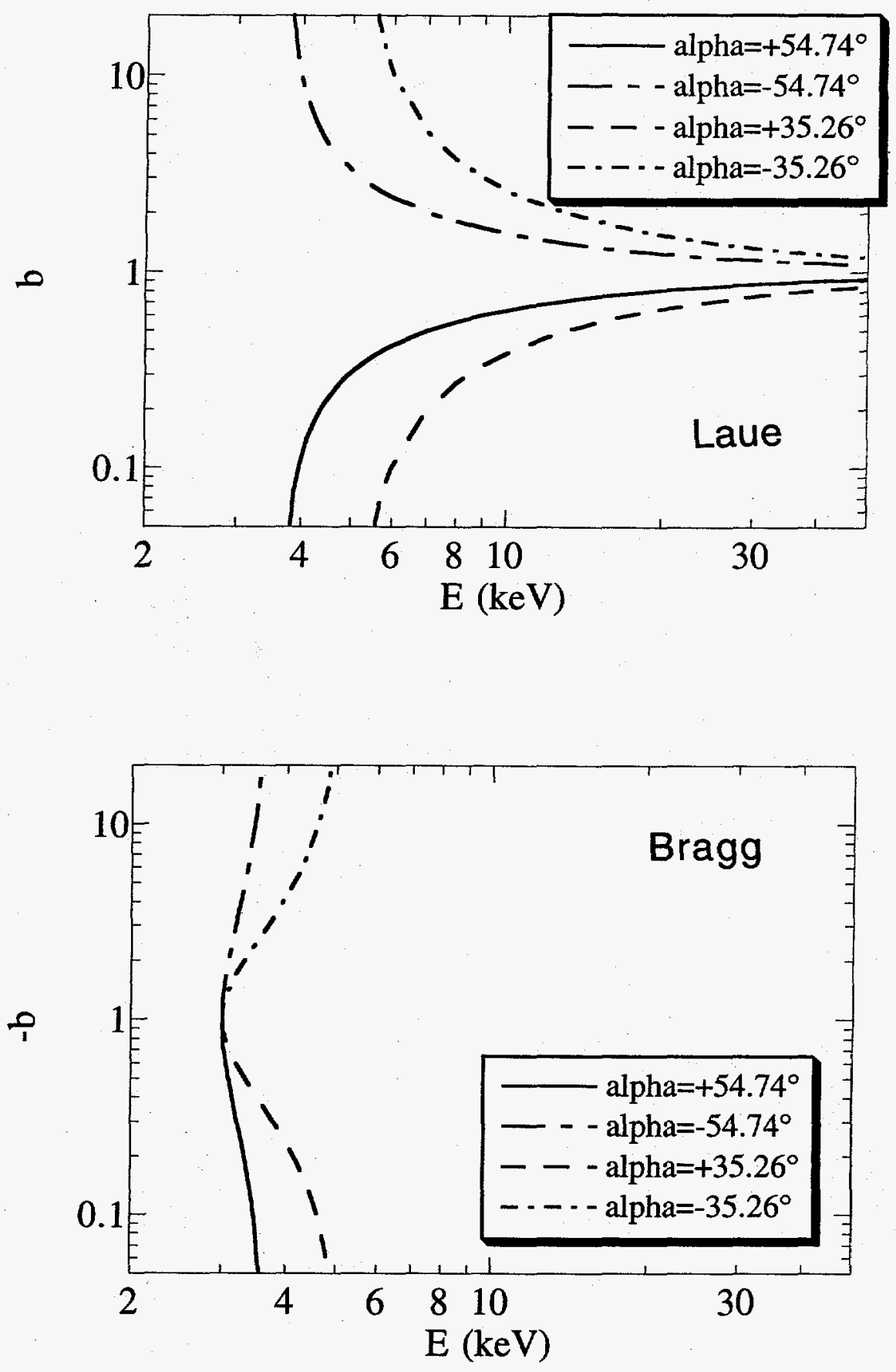

Figure 3.6. Asymmetry parameter $b$ for diamond (111) Laue (top plot) and Bragg (bottom plot) geometry reflections for conventional asymmetry angles naturally present in (100) and (110) oriented diamond plates. 

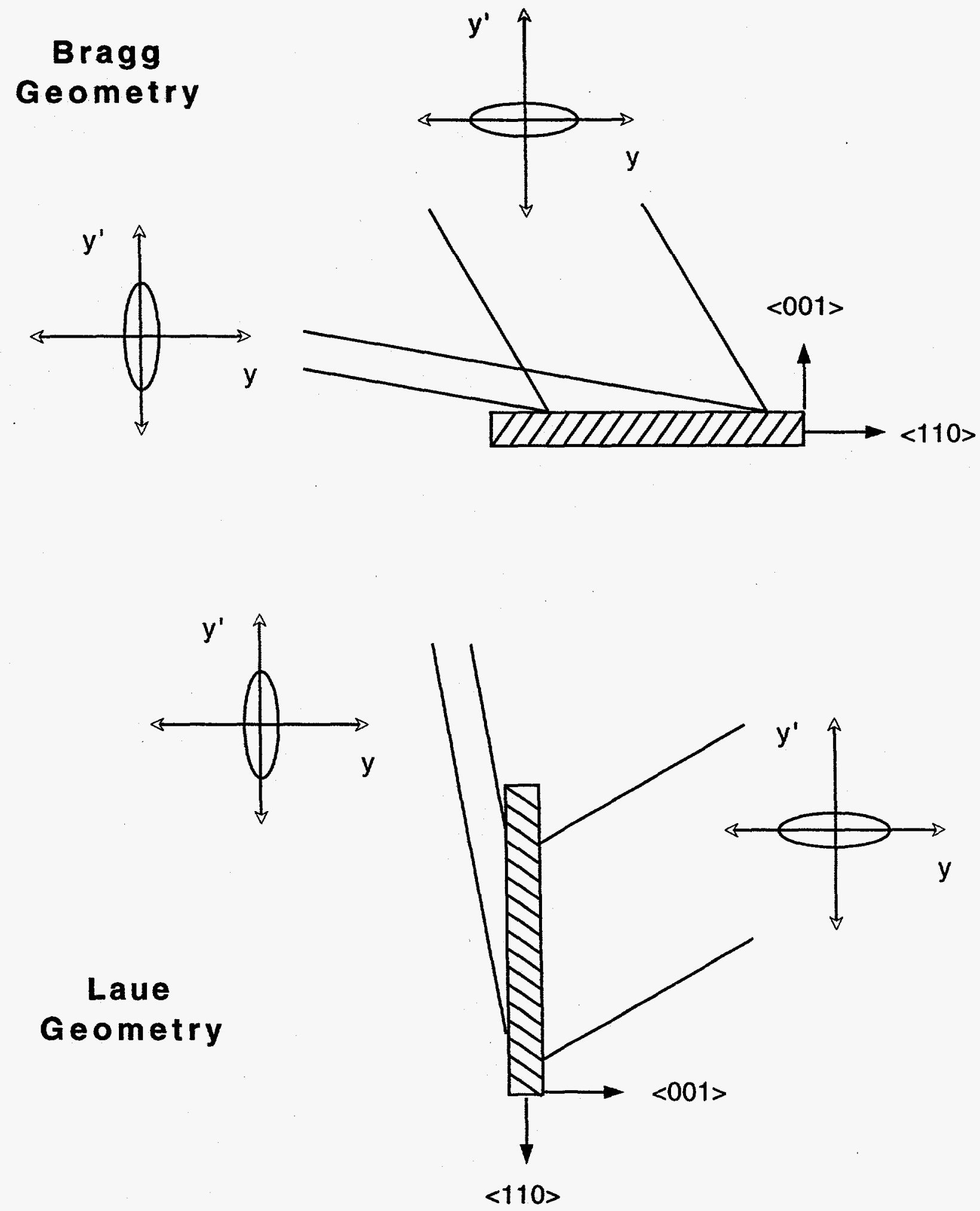

Figure 3.7. Schematic of the beam geometries for an asymmetric reflection from the (111) planes in a plate whose faces are parallel with the (001) planes in both the Bragg and Laue geometries. Also shown are schematics representations of the phase space of the incident/diffracted $x$-ray beams. Here $y^{\prime}$ denotes the angular acceptance and $y$ the spatial extent of the beam. 


\subsection{Reflection Geometry, Cutoff Energies, and Tuning Range}

Although silicon and germanium both have the diamond lattice structure, diamond has a smaller conventional cubic unit cell constant, $a_{0}$, and therefore a higher low-energy cutoff, $E_{c}$, in the Bragg reflectivity:

$$
E_{c}=\frac{h c}{2 a_{o}} \sqrt{H^{2}+K^{2}+L^{2}}
$$

Here $\mathrm{h}$ is Plank's constant, $\mathrm{c}$ is the speed of light, and $\mathbf{H}, \mathbf{K}$, and $\mathbf{L}$ are the Miller indices. This increase in the cutoff energy limits the range of operation of a diamond monochromator. Table 3.3 lists the cutoffs of diamond, germanium, and silicon for three of the lowest order reflections. The mechanical operations of the monochromator will typically limit the Bragg angle to less than or on the order of $60^{\circ}$, and so the practical cutoff energy will be increased about $15 \%$ above the theoretical limits of Table 3.3.14,28,29

Table 3.3. Lattice parameter, $a_{0}$, and Bragg energy cut-offs, $E_{c}$, of Diamond, Ge, and Si.

\begin{tabular}{|c|c|c|c|c|}
\hline Crystal & $\begin{array}{c}\mathbf{a}_{\mathbf{o}} \\
\left(\AA \text { at } 25^{\circ} \mathrm{C}\right) \\
\end{array}$ & $\begin{array}{l}\mathbf{E}_{\mathbf{c}}(\mathrm{keV} \\
(\mathbf{1 1 1}) \\
\end{array}$ & $\begin{array}{c}\text { for the Given } \\
(220) \\
\end{array}$ & $\begin{array}{r}\text { Reflection } \\
(400) \\
\end{array}$ \\
\hline Diamond & $3.56714^{14}$ & 3.010 & 4.916 & 6.952 \\
\hline Germanium & 5.6578228 & 1.898 & 3.099 & 4.383 \\
\hline Silicon & 5.4310629 & 1.977 & 3.229 & 4.566 \\
\hline
\end{tabular}

One consequence of the smaller lattice constant of diamond is that the motion of the second crystal in a fixed-exit-beam-height design, double crystal monochromator is reduced (see Fig. 3.8). For the choice of the location of the common Bragg angle rotation axis shown in Fig. 3.8, the total translation along $\mathrm{Z} 2$ required between 4 and $20 \mathrm{keV}$ for a vertical offset of $35 \mathrm{~mm}$ is 93 $\mathrm{mm}$ for diamond (111) compared with $142 \mathrm{~mm}$ for silicon (111). This could, in principle, allow a significant reduction in the size and weight of the typically rather bulky second-crystal mechanism.

\subsection{Absorption}

One of the most attractive features of diamond is its low x-ray absorption cross section, which can be used to allow a significant fraction (if not the majority) of the X-ray beam power to be transmitted through a diamond monochromator first crystal and deposited in an isolated beam stop. This is to be compared to the case of silicon and germanium, where essentially all of the incident $\mathrm{x}$ ray beam power is deposited as heat in the first crystal. This decreased heat load in the first crystal further reduces distortions of a first diamond crystal compared to a first silicon crystal.

Figures 3.9 and 3.10 show this dependence for the total absorbed power and peak absorbed power density of an unfiltered Undulator-A beam incident on symmetric (111) Laue and Bragg geometry crystals for a variety of thicknesses, $t$. The undulator is assumed to be tuned so 


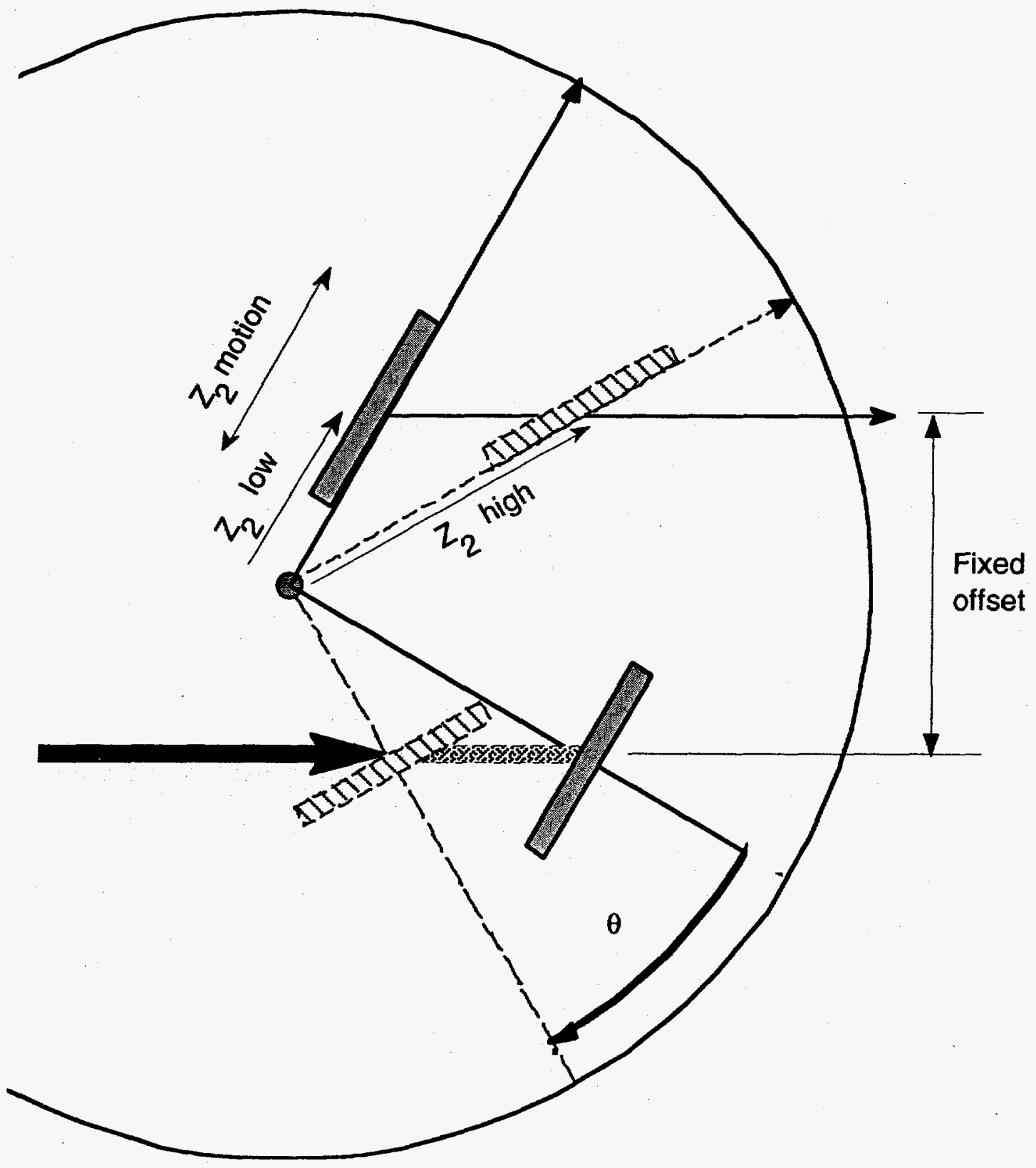

Figure. 3.8. Second crystal motion of a fixed-exit double crystal monochromator with a common Bragg angle rotation axis at the intersection of the normal to the first crystal surface and a line extended along the surface of the second crystal. The required travel of the second crystal along the $Z_{2}$ axis as the energy is changed from $E_{\text {low }}$ to $E_{\text {high }}$ is $Z_{2}$ high $-Z_{2}$ low. 
a)

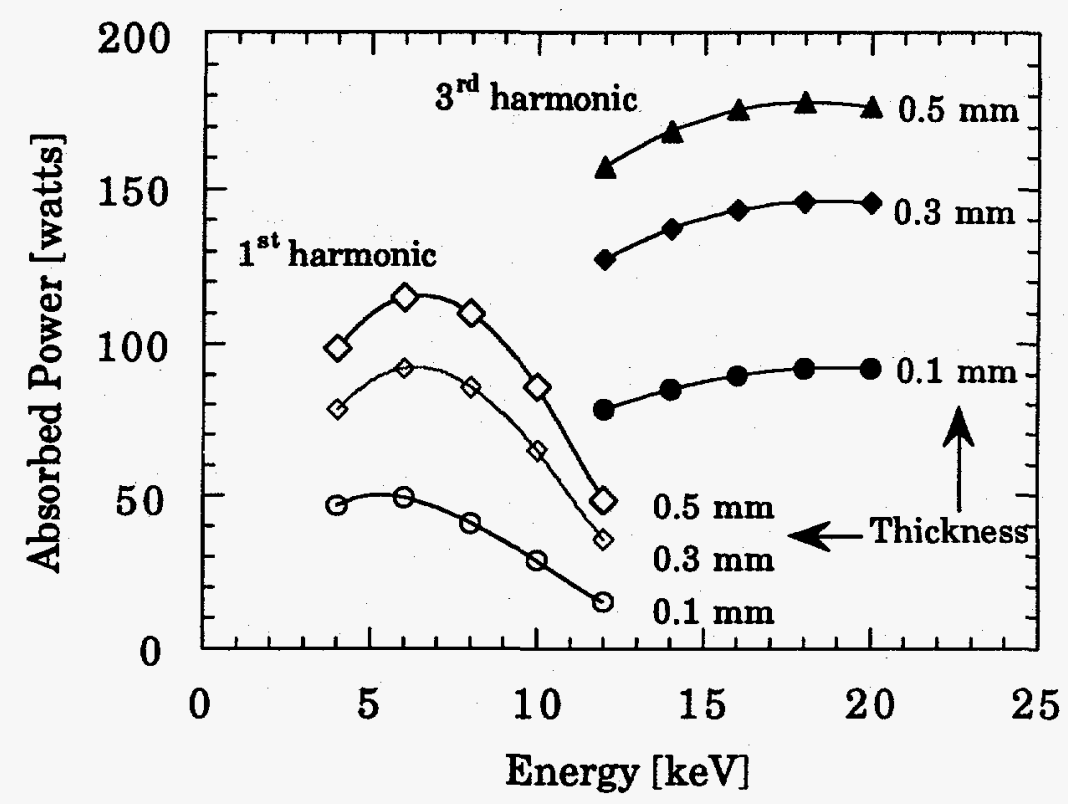

b)

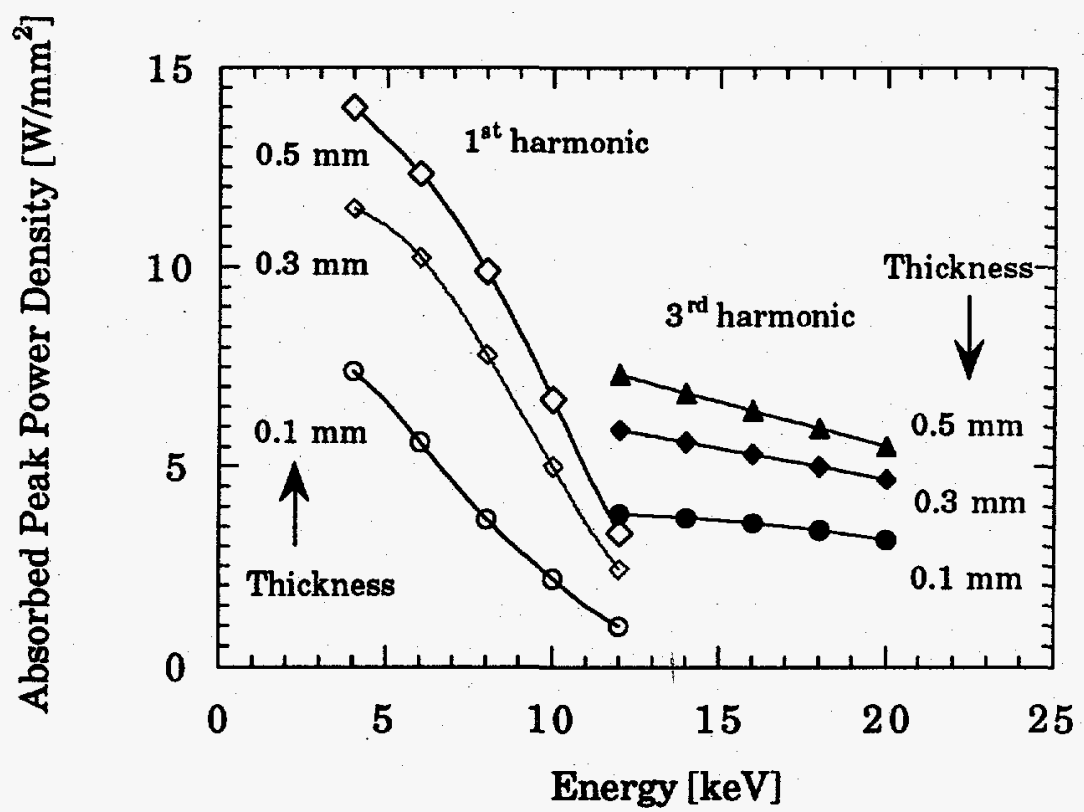

Figure 3.9. (a) Absorbed total power and (b) absorbed peak power density for symmetric Bragg geometry (111) diamonds of various thicknesses. The specified undulator harmonic as well as the monochromator bandpass are assumed tuned to the specified energy. No filters were assumed for the third-harmonic tunings, and so these estimates are conservative. 
a)

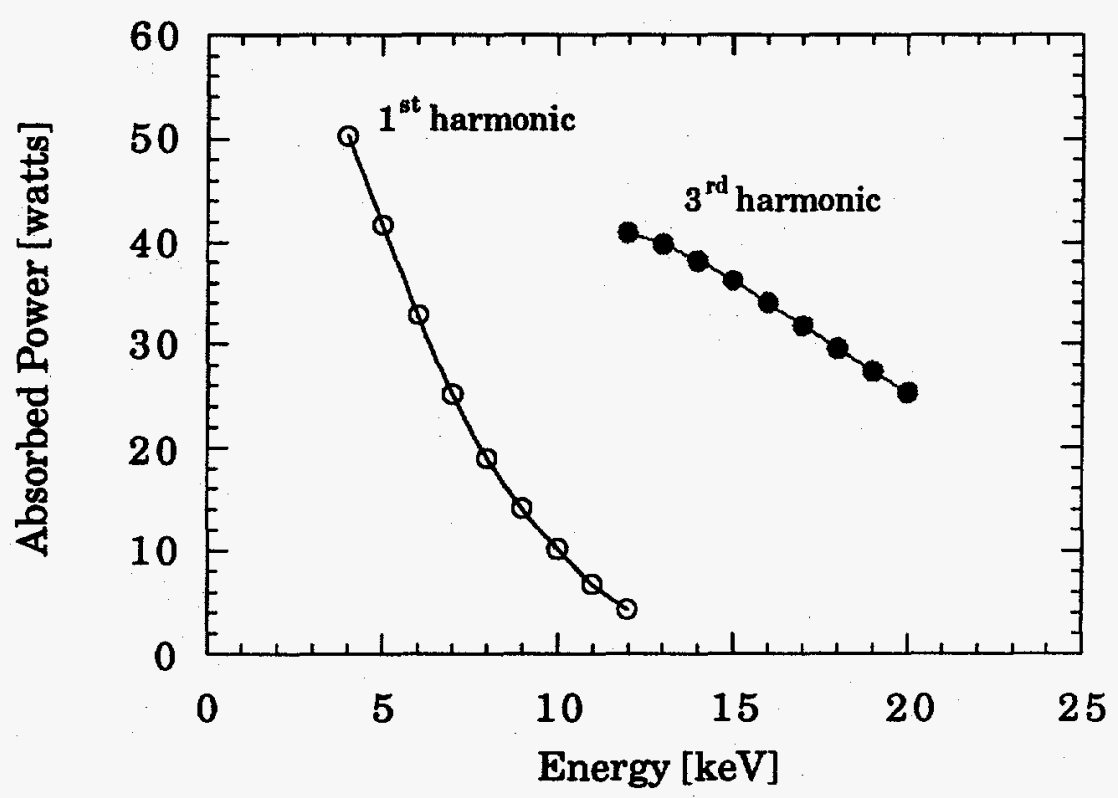

b)

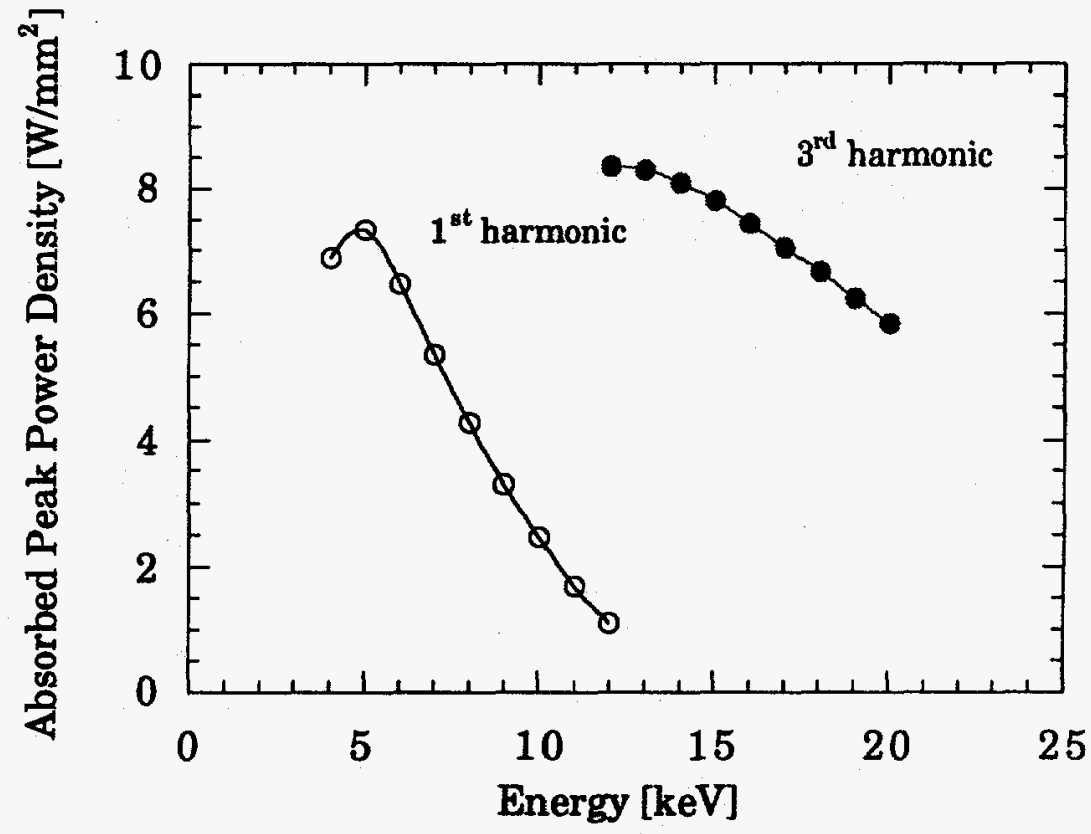

Figure 3.10. (a) Absorbed total power and (b) absorbed peak power density for a symmetric Laue geometry (111) diamond of $0.1 \mathrm{~mm}$ thickness. The specified undulator harmonic as well as the monochromator bandpass are assumed tuned to the specified energy. No filters were assumed for the third-harmonic tunings, and so these estimates are conservative. 
that the peak of the first (or third) harmonic coincides with the monochromator energy. The calculations are made for a storage ring energy and current of $7 \mathrm{GeV}$ and $100 \mathrm{~mA}$, respectively. The monochromator crystal is $30 \mathrm{~m}$ from the source, and a mask immediately upstream of the first crystal is assumed to define the beam to $1.5 \mathrm{~mm}$ vertical $\times 3.6 \mathrm{~mm}$ horizontal. The calculations were made using the UA program. 30 The results of the calculations are also tabulated in Appendix $\mathrm{C}$ for convenience.

\subsection{Non-Diamond Second Crystals}

Because of the small size of good diffracting diamonds, double-crystal monochromators (DCM) employing a diamond second crystal will require a more precise, motorized translation stage than is needed for a Si DCM in which the beam can be allowed to walk across the surface of the second crystal. The small size of a diamond second crystal also makes the design of a bending mechanism for sagittal focusing more problematic. These reasons have led some designers to contemplate the use of a non-diamond second crystal.

Because the source divergence in the plane of diffraction (normally the vertical plane) is very narrow, the losses due to dispersion mismatch can be kept to an inconsequential level if a relatively close $d$-spacing match between the diamond and the second crystal can be obtained. Table 3.4 shows the $d$-spacing mismatch for the first three allowed reflections in diamond and several closely matched silicon and germanium reflections. Here $\Delta d / d=\left(d_{x}-d_{c}\right) / d_{c}$, where $d_{c}$ is the diamond $\mathrm{d}$-spacing and $\mathrm{d}_{\mathrm{x}}$ is the Ge or Si d-spacing.

Table $3.4 \mathrm{~d}$-spacings of diamond, $\mathrm{Si}$, and $\mathrm{Ge}$ reflections at $25^{\circ} \mathrm{C}$.

\begin{tabular}{lcc}
\hline \hline Reflection & $\mathbf{d}(\mathbf{\AA})$ & $\Delta \mathbf{d} / \mathbf{d}$ \\
\hline \hline Diam $(1,1,1)$ & 2.059 & - \\
Si $(2,2,0)$ & 1.920 & -0.068 \\
Ge $(2,2,0)$ & 1.996 & -0.029 \\
\hline Diam $(2,2,0)$ & 1.261 & - \\
Si $(3,3,1)$ & 1.246 & -0.003 \\
Ge $(3,3,1)$ & 1.295 & +0.029 \\
\hline Diam $(4,0,0)$ & .8918 & - \\
Si $(5,3,1)$ & .9180 & +0.029 \\
Si $(6,2,0)$ & .9543 & +0.072 \\
Ge $(5,3,1)$ & .8587 & -0.037 \\
Ge $(6,2,0)$ & .8927 & +0.003 \\
\hline \hline
\end{tabular}

Perhaps the largest impact of a slightly dispersive geometry is that the twice diffracted beam will no longer be parallel to the incoming beam. Figures $3.11 \mathrm{a}-\mathrm{c}$ show the angular deviations $2 \Delta \theta=2 \theta_{B 2}-2 \theta_{B 1}$ from parallelism that the twice diffracted beam will experience relative to a non-dispersive arrangement. For moderate angular deviations, the twice reflected beam could be redirected parallel to the incident beam through the use of a post monochromator mirror. 
The use of non-identical first and second crystals would also provide enhanced harmonic rejection over the normal configuration of two identical crystals because the angular separation of the first and third harmonics are different if the d-spacings are not the same. Figure 3.12 shows the reflectivity curves for the first and third harmonics from diamond (111) and (333) (the second harmonic is diffracted from the forbidden (222) reflection and is not plotted) and two possible second crystal candidates, $\mathrm{Si}(220)$ and $\mathrm{Ge}(220)$. In this figure, the first harmonics have been aligned to provide maximum throughput. Note that the overlap of the reflectivity profiles of the third harmonics are sufficiently misaligned to have minimal throughput. This property may be particularly important when using high critical energy beamlines, such as those encountered at the APS.

\subsection{Beam Multiplexing}

The use of Laue (transmission) geometry monochromators using thin $(0.1 \mathrm{~mm})$ diamond crystals is being pioneered by Als-Nielsen and others on the TROIKA beamline at ESRF. 31 The goal is to multiplex the $x$-ray beam so that several hutches on the same beamline can operate simultaneously as is done commonly with neutron beams at thermal neutron research reactors such as the Institute Laue Langevin (ILL) in Grenoble. 32 (The various symmetric and asymmetric Laue and Bragg geometries were discussed earlier in Section 3.2. It is worth noting that some of these geometries may be advantageous for beam multiplexing as they naturally reduce the path length of the transmitted beam and therefore decrease the beam attenuation.) Such a monochromator would obviously be quite useful on a wiggler line if one could obtain substantially larger diamonds. The advantage, however, is not as clear for undulator radiation, which is concentrated in moderately narrow bandwidth peaks, as several stations operating simultaneously would have a much larger probability of interference. Yet, if one is interested in doing experiments at several fixed incident energies lying within the width of an undulator harmonic, there may be significant advantages to this approach. Its true utility will only be known when experience is gained on such lines that actually have multiple monochromators supplying beam simultaneously to multiple experiments. 
a)

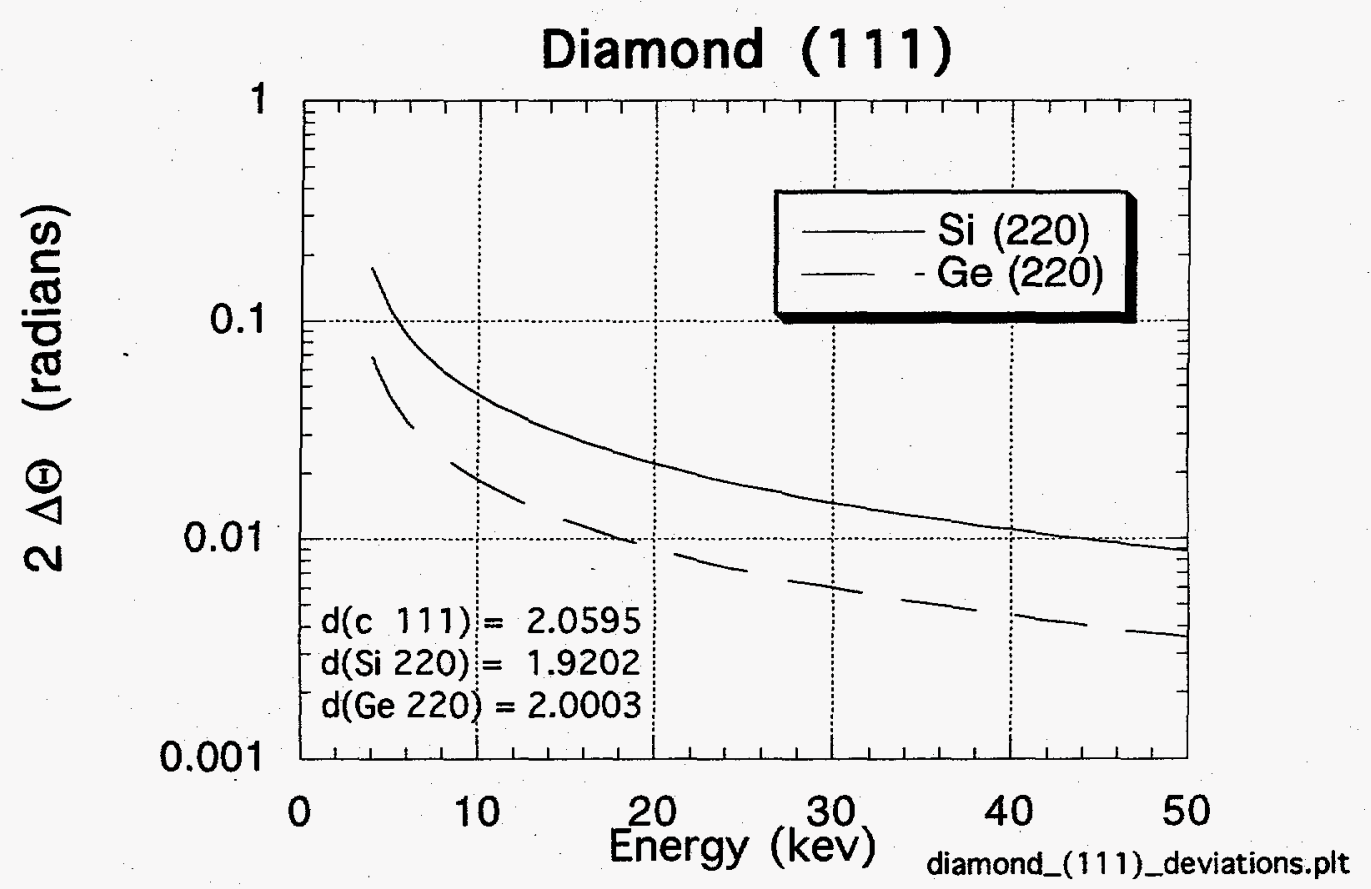

b)

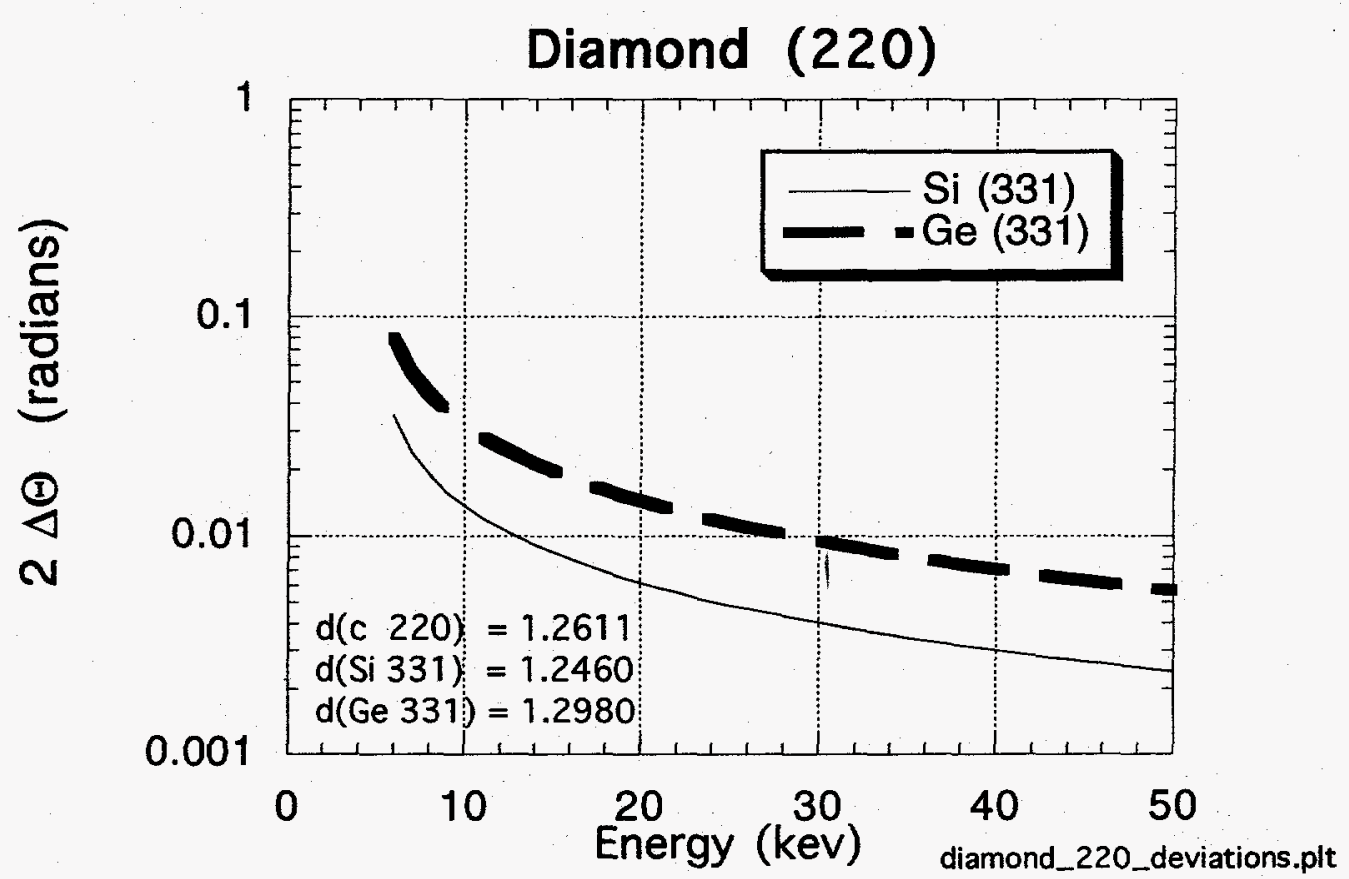

Figure 3.11. Exit beam angular deviation $2 \Delta \theta=2 \theta_{B 2}-2 \theta_{B 1}$ for (a) diamond (111), (b) diamond (220), and (c), and diamond (400) first crystal reflections and the specified second crystal reflection. Bold lines indicate that $2 \Delta \Theta$ is negative. 
c)

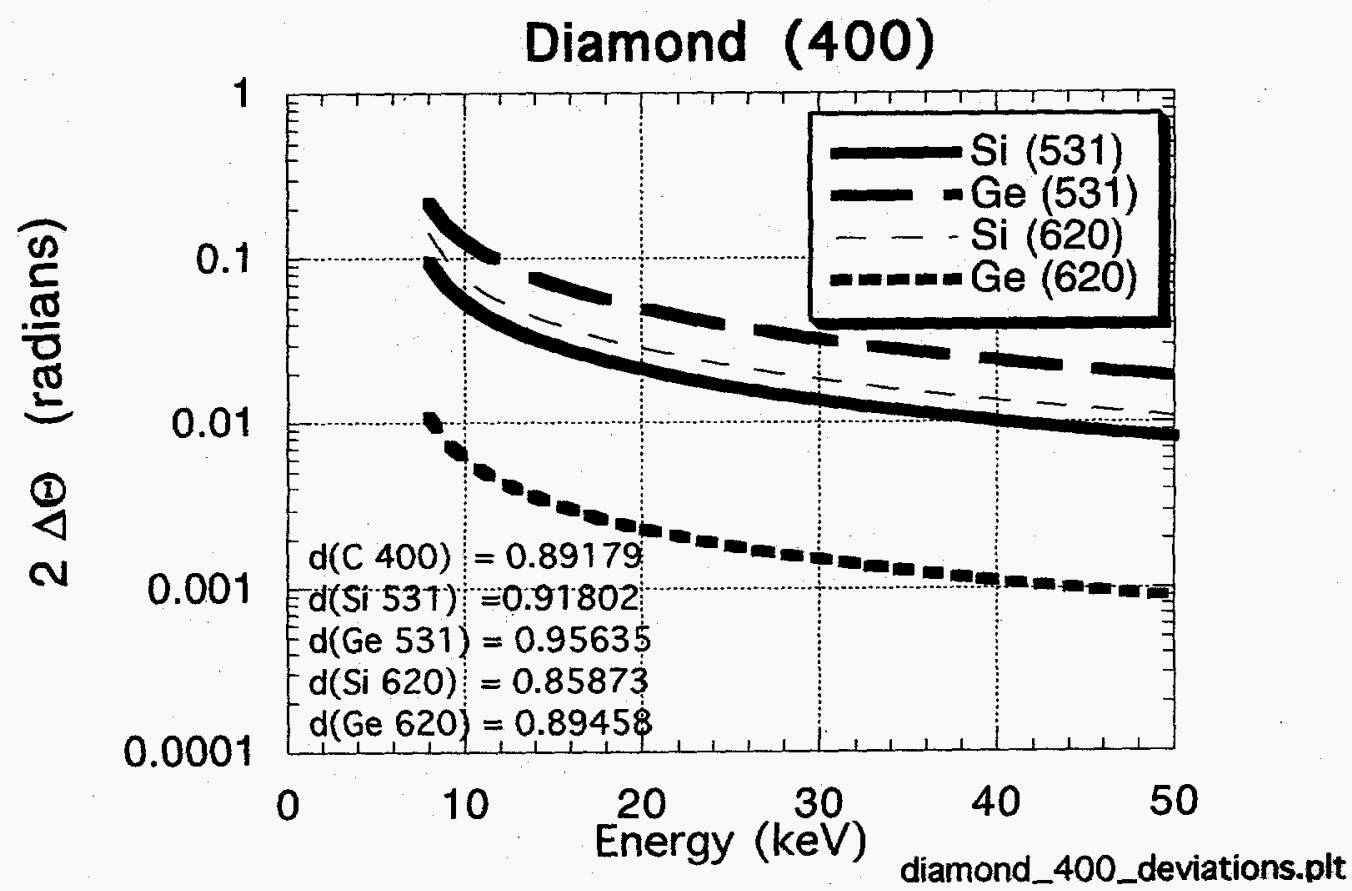



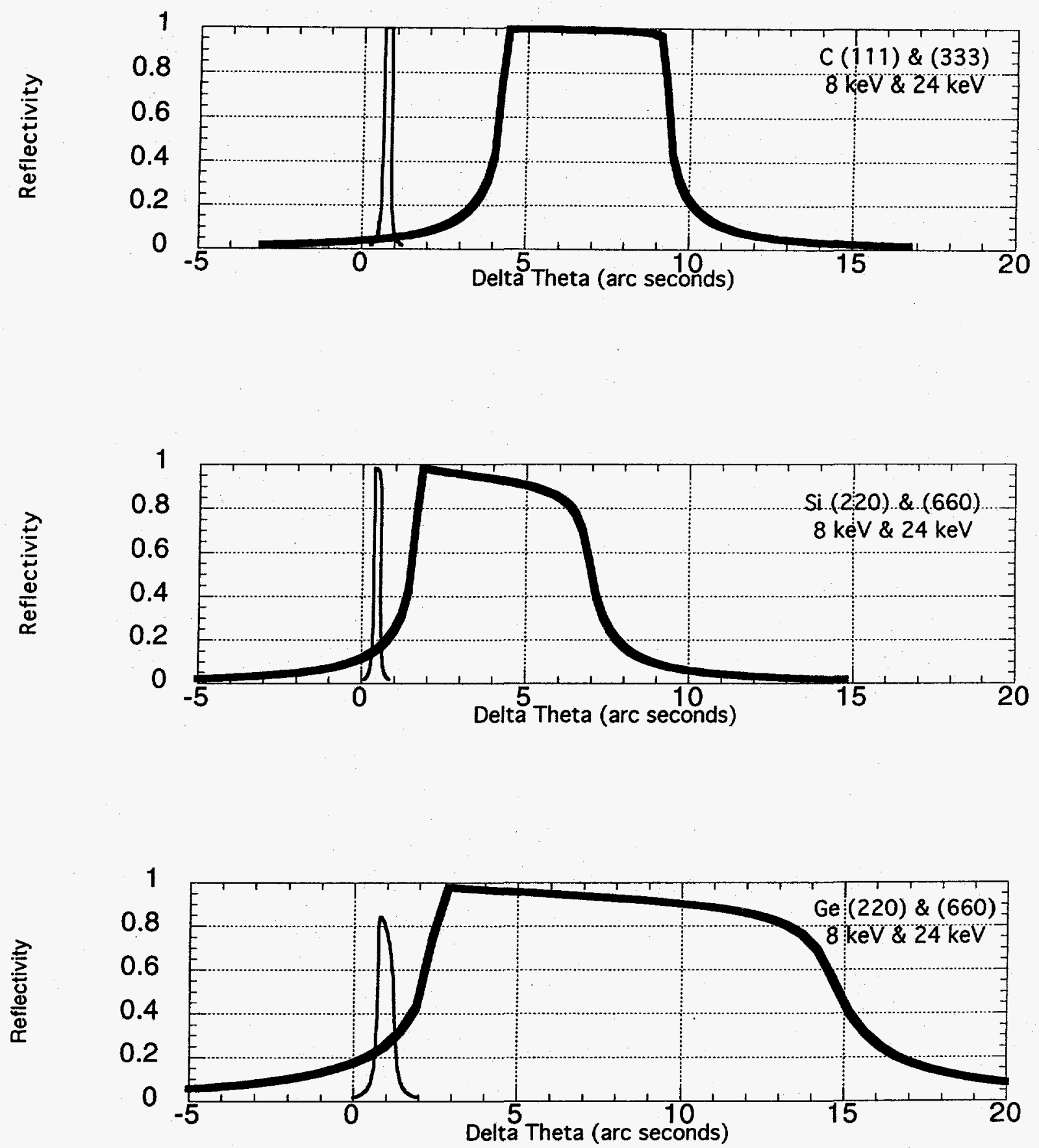

Figure 3.12. Natural harmonic rejection obtained through the use of a non-diamond second crystal. See the text for details. 


\section{THERMAL DESIGN OF DIAMOND MONOCHROMATORS}

\subsection{General Design Constraints}

To be useful, the diamond in a diamond monochromator must be mounted in a rigid but strain-free manner and, in the case of a first crystal, be either directly cooled and therefore sealed to a block with cooling channels or indirectly cooled and therefore thermally clamped to a directly cooled block. The temperature of the diamond needs to be stable to within the Darwin temperature defined in Eqn. (3.3) as the storage ring current (and therefore heat load) decays and to be not so large to produce bowing of the crystal. The temperature gradients should also be small enough that they do not produce significant strains/slope error variations within the beam footprint.

As mentioned above, one of the primary advantages of diamond over silicon is that due to its lower absorption length, much of the incident power will be transmitted through the diamond (recall Figs. 3.9 and 3.10). To the extent that this is true, the $\mathrm{x}$-ray beam power will be deposited nearly uniformly within the depth in the diamond, and so the heat flow will be approximately twodimensional, at least away from the thermal connection to the heat sink.

Ignoring emittance effects and errors in the magnetic field of the undulator, the angular half width of a harmonic peak is

$$
\sigma_{r^{\prime}} \approx \frac{1}{\gamma} \sqrt{\frac{1+K^{2} / 2}{2 N n}},
$$

while the angular half width of the power distribution is $1 / \gamma$. Here $\mathrm{K}$ is the deflection parameter, $\mathrm{N}$ is the number of periods in the magnet structure, and $n$ is the harmonic number. The power distribution at the monochromator is thus significantly wider than the distribution of the harmonic peak energy photons. One usually masks off the beam to the rough size of the harmonic peak distribution in order to reduce the total power. Such masks are typically rectangular in shape and, unless designed otherwise, produce a sharp edge to the power profile on the surface of the first monochromator crystal, which causes a corresponding slope error.

Assuming either a square or circular power distribution of uniform intensity, one obtains one of the four following heat flow models. The first is a one-dimensional heat flow in a plate and is appropriate for thin side-cooled diamonds. The second is radial heat flow in a circular plate, which is appropriate when the beam size is small compared to the radius of the heat sink. The last two models are radial heat flow from a half cylinder and radial heat flow from a half sphere appropriate to cases in which the thickness of the diamond is significant compared to the absorption length.

To evaluate the performance of a diamond monochromator under the heat load from the APS Undulator beam, a three-dimensional model of a diamond crystal was developed using the ANSYS $^{33}$ finite element analysis code in which a side-cooling scheme was applied. The result of the analyses are presented in Section 4.5. To estimate the temperature gradient on the surface of a diamond monochromator cooled from the sides, one could possibly use a model of a fraction of a centrally heated circular plate cooled at its rim and uniformly heated through the thickness 4 (see Figure. 4.1). The heat conduction equation can be written as follows: 


$$
A q^{\prime \prime}=2 \pi t k(T) \frac{d T}{d r}
$$

where $q^{\prime \prime}$ is the heat flux, A the area of the heated spot, $k(T)$ is the thermal conductivity, and $t$ is the thickness . For Type-Ila diamond, the thermal conductivity between $20^{\circ} \mathrm{C}$ and $127^{\circ} \mathrm{C}$ can be approximated within $3 \%$ error by 17

$$
k(\Delta T)=k_{o}(1-\beta \Delta T)
$$

with $\beta=0.007807 \mathrm{~K}^{-1}$, where $\mathrm{k}_{0}$ is the thermal conductivity at $20^{\circ} \mathrm{C}(=2.3562 \mathrm{~W} / \mathrm{mm}-\mathrm{K}),{ }^{17} \Delta \mathrm{T}$ is the increase of the crystal temperature (from $20^{\circ} \mathrm{C}$, the reference temperature). The solution of Eqn. (4.2) is

$$
\Delta T=\frac{1}{\beta}\left(1-\sqrt{1-2 \beta \Delta T_{o}}\right),
$$

where

$$
\Delta T_{o}=\frac{P}{f_{c} 2 \pi t k_{o}} \ln \left(\frac{R_{2}}{R_{1}}\right)
$$

is the solution of Eqn. (4.2) for a constant thermal conductivity, $P=\pi R_{1}^{2} q^{\prime \prime}$ is the total power deposited in the crystal, $t$ is the crystal thickness, $R_{1}$ is the radius of the beam footprint, and $R_{2}$ and $f_{c}$ are, respectively, the radius and the fraction of the cooled circumference.

It follows that the temperature difference across the crystal surface depends on the logarithm of the ratio of the crystal size to the beam size. However, this model assumes a circular beam footprint, which is not always the case. The shape of the beam footprint is often rectangular or square with almost uniform heat flux. Therefore, the approximation is accurate only when the beam footprint is much smaller than the size of the crystal. Let us consider the case simulated in Section 4.5 of this document, with the following parameters:

- Size of the beam footprint

- Equivalent beam radius $\left(\mathrm{R}_{1}\right)$

- Crystal surface area

- Cooled area

- Crystal thickness

- Total absorbed power from Undulator A
$3.6 \mathrm{~mm} \times 2.9 \mathrm{~mm}$

$1.82 \mathrm{~mm}$

$6 \mathrm{~mm} \times 6 \mathrm{~mm}$

$27.6 \mathrm{~mm}^{2}$

$0.3 \mathrm{~mm}$

92 watts

Using Eqn. 4.5 with an average radius of the cooled area, $R_{2}$, equal to $2.5 \mathrm{~mm}$, and $f_{0}=0.55$, we obtain a maximum temperature drop across the crystal of about $12.5^{\circ} \mathrm{C}$. The finite element analyses (Section 4.5) give a temperature drop of $15.6^{\circ} \mathrm{C}$ in the sagittal direction and $9.0^{\circ} \mathrm{C}$ in the tangential direction. 


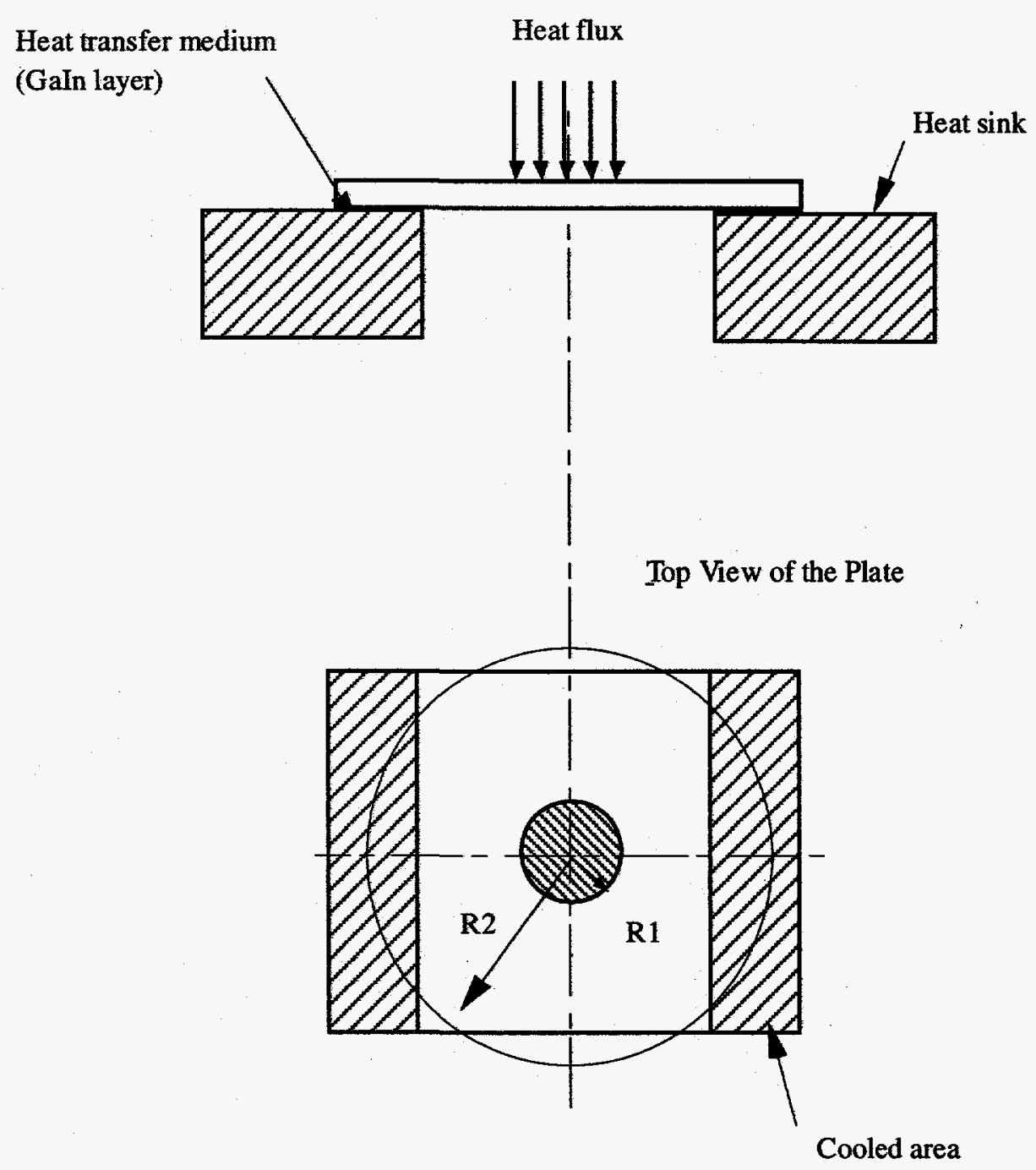

Figure 4.1. Model of a fraction of a centrally heated circular plate cooled at its rim and uniformly heated through the thickness. 


\subsection{Direct Cooling of Diamonds}

Diamonds can be laser machined to high accuracy ( \pm 0.001 " or better) and in principal could be directly cooled with internal water microchannels or more complex heat exchanger patterns machined into the back of the diamond or water jet cooling on the back face of the diamond as done by Berman and Hart. 6 Whatever the mechanism, diamond provides better heat transport than the cooling material and any practical coolant placed behind the diamond will absorb a significant amount of $\mathrm{x}$-rays thereby worsening the heat loading problem.

\subsection{Operation at Cryogenic Temperatures}

As is the case with silicon, improved thermal and mechanical performance can be expected with diamond when cooled to cryogenic temperatures. Diamond is an attractive candidate for liquid nitrogen cooling because only a small portion of the total incident power is typically deposited in the diamond, thereby reducing the cooling capacity requirements and liquid nitrogen usage of the cooling system.

Recently several members of the APS staff collaborated with staff members from the ESRF and SPRing- 8 on the first tests of a cryogenically cooled, single crystal diamond monochromator. This experiment, coordinated by Hitoshi Yamaoka of SPRing-8, was performed at the BL3 (focused wiggler) line at the ESRF. Mounting strains from the differential thermal expansion severely hampered these experiments with the thin synthetic Type IIa diamond manufactured by Sumitomo Ltd. (diamond size $5 \mathrm{~mm} \times 4 \mathrm{~mm} \times 0.2 \mathrm{~mm}$ ). Nonetheless, narrow rocking curves $(3.2$ arc seconds), but not at the theoretical values were finally achieved at a diffracted energy of 23.8 $\mathrm{keV}$ under incident surface power densities of $90 \mathrm{~W} / \mathrm{mm}^{2} .34$ Although in principle, cryogenically cooled diamonds will out perform diamonds at room temperature, clearly a considerable amount of effort still needs to be invested into this area, particularly in the development of strain-free mountings.

\subsection{Cooling through a Liquid Ga/In Layer}

One of the simplest ways of mounting diamond crystals strain free, an approach used frequently at the ESRF, is with a thin liquid layer of $\mathrm{Ga} / \mathrm{In}$ at the sides of the crystal (side cooling). ${ }^{4}$ The surface tension of the liquid holds the crystal in place while providing a strain-free, thermal contact to the cooled substrate, often a water-cooled copper block. As mentioned previously, experiments carried out at the ESRF 23 indicate that $\mathrm{h}=0.04 \mathrm{~W} / \mathrm{mm}^{2}-\mathrm{K}$ seems close to the value which is consistant with experiments. If that is the case, for a $6 \mathrm{~mm} \times 6 \mathrm{~mm} \times 0.3 \mathrm{~mm}$ crystal cooled from two sides with a $1 \mathrm{~mm}$ contact-width on the top and bottom faces (i.e., total wetted area equal to about $27.6 \mathrm{~mm}^{2}$ ), the temperature drop at the GaIn layer would be more than $160^{\circ} \mathrm{C}$ for a crystal absorbing 92 watts (the heat transfer coefficient was divided by 2 for the two interfaces: diamond-GaIn and GaIn-copper). The maximum temperature at the center of crystal will increase by roughly the same amount. Because the thermal conductivity and the coefficient of thermal expansion depend on the temperature, the temperature drop across the crystal and the resulting distortions will also increase dramatically. However, if we assume that single crystal synthetic diamonds of larger sizes up to $1 \mathrm{~cm} \mathrm{x} 1 \mathrm{~cm}$ could be available soon, one could increase the wetted area to the point where the temperature drop is acceptable. For example, for an $10 \mathrm{~mm}$ $\mathrm{x} 10 \mathrm{~mm}$ diamond crystal with a $0.3 \mathrm{~mm}$-thickness (and keeping the same clearance for the incident beam), the contact area may be increased to about $122 \mathrm{~mm}^{2}$, which reduces the temperature drop to 
about $36.5^{\circ} \mathrm{C}$. The peak temperature will increase to about $84.5^{\circ} \mathrm{C}(=36.5+48)$, which is still an acceptable value. Moreover, by reducing the crystal thickness, the absorbed power decreases, thereby decreasing the heat flux at the interface. With a $10 \mathrm{~mm} \times 10 \mathrm{~mm} \times 0.1 \mathrm{~mm}$ crystal, the temperature difference across the interface will go down to about $21.64{ }^{\circ} \mathrm{C}$. In this case, the thermal conductivity and the thermal expansion of diamond will be only slightly affected. Therefore, we expect the temperature gradient and, consequently, the distortions in the crystal to increase only by a small amount.

Table 4.1 summarizes the expected temperature drop across the diamond heat sink interface for various power loads and diamond sizes, when a liquid gallium layer is used as a heat transfer media. The calculation are for Undulator-A beam at $\mathrm{K}=1.644$ and for a diamond (111) crystal set to diffract 6-keV photons (symmetric Bragg reflection) $30 \mathrm{~m}$ from the source, with no filters or windows. The beam slits are set to $3.6 \mathrm{~mm}$ horizontal by $1.5 \mathrm{~mm}$ vertical. The crystal is cooled from two sides and edges. (The front and the back side are free.) The wetted area was calculated assuming the width of the reflecting surface constant and equal to $4 \mathrm{~mm}$ (i.e., slightly larger than the horizontal slit opening), the heat conductance at the boundary layer was set at $0.02 \mathrm{~W} / \mathrm{mm}^{2}-\mathrm{K}$, and the thickness of the liquid gallium layer was equal to $100 \mu \mathrm{m}$, which is much higher than needed.

Table 4.1. The expected temperature drop across the diamond heat sink interface for various power loads and diamond sizes, when a liquid gallium layer is used as a heat transfer medium. The crystal is exposed to the UA beam at $7 \mathrm{GeV}-100 \mathrm{~mA}$ operation and is oriented to diffract $6 \mathrm{keV}$ photons (symmetric (111) Bragg reflection) with a slit opening of $3.6 \mathrm{~mm} \times 1.5 \mathrm{~mm}$ at $30 \mathrm{~m}$ from source, and it is cooled from two sides (the front and the back side are free). The wetted area was calculated assuming the width of the reflecting surface constant and equal to $4 \mathrm{~mm}$ (i.e., slightly larger than the horizontal slit opening), and the heat conductance was set to $0.02 \mathrm{~W} / \mathrm{mm}^{2}-\mathrm{K} . \Delta \mathrm{T}_{\text {int }}$ is the temperature drop due the boundary layer; $\Delta \mathrm{T}_{\mathrm{Ga}}$ is the temperature drop due conduction through $0.100 \mathrm{~mm}$ thickness of gallium.

\begin{tabular}{|c|c|c|c|c|c|c|}
\hline Crystal surface & $\begin{array}{c}\text { Crystal } \\
\text { thickness } \\
(\mathbf{m m}) \\
\end{array}$ & $\begin{array}{c}\text { Absorbed } \\
\text { power } \\
\text { (watts) }\end{array}$ & $\begin{array}{c}\text { Wetted } \\
\text { area } \\
\left(\mathbf{m m}^{2}\right) \\
\end{array}$ & $\begin{array}{c}\Delta \mathbf{T}_{\text {int }} \\
\left({ }^{\circ} \mathbf{C}\right)\end{array}$ & $\begin{array}{c}\Delta \mathbf{T}_{\mathbf{G a}} \\
\left({ }^{\circ} \mathbf{C}\right)\end{array}$ & $\begin{array}{c}\Delta \mathbf{T}_{\text {total }} \\
\left({ }^{\circ} \mathbf{C}\right)\end{array}$ \\
\hline \multirow[t]{2}{*}{$6 \mathrm{~mm} \times 6 \mathrm{~mm}$} & 0.1 & 49.0 & 25.2 & 97.9 & 5.0 & 102.9 \\
\hline & 0.3 & 92.0 & 27.6 & 166.1 & 10.1 & 176.2 \\
\hline \multirow[t]{2}{*}{$8 \mathrm{~mm} \times 8 \mathrm{~mm}$} & 0.1 & 49.0 & 65.6 & 37.4 & 2.3 & 39.7 \\
\hline & 0.3 & 92.0 & 68.8 & 66.9 & 4.05 & 70.95 \\
\hline \multirow[t]{2}{*}{$10 \mathrm{~mm} \times 10 \mathrm{~mm}$} & 0.1 & 49.0 & 122.0 & 20.1 & 1.2 & 21.3 \\
\hline & 0.3 & 92.0 & 126.0 & 36.5 & 2.2 & 38.7 \\
\hline
\end{tabular}


This table shows the importance of the size of the wetted area/crystal. The temperature drop across the joint diamond heat sink is too high for small crystal sizes and high powers, which might make the crystal useless. Remember, however, that our preliminary measurements, presented in Section 2 , indicate that the boundary heat conductance might actually be much larger than the number used in the above calculations. Note that, liquid gallium has a relatively poor thermal conductivity $(0.03$ $\mathrm{W} / \mathrm{mm}-\mathrm{K}$ at $30^{\circ} \mathrm{C}$, to be compared with that of copper, for example, which is about $0.38 \mathrm{~W} / \mathrm{mm}$ $\mathrm{K}$ ). Therefore, it is important to keep the thickness of the liquid gallium (or GaIn eutectic) layer as thin as possible.

One possible way to eliminate the GaIn layer is by directly growing a single crystal or to bond a diamond platelet on a polycrystalline diamond heat sink. Polycrystalline diamond with a thermal conductivity that is $90 \%$ that of single crystal can be produced. However, a difference in thermal expansion coefficient or strain due to bonding should be considered.

\subsection{Finite Element Analysis of a Side-Cooled Diamond}

To evaluate the performance of a side-cooled diamond monochromator under the heat load from the APS Undulator-A beam, a three-dimensional model was developed using the ANSYS 33 finite element analysis code.

The modeled geometry and crystal dimensions are shown in Fig. 4.2. The cooling of the monochromator is achieved by flowing water through four $6 \mathrm{~mm}$-diameter circular channels located symmetrically relative to the crystal plane. Because of symmetry, only $1 / 4$ of the monochromator was modeled. To define the worst-case scenario, one has to look at many different parameters, such as the absorbed power, the relative size of the footprint to the crystal size (see Eqn. 4.5), and finally the absorbed peak power density. The relevant quantity used for comparison of the results is the ratio of the thermally induced slope error to the Darwin width $\left(\phi_{\max } / \mathrm{w}_{\mathrm{D}}\right)$.

In these FEA analyses, we choose to model a 0.3-mm-thick diamond crystal (with (111) orientation), which is about the thickness of the crystal we have at the APS. The analyses were performed for the first harmonics at $6 \mathrm{keV}$ (Bragg angle $\left.=30.126^{\circ}\right)$, and $4 \mathrm{keV}(\mathrm{Bragg}$ angle $=48.826^{\circ}$ ), which correspond to the maximum absorbed power and to the largest absorbed peak power density and the smallest beam footprint, respectively. The FEA calculations showed that these two cases are comparable. They lead approximately to the same ratio $\phi_{\max } / w_{D}$. Therefore, only the $6 \mathrm{keV}$-case is detailed here. For comparison, results of the $4 \mathrm{keV}$-case are also given in Table 4.2. At the ring energy of $7 \mathrm{GeV}$ and a current of $100 \mathrm{~mA}$, Undulator A will radiate a total power of about $2.1 \mathrm{~kW}$ for the first harmonic at $6 \mathrm{keV}(\mathrm{K}=1.6)$. The normal incidence peak heat flux at $30 \mathrm{~m}$ from source, the monochromator location, is about $103 \mathrm{~W} / \mathrm{mm}^{2}$. Slits 3.6 $\mathrm{mm}$ vertical by $1.5 \mathrm{~mm}$ horizontal were used to allow most of the central cone of radiation to pass and impinge onto the crystal. This reduces the incident power to about 489 watts. The crystal ( $0.3 \mathrm{~mm}$ thick) absorbs about 92 watts of this power. The absorbed power was computed, using the UA code, 30 by dividing the crystal into four layers of equal thickness and calculating the power profile absorbed by each layer. A heat transfer coefficient of $1 \mathrm{~W} / \mathrm{cm}^{2}-\mathrm{K}$ was applied to the surfaces of the channels. The diamond thermal conductivity and coefficient of thermal expansion are taken from ref. 17. Variable material properties as a function of temperature are considered in the analysis.

For simplicity, the GaIn layer was omitted in the thermal finite element analysis, and, instead, an ideal contact was assumed between the crystal and the copper heat sink. The GaIn layer will certainly produce some resistance to the heat flow, which will result in some temperature 


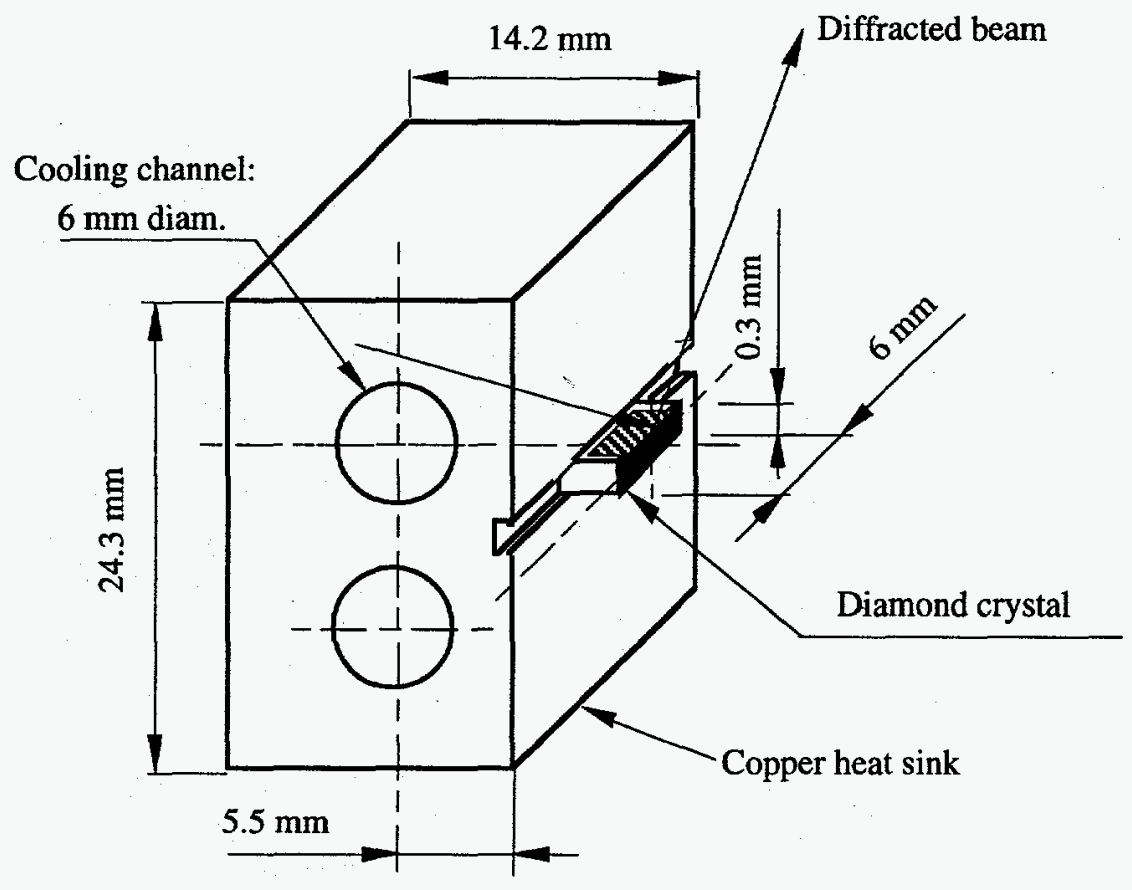

Figure 4.2. A perspective view of the geometry of the diamond modeled by the finite element analyses calculations. The crystal is cooled at the sides via a water-cooled copper heat sink with four circular channels located symmetrically relative to the crystal midplane. (Note that in the actual design the two copper blocks should be connected together to form a rigid structure and a clearance should be provided for the transmitted $\mathrm{x}$-ray beam.) 
drop across the interface. Consequently, the crystal temperature will be offset by roughly the same amount. The temperature drop across the crystal will remain the same because it depends primarily on the thermal conductivity of the diamond. Fortunately the thermal conductivity of diamond does not drop dramatically with temperature in the range of interest here. Therefore, if the temperature drop in the Galn layer is not too large, the increase in the crystal distortion will be minimal.

Figure 4.3 shows the temperature contours in the crystal. A maximum temperature drop of $9.0^{\circ} \mathrm{C}$ is obtained across the crystal surface in the tangential direction and about $15.6{ }^{\circ} \mathrm{C}$ in the sagittal direction. The peak temperature is about $48^{\circ} \mathrm{C}$ (at the center of the crystal), and the minimum temperature is $24.3^{\circ} \mathrm{C}$ (the coolant temperature was set to $20^{\circ} \mathrm{C}$ ).

To compute the distortions, the crystal was held at one point at the center and its edges are left free. Because of the excellent thermal conductivity of diamond, the temperature drop across the crystal thickness is relatively small (= about $0.120^{\circ} \mathrm{C}$ ). This gives a very small bending component, as expected. Therefore, the overall crystal distortions are mainly due to the temperature gradient across the crystal surface. Figure 4.4 shows the maximum displacement and slope error profiles on the crystal surface in the tangential and sagittal directions. A maximum tangential slope error of 1 arcsec (twice the value of the peak slope error) was obtained, which is much lower than the Darwin width of 7.0 arc seconds for $6 \mathrm{keV}$ and symmetric (111) reflection. The slope error in the sagittal direction is about 1 arc second. Similar calculations were performed by the SPring- 8 group. 35 A distortion angle of 0.5 arc seconds was obtained for a power and power density of 46 watts and 10 watts $/ \mathrm{mm}^{2}$, respectively, and the FEA calculations were in good agreement with the analytical model of a circular plate. In Table 4.2, we compare the results of the $6 \mathrm{keV}$ and $4 \mathrm{keV}$ cases. We see from this table that these cases are comparable. However, as mentioned previously, these calculations do not include the GaIn layer contribution. The temperature across the GaIn layer depends on the absorbed power for a fixed contact area. The absorbed power at $6 \mathrm{keV}$ is about $18 \%$ higher than at $4 \mathrm{keV}$ (92 watts versus 78 watts) therefore the $6 \mathrm{keV}$ case will give the higher ratio $\phi_{\max } / \mathrm{w}_{\mathrm{D}}$.

In summary, the cases studied here (the geometries for 6 and $4 \mathrm{keV}$ photons) correspond to the worst-case scenarios. The FEA results show that both cases are comparable. The thermally induced slope errors are much smaller than the Darwin widths for the corresponding energies. In this model, we have omitted the effect the GaIn layer because we believe that the temperature across the joint diamond heat sink can be minimized by optimizing the size of the contact area (see Section 4.4). Because of smaller Bragg angles, the absorbed power is much higher for the higher harmonic energies. However in this case, one can simply use filters to cut off the unwanted radiation from lower energy photons, thereby reducing significantly the power load on the crystal. Therefore we conclude from this analyses that a diamond crystal is a good option as a monochromator for the APS Undulator A.

\subsection{Effect of the Vertical Slits}

As mentioned previously, the temperature drop across the crystal thickness is relatively small, and the slope error on the crystal surface is essentially due to the variation of the temperature on the crystal surface, which is introduced by the sharp cut of the heat flux by the slits. It has been shown 12 that, for side-cooled thin diamond crystals, if the vertical slit opening is wider that the crystal size, (see Figure 4.5), the temperature profile in the tangential direction becomes almost flat, thereby reducing the slope error to a minimum under the useful beam. This, of course, will result in a slight increase of the sagittal slope error due to the increase in the absorbed power compared to a smaller beam and same crystal size. However, considering the good thermal (and absorption) properties of diamond combined with the small size of the crystal, the extra power absorbed by diamond will have only a small effect. 
Table 4.2. Summary of thermal and distortion results for 6 and $4 \mathrm{keV}$ cases. These results are for Undulator $\mathrm{A}$ beam at $7 \mathrm{GeV} 100 \mathrm{~mA}$ operation with $1.5 \mathrm{~mm} \times 3.6 \mathrm{~mm}$ slit opening at 30 from the source, the monochromator location. No filters or windows are considered here. $E_{1}$ is the energy of the first harmonic, $P$ is the absorbed power, $\mathrm{Pd}$ is the absorbed peak power density, $\mathrm{T}_{\max }$ is the temperature at the center of the crystal, $\Delta \mathrm{T}_{\mathrm{T}}$ ang and $\phi \mathrm{Tang}$ are, respectively, the temperature drop and the slope error across the crystal surface in the tangential direction, $\Delta \mathrm{T}_{\text {sag }}$ and $\phi$ Sag are, respectively, the temperature drop and the slope error across the crystal surface in the sagittal direction. The symmetric (111) diamond Darwin width, wD, is equal to about 7.0 arsec at $6 \mathrm{keV}$ and 13.9 arcsec at $4 \mathrm{keV}$.

\begin{tabular}{|c|c|c|c|c|c|c|c|c|c|}
\hline \hline $\mathbf{E}_{1}$ & $\theta_{\text {Bragg }}$ & $\mathbf{P}$ & $\mathbf{P d}$ & $\mathbf{T}_{\mathbf{m a x}}$ & $\Delta \mathbf{T}_{\text {Tang }}$ & $\Delta \mathbf{T}_{\text {sag }}$ & $\phi_{\text {Tang }}$ & $\phi_{\text {Sag }}$ & $\phi_{\text {max }} / \mathbf{w D}_{\mathbf{D}}$ \\
$(\mathbf{k e V})$ & $(\mathbf{d e g .})$ & $(\mathbf{w a t t s})$ & $\left(\mathbf{W} / \mathbf{m m}^{2}\right)$ & $\left({ }^{\circ} \mathbf{C}\right)$ & $\left({ }^{\circ} \mathbf{C}\right)$ & $\left({ }^{\circ} \mathbf{C}\right)$ & $($ arsec. $)$ & $($ arsec. $)$ & \\
\hline \hline 4.0 & 48.826 & 78.0 & 10.9 & 65.0 & 11.85 & 25.2 & 2.0 & 3.2 & 0.138 \\
\hline & & & & & & & & & \\
6.0 & 30.126 & 92.0 & 10.3 & 48.0 & 9.1 & 15.6 & 1.0 & 1.3 & 0.137 \\
\hline \hline
\end{tabular}


a)

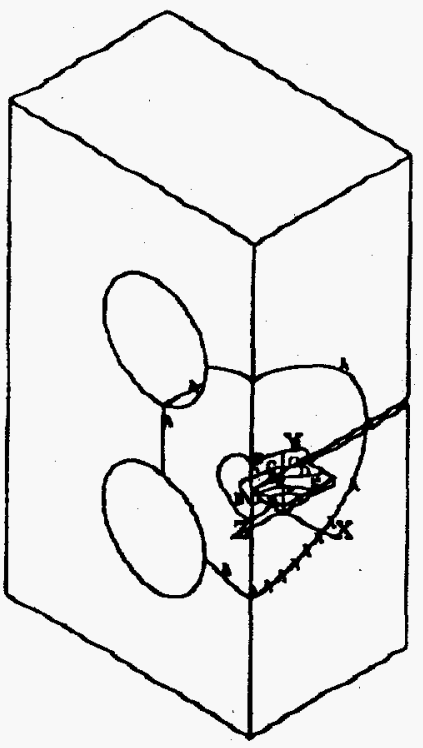

b)

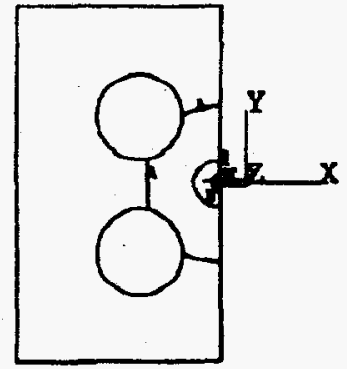

ANSYS $5.0 \mathrm{~A}$

c)

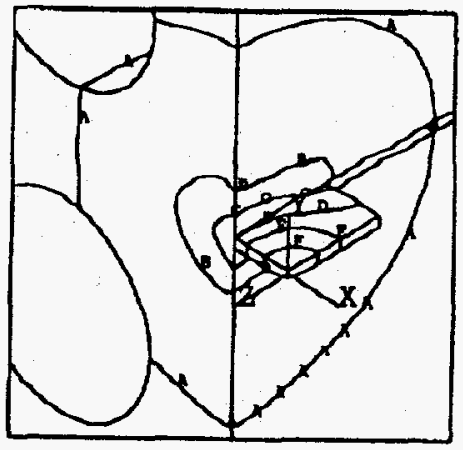

NODAL SOLUTION

TEMP

$S M N=24.326$

SNX $=47.984$

A $\quad=26.298$

B $\quad=30.241$

C $\quad=34.184$

D $=38.127$

$E \quad=42.069$

d)

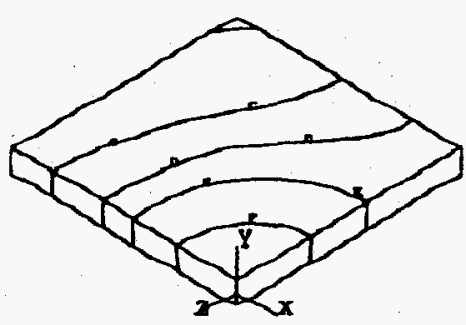

Figure 4.3. Temperature contours of a diamond crystal under Undulator A beam at $7 \mathrm{GeV}$ and $100 \mathrm{~mA}$. The figure shows (a) $1 / 4$ of the entire structure crystal-heat-sink, (b) one half of the end view (at reduced scale, (c) a close-up view around the crystal, and (d) a perspective view of 1/4 of the crystal alone. The values of the isotherms are indicated with letters, SMX amd SMN are the maximum and minimum temperatures, respectively. The crystal was assumed to have (111) orientation and was set to diffract the first harmonic at $6 \mathrm{keV}\left(\mathrm{K}=1.644\right.$, Bragg angle $\left.=30.126^{\circ}\right)$. A heat transfer coefficient of $1 \mathrm{~W} / \mathrm{cm}^{2}$ was applied to the surface of the channels. The GaIn layer was not included in this model, and, instead an ideal contact (i.e. no contact thermal resistance) was assumed between the crystal and the heat sink. 
a)

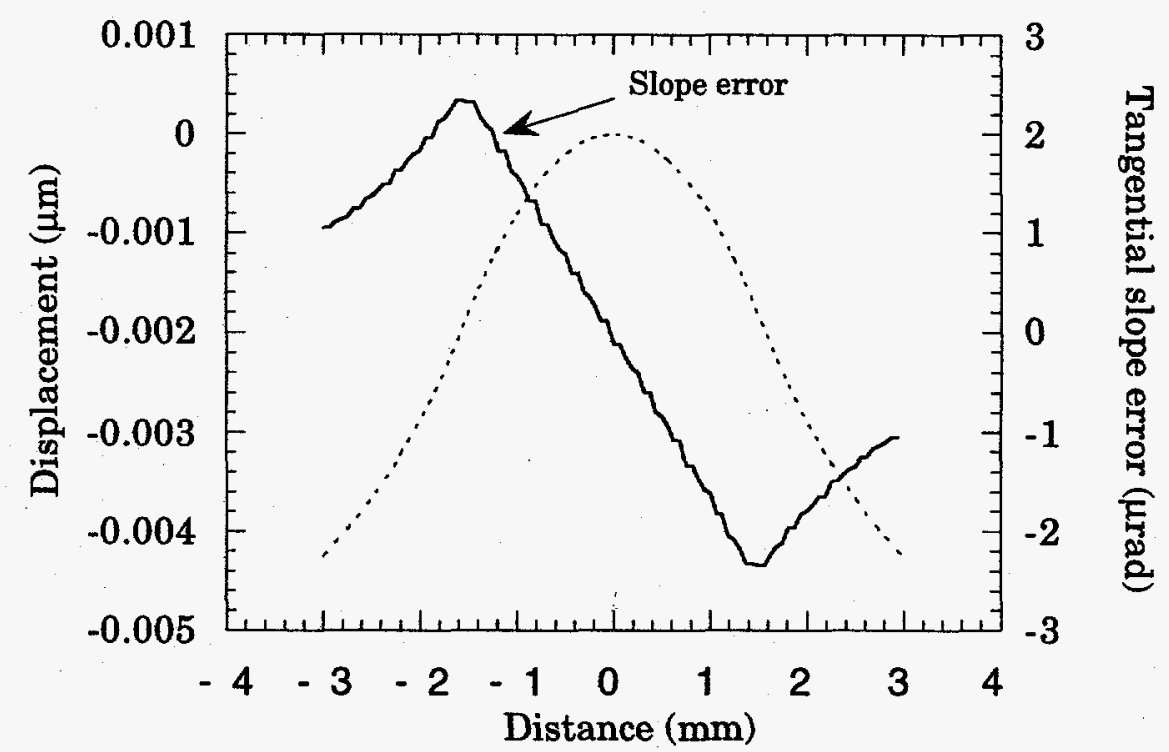

b)

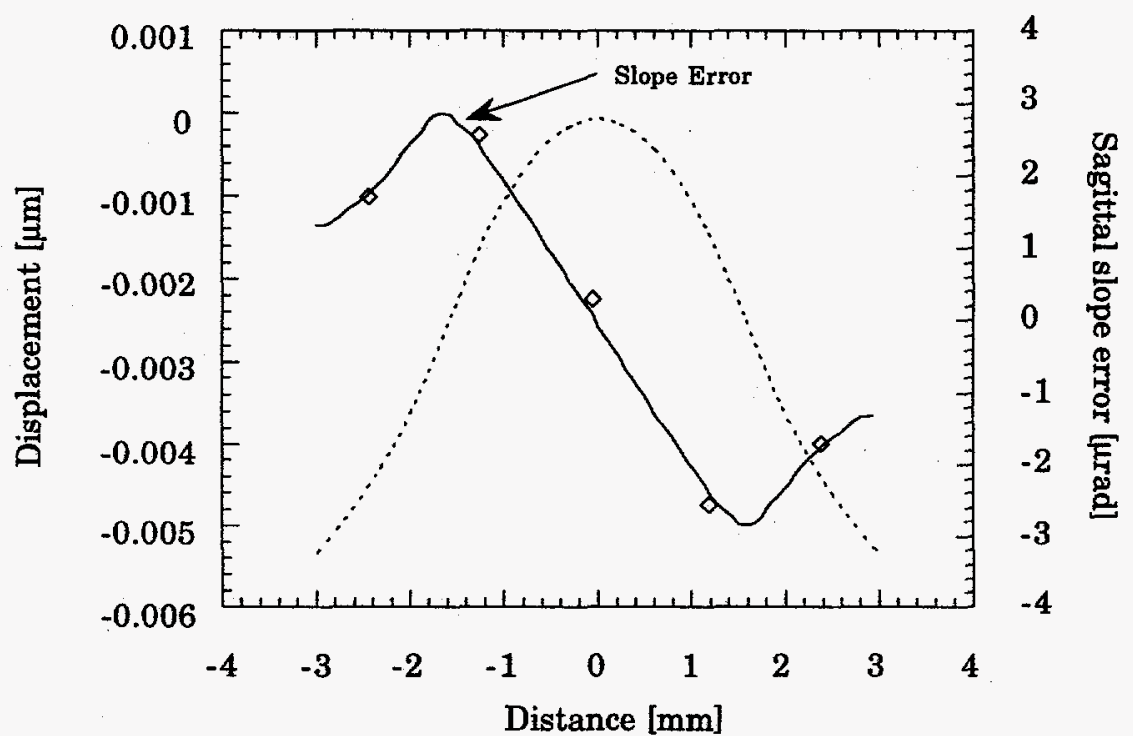

Figure 4.4. Displacement and slope error profiles along the crystal's axis in the (a) tangential and (b) sagittal directions, on the surface of a diamond crystal under Undulator A beam at a ring energy of $7 \mathrm{GeV}$ and a current of $100 \mathrm{~mA}$. The crystal $(0.3-\mathrm{mm}$ thick) has (111) orientation and was set to diffract the first harmonic at $6 \mathrm{keV}\left(\mathrm{k}=1.644\right.$, Bragg angle $\left.=30.126^{\circ}\right)$. No filters or windows were considered in the calculations. (The "stairs" on the curves are due to numerical error.) 

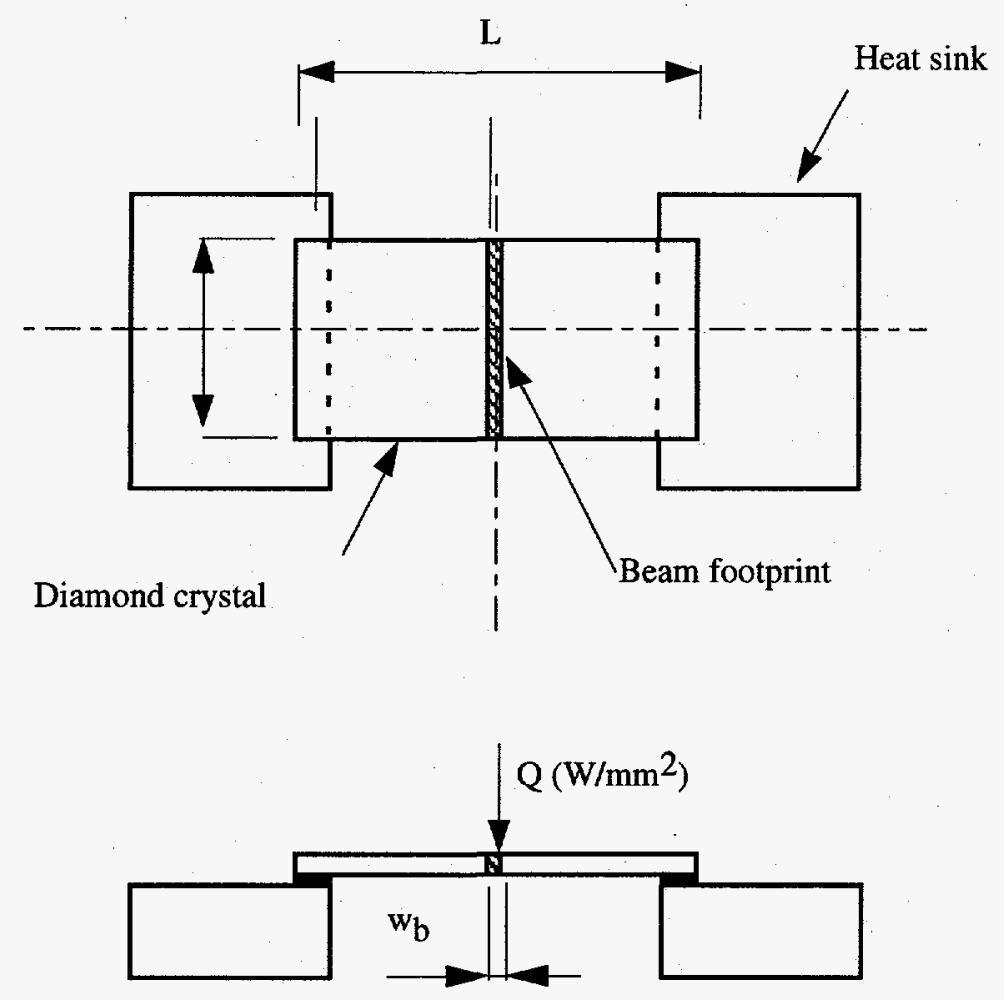

Figure 4.5. A side-cooled thin crystal with the vertical slit opening wider than the crystal dimension will avoid the sharp temperature gradient along the beam direction, thereby reducing the slope error (in this direction) to a minimum. This, of course, will result in a slight increase of the sagittal slope error compared with a smaller beam and the same crystal size. 


\section{SUMMARY AND APS RESEARCH PLANS}

No attempt is made in this report to produce a list of "pros" and "cons" on the use of diamonds as high heat load monochromators, although such information is dispersed throughout the text. The reason for this is that it is difficult to generically weigh each of the advantages or disadvantages - that is too dependent on the requirements of the particular science to be performed at the beamlines. The purpose of this manuscript is to provide the researcher with some basic properties of diamonds (and a set of references). In addition we have tried to highlight some of the principal differences in the use of diamonds for monochromators as compared to silicon, a familiar monochromator material, and where appropriate to point out some of the problems associated with the use of diamonds that as of yet do not have completely satisfactory solutions.

There is no doubt that the thermal and mechanical properties of diamonds make it an ideal candidate for high heat flux x-ray monochromators. Although the current difficulties in the procurement of high quality single-crystal diamonds may be considered an impediment to their routine use, perhaps the primary factor that must be considered when choosing diamonds as monochromating crystals is whether the loss of a factor of two in the flux when using diamond (as compared with Si (111)) is acceptable for a particular scientific program. In some instances, this loss of flux can be compensated for by the potential of using the transmitted beam through the diamond monochromator for other experiments, as has been proposed by the Troika beamline at the ESRF. This is only one example of the many variables that need to be weighed in the decision making process.

Diamonds with the (400) planes parallel to the large surface are more readily available. Unfortunately, the loss of flux when using (400) diamonds crystals is simply too large to tolerate, and, therefore for a majority of applications, [400] oriented platelets should be considered unacceptable as monochromating crystals. The [400] plates can be oriented to diffract $\mathrm{x}$-rays from the asymmetrical (111) planes in a Laue geometry, however the reduction of flux from the Laue geometry and the narrower energy bandwidth cannot be compensated for by the asymmetrical aspect of the reflection over any appreciable energy range.

Good quality diamonds of the required size $(8 \mathrm{~mm} \times 8 \mathrm{~mm}$ is probably the required to have adequate surface area available to remove the deposited heat from the APS undulator beam) are difficult to obtain in a consistent fashion.

Procedures for assuring strain-free mounting while maintaining good thermal contact with the cooled substrate is an area where more work needs to be done. The use of the surface tension of liquid metals to perform this task may be adequate, however other approaches need to be explored.

To summarize, our current program on the use of diamonds for high heat load monochromator has lead us to investigate the following areas:

(i) development of sources of good diffraction diamonds

(ii) measurements of the boundary heat transfer conductance between $\mathrm{Cu} / \mathrm{GaIn} /$ diamond

(iii) HHL testing of those diamonds we now have in hand

(iv) FEA and analytical modeling of diamonds subjected to HHL synchrotron beams

(v) methods of attachment of diamonds to substrates 


\section{ACKNOWLEDGEMENTS}

The authors would like to thank Andreas Freund for very useful discussions on diamond mounting techniques using liquid gallium, Patricia Fernandez and Ali Khounsary for their comments on this manuscript and Susan Picologlou for her editorial assistance. In addition, we would like to thank Michael Hart for the use of his jet-cooled mount for the diamond tests made at CHESS with the APS/CHESS prototype undulator and for pointing out the utility of expressing the Darwin width in terms of temperatures. This work was supported by the Department of Energy under Contract No. W-31-109-ENG-38. 


\section{REFERENCES}

1. S. Sharma, L. E. Berman, J. B. Hastings, and M. Hart, "Adaptive Optics for High Power Beamlines Using Diamond Crystal Monochromators," SPIE 1739: High Heat Flux Engineering, $604-614,1992$.

2. J. D. Stephenson, "A Choice of Diamond Single Crystals for First SR-(Undulator-) Monochromators," Phys. Stat. Sol A134, p 373, 1992.

3. A. M. Khounsary, R. K. Smither, and S. Davey, "Diamond Monochromator for High Heat Flux Synchrotron X-ray Beams," SPIE 1739: High Heat Flux Engineering, p629, 1992.

4. A. K. Freund, "Experience with Diamond Monochromators," Thermal Management of Xray Optical Components for Synchrotron Radiation Workshop at Argonne National Laboratory, as part of The International Conference on Synchrotron Radiation Instrumentation, Stony Brook NY, USA (1994); "Diamond Single Crystals: The Ultimate Monochromator Material for High Power X-Ray Beams," Opt. Eng., 34, 432-440, 1995.

5 L. E. Berman, J. B. Hastings, D. P. Siddons, M. Koike, V. Stojanoff, and M. Hart, "Diamond Crystal X-ray Optics for High-Power-Density Synchrotron Radiation Beams," Nuc. Inst. Meths. Phys. Res. A 329, p 555-563 (1993). The authors' estimate of the highest power fwhm $(19.9 \mu \mathrm{rad})$ based upon the change in the peak amplitude of the rocking curve has been replaced in Table 1.1 with the fwhm $(27.5 \mu \mathrm{rad})$ as measured from the authors' Fig. 4.

6. L. E. Berman and M. Hart, "Preserving the High Finesse of X-ray Undulator Beams from Perfect Water-Jet-Cooled Diamond Monochromators," Nuc. Inst. Meths. Phys. Res. A334, 617-620 (1993).

7. J. Als-Neilsen, A. K. Freund, and G. Grubel, "Diamond Crystal Monochromator Performance under Full Load from ESRF Undulator", ESRF Newsletter 16, 9-10 (Jan., 1993).

8. T. Ishikawa, private communications.

9. In order to achieve the expected total power and peak power density of an APS or SPring-8 beam it is necessary to doubly focus one of the existing high power wiggler beams. This necessarily produces a strongly convergent beam incident on the first crystal (located at the focus) and therefore a strongly divergent beam at the second crystal. This severely limits the information that can be obtained on the beam walk and beam spreading due to thermal and mounting distortions. Typically, only the beam throughput is measured.

10. R. C. Blasdell, A. T. Macrander, and W. K. Lee, "A Ray-Tracing Study of Inclined Double-Crystal Monochromators," Nucl. Instr. Meths. Phys. Res. A347, 327-330 (1994).

11. A. K. Freund, "Recent Results of High Heat Load Crystal Optics Experiments at the ESRF," SPIE 1997: High Heat Load Engineering II, 208-222 (1993).

12. L. Assoufid and D. M. Mills, "Thermal and Structural Analysis for a Diamond Monochromator Subjected to the APS Undulator A X-ray Beam," presented at the 
Workshop on the Thermal Management of X-ray Optical Components for Synchrotron Radiation, July 14-15, 1994, Argonne National laboratory.

13. J. Wilks and E. Wilks, Properties and Applications of Diamond, Butterworth-Heinemann Ltd., Boston (1991).

14. J. E. Field ed., The Properties of Diamond, Academic Press Limited, New York (1979).

15. W. Kaiser and W. L. Bond,"Nitrogen, A Major Impurity in Common Type I Diamond," Phys. Rev. 115, 857 (1959).

16. H. Holloway, K. C. Hass, M. A. Tamor, T. R. Anthony, and W. F. Banholzer, "Isotopic Dependence of the Lattice Constant of Diamond," Phys. Rev. B44, 7123 (1991).

17. Y.S. Touloukian, R.W. Powell, C.Y. Ho and P.G. Klemens, Thermophysical Properties of Matter, Vols. 2 and 13, IFI/Plenum, New York (1970).

18. J. W. Vandersande, "Thermal Conductivity of Natural-Isotope Diamond," pp. 33-35 in Properties and Growth of Diamond, G. Davies, ed., INSPEC, London (1994).

19. K. Haruna and H. Maeta, "Thermal Expansion of Synthetic Diamond Single Crystals at Low Temperatures," Diamond and Related Materials 2, 859-861 (1993).

20. H. J. McSkimin and P. Andreatch, Jr., "Elastic Moduli of Diamond as a Function of Pressure and Temperature," J. Appl. Phys. 43(7), 2944-2948 (1972).

21. U. Schumacher and R. Nolte, "Local Crystal Lattice Curvature Measurements for BentCrystal Spectrometers," Rev. Sci. Instrum. 61, 121 (1990).

22. R. K. Smither, G. A. Forster, D. H. Bilderback, M. Bedzyk, K. Finkelstein, C. Henderson, J. White, L. E. Berman, P. Stefan, and T. Oversluizen, "Liquid Gallium Cooling of Silicon Crystals in High Intensity Photon Beams," Rev. Sci. Instrum. 60, 1486-1492 (1989).

23. J. Als-Nielsen, A. K. Freund, M. Wulff, M. Hanfland, and D. Hausermann, "Performance of Diamond as X-ray Monochromator under Very High Heat Flux in a Synchrotron Beam," Nuc, Inst. Methods B94, 348-350, 1994.

24. M. Hart, Notes from the Inter-CAT Technical Working Group: September 19, 1994.

25. The diamond was cleaned between the second and third measurements in order to test whether the apparent pits were real. It is also possible that water or some other fluid accumulated in the pits but was not completely removed, resulting in the disappearance of the pits in the third set of optical measurements. In this case, the prior two measurements of the etch rate (which agree) might be correct.

26. B. W. Batterman and H. Cole, "Dynamical Diffraction of X-rays by Perfect Crystals," Rev. Mod. Phys 36, 681-717 (1964).

27. W. H. Zachariasen, Theory of X-ray Diffraction in Crystals, John Wiley \& Sons, Inc., New York (1945). 
28. T. Hon, W. Kiszenick, and B. Post, "Accurate Lattice Constants from Multiple Reflection Measurements II. Lattice Constants of Germanium, Silicon, and Diamond," J. Appl. Cryst. 8, 457-458, 1975.

29. Richard Deslattes and Albert Henins, "X-ray to Visible Wavelength Ratios," Phys. Rev. Letts, 31, 972-975, 1973.

30. R. Dejus, ANL, unpublished information, 1994.

31. Jens Als-Nielsen, A. K. Freund, G. Grubel, J. Linderholm, M. Nielsen, M. Sanchez del Rio, J.P.F. Sellschop, "Multiple Station Beamline at an Undulator X-ray Source," Nucl. Inst. and Meth. B 94, 306, 1994.

32. See for example A Guide to Neutron Research Facilities at the ILL, Herma Blank and Bernd Mair, eds., Institut Max von Laue - Paul Langevin, Grenoble France, 1988 or other descriptions of ILL beamline layouts.

33. ANSYS-A general purpose finite element analysis program, Rev. 5.0.a, Swanson Analysis System, Inc., Houston, PA 15342, USA.

34. H. Yamaoka, A.K. Freund, J. Holmberg, M. Rossat, M.. Wulff, M. Hanfland, W-K. Lee, D. M. Mills, and S. Rogers, "Experience from a Cryogenically Cooled Diamond Crystal Monochromator," submitted for publication to Nuclear Instruments and Methods.

35. Hitoshi Yamaoka, Kiyotaka Ohtomo, and Tetsuya Ishikawa, "Diamond Crystal Monochromator in a SPring-8 Undulator Beamline", Rev. Sci. Instrum. 66, 2116-2118, 1995. 


\section{Appendix A: Thermal Properties of Diamond}

Table A1 gives suggested values of the thermal conductivity, $\mathrm{k}$, of type I, IIa, and IIb diamond with the natural isotope concentration $\left(98.93 \%{ }^{12} \mathrm{C}, 1.07 \%{ }^{13} \mathrm{C}\right)$ as a function of temperature, T. 17 Columns 2, 3, and 7 are suggested literature average values from 1970.17 Columns 3,5, and 6 are from a 1994 reveiw of recent experimental data. 18

Table A2 gives suggested values of the thermal expansion coefficient.

Table A1. Suggested values of the thermal conductivity of diamond.

\begin{tabular}{|c|c|c|c|c|c|c|}
\hline \multirow{2}{*}{$\begin{array}{c}\mathrm{T} \\
{[\mathrm{K}]}\end{array}$} & \multicolumn{6}{|c|}{$\mathrm{k}[\mathrm{W} / \mathrm{cm}-\mathrm{K}]$} \\
\hline & Type I & Several Ia & Type Ia & Best IIa & $\begin{array}{l}\text { Isotop. } \\
\text { pure }\end{array}$ & Type IIb \\
\hline 10.0 & 1.42 & $1-2$ & 3.24 & 2.0 & & 2.07 \\
\hline 11.0 & 1.82 & & 4.09 & & & 2.63 \\
\hline 12.0 & 2.28 & & 5.10 & & & 3.29 \\
\hline 13.0 & 2.81 & & 6.20 & & & 4.02 \\
\hline 14.0 & 3.39 & & 7.45 & & & 4.87 \\
\hline 15.0 & 4.03 & & 8.77 & & & 5.77 \\
\hline 16.0 & 4.72 & & 10.2 & & & 6.75 \\
\hline 18.0 & 6.27 & & 13.5 & & & 8.90 \\
\hline 20.0 & 8.00 & & 17.1 & & & 11.4 \\
\hline 25.0 & 13.1 & & 27.4 & & & 18.5 \\
\hline 30.0 & 19.0 & & 39.5 & & & 26.9 \\
\hline 35.0 & 24.9 & & 52.5 & & & 35.6 \\
\hline 40.0 & 29.7 & & 66.7 & & & 44.6 \\
\hline 45.0 & 33.2 & & 80.2 & & & 53.0 \\
\hline 50.0 & 35.6 & & 93.0 & & & 59.6 \\
\hline 60.0 & 37.5 & & 113.0 & & & 68.0 \\
\hline 70.0 & 37.1 & & 120.0 & & & 69.1 \\
\hline 80.0 & 35.3 & & 117.0 & & & 65.9 \\
\hline 90.0 & 32.8 & & 110.0 & & & 60.3 \\
\hline 100.0 & 30.1 & $12-52$ & 100.0 & 125 & - & 54.5 \\
\hline 150.0 & 19.5 & & 60.5 & & & 32.6 \\
\hline 200.0 & 14.2 & $10-30$ & 40.4 & 55 & 75 & 22.6 \\
\hline 250.0 & 11.1 & & 29.7 & & & 17.1 \\
\hline 273.2 & 10.0 & & 26.3 & & & 15.3 \\
\hline 300.0 & 9.00 & $5-18$ & 23.1 & 25 & 32 & 13.5 \\
\hline 350.0 & 7.58 & & 18.6 & & & 11.2 \\
\hline 400.0 & 6.52 & & 15.5 & & & 9.36 \\
\hline 450.0 & - & $4-12$ & - & 13 & 18 & - \\
\hline
\end{tabular}


Table A2. Suggested values of the linear thermal expansion, $\Delta \mathrm{L} / \mathrm{L} 293 \mathrm{~K}$, and the linear thermal expansion coefficient, $\alpha$, of diamond. ${ }^{17}$ The thermal expansion is claimed to be accurate to $\pm 7 \%$. The low temperature values of $\alpha$ are therefore of marginal significance. 19

\begin{tabular}{ccc}
\hline \hline $\mathrm{T}$ & $\begin{array}{c}\Delta \mathrm{L} / \mathrm{L} 293 \mathrm{~K} \\
\left(10^{-2}\right)\end{array}$ & $\begin{array}{c}\alpha \\
\left(10^{-6} / \mathrm{K}\right)\end{array}$ \\
\hline \hline 25 & -0.011 & -0.1 \\
50 & -0.012 & -0.06 \\
100 & -0.012 & 0.05 \\
150 & -0.011 & 0.2 \\
200 & -0.009 & 0.4 \\
250 & -0.005 & 0.7 \\
293 & 0.000 & 1.0 \\
350 & 0.008 & 1.5 \\
400 & 0.016 & 1.8 \\
500 & 0.037 & 2.3 \\
600 & 0.062 & 2.8 \\
700 & 0.093 & 3.2 \\
800 & 0.127 & 3.7 \\
900 & 0.166 & 4.0 \\
\hline \hline
\end{tabular}




\section{Appendix B: Structure Factors, Widths, and Reflectivities}

Calculations were done using the MAKE_PCSF program, which is a heavily modified version of the SHADOW program BRAGG. Unmodified atomic scattering factors are experimental values from the literature, Honl corrections are from the SHADOW code's internal tables. The Darwin width cited is a form that incorporates absorption and so will be slightly different than the zero absorption result usually given. The reflectivity curves are integrated numerically and so the range and step sizes are given. The errors will be largely dominated by the uncertainty in $f_{0}$, the Debye Waller amplitude factor (DWAF), and the Honl corrections and may amount to a percent or two in the value of the structure factor and as much as a percent or two in the results. The numerical integrations should be more accurate though this was not tested.

\section{Diamond (111)}

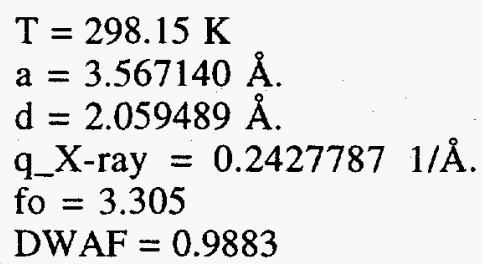

\begin{tabular}{|c|c|c|c|c|c|c|}
\hline Energy (keV) & 4.000 & 6.000 & 8.000 & 10.000 & 15.000 & 20.000 \\
\hline & & & & & & \\
\hline (electrons/atom) & 0.062 & 0.032 & 0.019 & 0.012 & 0.001 & -0.004 \\
\hline (electrons/atom) & 0.043 & 0.018 & 0.010 & 0.006 & 0.002 & 0.001 \\
\hline $\begin{array}{lll}\text { Kinematic Bragg } & \text { Angle } \\
\text { (deg.) }\end{array}$ & 48.809487 & 30.111385 & 22.102332 & 17.518251 & 11.576320 & 8.656181 \\
\hline $\begin{array}{l}\text { Dynamical Bragg } \\
\text { (deg.) }\end{array}$ & 48.814810 & 30.114073 & 22.104211 & 17.519709 & 11.577265 & 8.656883 \\
\hline Darwin Width $(\mu \mathrm{rad})$ & 72.14 & 36.28 & 25.30 & 19.63 & 12.69 & 9.42 \\
\hline$R_{\text {_max }}$ & 0.974 & 0.989 & 0.994 & 0.996 & 0.999 & 0.999 \\
\hline Delta theta $( \pm \mu \mathbf{r a d})$ & 300 & 150 & 100 & 80 & 60 & 40 \\
\hline dTheta $(\mu \mathbf{r a d})$ & 1.00 & 0.50 & 0.25 & 0.20 & 0.20 & 0.10 \\
\hline $\begin{array}{lll}\text { FWHM } & \text { R(theta }) & (\mu \mathrm{rad})\end{array}$ & 76.78 & 38.58 & 26.87 & 20.83 & 13.49 & 9.99 \\
\hline $\begin{array}{lll}\text { Integral } & R \text { (theta }) & (\mu \mathrm{rad})\end{array}$ & 90.16 & 46.41 & 32.60 & 25.42 & 16.53 & 12.27 \\
\hline FWHM $R^{\wedge} 2$ (theta) $(\mu$ rad) & 73.00 & 36.85 & 25.74 & 19.96 & 12.94 & 9.58 \\
\hline $\begin{array}{ll}\text { Integral } & R^{\wedge} 2(\text { theta }) \\
(\mu \mathrm{rad}) & \end{array}$ & 69.66 & 37.03 & 26.33 & 20.65 & 13.43 & 10.03 \\
\hline $\begin{array}{lll}\text { Delta } & \text { E }( \pm \mathrm{eV})\end{array}$ & 1.2 & 1.5 & 2.0 & 3.0 & 4.0 & 5.0 \\
\hline $\mathrm{dE}(\mathrm{eV})$ & 0.004 & 0.005 & 0.005 & 0.010 & 0.010 & 0.010 \\
\hline $\begin{array}{lll}\text { FWHM } & \text { R(E) } & (\mathrm{eV})\end{array}$ & 0.2688 & 0.3988 & 0.5292 & 0.6598 & 0.9866 & 1.3131 \\
\hline $\begin{array}{lll}\text { Integral } & R(E) & (\mathrm{eV})\end{array}$ & 0.3164 & 0.4795 & 0.6424 & 0.8087 & 1.2089 & 1.6094 \\
\hline $\begin{array}{lll}\text { FWHM } & R^{\wedge} 2(E) & (\mathrm{eV}) \\
\end{array}$ & 0.2552 & 0.3811 & 0.5071 & 0.6550 & 0.9450 & 1.2576 \\
\hline $\begin{array}{lll}\text { Integral } & R^{\wedge} 2(E) & (\mathrm{eV})\end{array}$ & 0.2437 & 0.3828 & 0.5188 & 0.6354 & 0.9852 & 1.3158 \\
\hline
\end{tabular}




\section{Si (111)}

$\mathrm{T}=298.15 \mathrm{~K}$

$\mathrm{a}=5.431054 \AA$

$\mathrm{d}=3.135620 \AA$

q_X-ray $=0.1594581 \quad 1 / \AA$

fo $=10.782$

$\mathrm{DWAF}=0.9884$

\begin{tabular}{|c|c|c|c|c|c|c|}
\hline Energy (keV) & 4.000 & 6.000 & 8.000 & 10.000 & 15.000 & 20.000 \\
\hline (electrons/atom) & 0.400 & 0.344 & 0.256 & 0.194 & 0.090 & 0.043 \\
\hline (electrons/atom) & 1.191 & 0.567 & 0.329 & 0.214 & 0.096 & 0.053 \\
\hline $\begin{array}{l}\text { Kinematic Bragg Angle } \\
\text { (deg.) }\end{array}$ & 29.621033 & 19.238876 & 14.307775 & 11.402751 & 7.573790 & 5.673079 \\
\hline $\begin{array}{l}\text { Dynamical Bragg Angle } \\
\text { (deg.) }\end{array}$ & 29.625202 & 19.241408 & 14.309612 & 11.404196 & 7.574735 & 5.673783 \\
\hline Darwin Width $(\mu \mathrm{rad})$ & 29.63 & 47.70 & 34.52 & 27.13 & 17.71 & 13.17 \\
\hline$R_{\text {_max }}$ & 0.805 & 0.901 & 0.941 & 0.961 & 0.982 & 0.990 \\
\hline Delta theta $( \pm \mu$ rad $)$ & 300 & 100 & 100 & 100 & 80 & 40 \\
\hline dTheta $(\mu \mathrm{rad})$ & 1.00 & 0.50 & 0.50 & 0.25 & 0.20 & 0.10 \\
\hline FWHM R(theta) ( $\mu$ rad) & 80.18 & 50.28 & 36.66 & 28.85 & 18.82 & 13.99 \\
\hline Integral $R($ theta $) \quad(\mu \mathrm{rad})$ & 75.77 & 51.79 & 40.47 & 33.09 & 22.45 & 16.73 \\
\hline FWHM $R^{\wedge} 2($ theta $) \quad(\mu r a d)$ & 66.17 & 45.27 & 34.14 & 27.22 & 17.94 & 13.37 \\
\hline $\begin{array}{ll}\text { Integral } & R^{\wedge} 2(\text { theta }) \\
(\mu \mathrm{rd}) & \\
\end{array}$ & 42.13 & 35.46 & 29.51 & 24.93 & 17.60 & 13.49 \\
\hline Delta E $( \pm \mathrm{eV})$ & 2 & 2 & 4 & 4 & 8 & 10 \\
\hline $\mathrm{dE}(\mathrm{eV})$ & 0.01 & 0.01 & 0.01 & 0.01 & 0.02 & 0.03 \\
\hline FWHM R(E) (eV) & 0.5642 & 0.8643 & 1.1494 & 1.4302 & 2.1233 & 2.8175 \\
\hline Integral $R(E) \quad(e V)$ & 0.5320 & 0.8973 & 1.2798 & 1.6293 & 2.5250 & 3.3903 \\
\hline FWHM $\quad R^{\wedge} 2(E) \quad(e V)$ & 0.4657 & 0.7780 & 1.0699 & 1.3494 & 2.0259 & 2.6933 \\
\hline Integral $\quad R^{\wedge} 2(E) \quad(e V)$ & 0.2963 & 0.6096 & 0.9256 & 1.2359 & 1.9854 & 2.7175 \\
\hline
\end{tabular}




\section{Ge (111)}

$\mathrm{T}=298.15 \mathrm{~K}$

$\mathrm{a}=5.657820 \AA$

$\mathrm{d}=3.266544 \AA$.

q_X-ray $=0.1530671 / \AA$

fo $=27.908$

DWAF $=0.9868$

\begin{tabular}{|c|c|c|c|c|c|c|}
\hline Energy (keV) & 4.000 & 6.000 & 8.000 & 10.000 & 15.000 & 20.000 \\
\hline (electrons/atom) & 0.072 & & & -2.098 & & \\
\hline$f^{\prime \prime} \quad$ (electrons/atom) & 3.098 & & & 0.622 & & \\
\hline $\begin{array}{lll}\text { Kinematic Bragg } & \text { Angle } \\
\text { (deg.) }\end{array}$ & 28.323610 & & & 10.939969 & & \\
\hline $\begin{array}{l}\text { Dynamical Bragg Angle } \\
\text { (deg.) }\end{array}$ & 28.332075 & & & 10.942770 & & \\
\hline Darwin Width ( $\mu$ rad) & 180.14 & & & 58.90 & & \\
\hline $\mathbf{R}$ max & 0.798 & & & 0.952 & & \\
\hline Delta theta $( \pm \mu \mathbf{r a d})$ & 700 & & & 200 & & \\
\hline dTheta $(\mu \mathrm{rad})$ & 2.00 & & & 0.50 & & \\
\hline FWHM R(theta) $(\mu \mathrm{rad})$ & 182.76 & & & 62.58 & & \\
\hline Integral R(theta) $(\mu \mathrm{r}$ a d $)$ & 171.66 & & & 70.64 & & \\
\hline FWHM $\quad R^{\wedge} 2($ theta $) \quad(\mu \mathrm{rad})$ & 150.05 & & & 58.69 & & \\
\hline $\begin{array}{l}\text { Integral } R^{\wedge} 2(\text { theta }) \\
(\mu \mathrm{rad})\end{array}$ & 94.23 & & & 52.39 & & \\
\hline Delta $\quad$ E $( \pm \mathrm{eV})$ & 5 & & & 12 & & \\
\hline $\mathrm{dE} \quad(\mathrm{eV})$ & 0.02 & & & 0.03 & & \\
\hline FWHM $\quad$ R(E) (eV) & 1.3560 & & & 3.2376 & & \\
\hline Integral $\mathbf{R}(\mathbf{E}) \quad$ (eV) & 1.2719 & & & 3.6694 & & \\
\hline FWHM $R^{\wedge} 2(E) \quad(e V)$ & 1.1136 & & & 3.0372 & & \\
\hline Integral $R^{\wedge} 2(E) \quad(e V)$ & 0.6990 & & & 2.7096 & & \\
\hline
\end{tabular}

$\mathrm{R} \max$

Delta theta

dTheta

FWHM R(theta)

Integral R(theta)

FWHM R^2(theta)

Integral $R^{\wedge}$ 2(theta)

Delta E

$\mathrm{dE}$

FWHM R(E)

Integral $R(E)$

FWHM R^2(E)

Integral $R^{\wedge} 2(E)$ maximum value of reflectivity curve

range of integration over angle

step size for angle integration

full width at half maximum of the reflectivity vs. angle curve

integral of the reflectivity vs. angle curve

full width at half maximum of the square of the reflectivity vs. angle curve

integral of the square of the reflectivity vs. angle curve

range of integration over energy

step size for energy integration

full width at half maximum of the reflectivity vs. energy curve integral of the reflectivity vs. energy curve

full width at half maximum of the square of the reflectivity vs. energy curve

integral of the square of the reflectivity vs. energy curve 


\section{Appendix C: Results of Absorption Calculations}

Table C1. Absorbed power for the first harmonic energies, symmetric diamond (111)

Bragg geometry.

\begin{tabular}{|c|c|c|c|}
\hline \hline \multirow{2}{*}{$\mathrm{E}_{1}[\mathrm{keV}]$} & \multicolumn{3}{|c|}{ Absorbed power [watts] } \\
\cline { 2 - 4 } & $\mathrm{t}=0.1 \mathrm{~mm}$ & $\mathrm{t}=0.3 \mathrm{~mm}$ & $\mathrm{t}=0.5 \mathrm{~mm}$ \\
\hline \hline 4.0000 & 46.94 & 78.390 & 98.580 \\
\hline 5.0000 & 50.08 & 87.632 & 109.43 \\
\hline 6.0000 & 49.30 & 91.948 & 114.69 \\
\hline 7.0000 & 45.96 & 91.164 & 114.73 \\
\hline 8.0000 & 41.028 & 85.788 & 109.62 \\
\hline 9.0000 & 35.153 & 76.712 & 99.768 \\
\hline 10.000 & 28.752 & 64.904 & 85.850 \\
\hline 11.000 & 21.460 & 49.892 & 67.144 \\
\hline 12.000 & 15.047 & 35.643 & 48.536 \\
\hline
\end{tabular}

Table C2. Absorbed power for the third harmonic energies, symmetric diamond (111) Bragg geometry.

\begin{tabular}{|c|c|c|c|}
\hline \multirow{2}{*}{$\mathrm{E}_{3}[\mathrm{keV}]$} & \multicolumn{3}{|c|}{ Absorbed power [watts] } \\
\cline { 2 - 4 } & $\mathrm{t}=0.1 \mathrm{~mm}$ & $\mathrm{t}=0.3 \mathrm{~mm}$ & $\mathrm{t}=0.5 \mathrm{~mm}$ \\
\hline \hline 12.000 & 78.388 & 127.28 & 157.22 \\
\hline 13.000 & 81.996 & 132.74 & 163.56 \\
\hline 14.000 & 85.076 & 137.19 & 168.75 \\
\hline 15.000 & 87.632 & 140.67 & 172.78 \\
\hline 16.000 & 89.648 & 143.26 & 175.68 \\
\hline 17.000 & 91.084 & 144.96 & 177.48 \\
\hline 18.000 & 91.948 & 145.87 & 178.09 \\
\hline 19.000 & 92.236 & 146.05 & 177.76 \\
\hline 20.000 & 91.968 & 145.56 & 176.52 \\
\hline
\end{tabular}


Table C3. Absorbed peak surface power density for the first harmonic energies, symmetric diamond (111) Bragg geometry.

\begin{tabular}{|c|c|c|c|}
\hline \hline \multirow{2}{*}{$\mathrm{E}_{1}[\mathrm{keV}]$} & \multicolumn{3}{|c|}{ Absorbed power [watts] } \\
\cline { 2 - 4 } & $\mathrm{t}=0.1 \mathrm{~mm}$ & $\mathrm{t}=0.3 \mathrm{~mm}$ & $\mathrm{t}=0.5 \mathrm{~mm}$ \\
\hline \hline 4.0000 & 7.3978 & 11.464 & 14.000 \\
\hline 5.0000 & 6.6179 & 11.002 & 13.206 \\
\hline 6.0000 & 5.6203 & 10.227 & 12.325 \\
\hline 7.0000 & 4.6152 & 9.1228 & 11.230 \\
\hline 8.0000 & 3.6939 & 7.8056 & 9.8830 \\
\hline 9.0000 & 2.8771 & 6.4032 & 8.3436 \\
\hline 10.000 & 2.1784 & 5.0101 & 6.6962 \\
\hline 11.000 & 1.5109 & 3.5938 & 4.9185 \\
\hline 12.000 & 0.9855 & 2.4027 & 3.3370 \\
\hline \hline
\end{tabular}

Table C4. Absorbed peak surface power density for the third harmonic energies, symmetric diamond (111) Bragg geometry.

\begin{tabular}{|c|c|c|c|}
\hline \hline \multirow{2}{*}{$E_{3}[\mathrm{keV}]$} & \multicolumn{3}{|c|}{ Absorbed power [watts] } \\
\cline { 2 - 4 } & $\mathrm{t}=0.1 \mathrm{~mm}$ & $\mathrm{t}=0.3 \mathrm{~mm}$ & $\mathrm{t}=0.5 \mathrm{~mm}$ \\
\hline \hline 12.000 & 3.8192 & 5.9258 & 7.3189 \\
\hline 13.000 & 3.7781 & 5.7743 & 7.0825 \\
\hline 14.000 & 3.7281 & 5.6229 & 6.8529 \\
\hline 15.000 & 3.6669 & 5.4714 & 6.6408 \\
\hline 16.000 & 3.5953 & 5.3216 & 6.4168 \\
\hline 17.000 & 3.5082 & 5.1664 & 6.1908 \\
\hline 18.000 & 3.4088 & 5.0109 & 5.9700 \\
\hline 19.000 & 3.2966 & 4.8529 & 5.7485 \\
\hline 20.000 & 3.1731 & 4.6924 & 5.5263 \\
\hline \hline
\end{tabular}


Table C5. Absorbed power and power density for the first harmonic energies in the Laue geometry. $E_{1}$ is the energy of the first harmonic, teff is the effective thickness $\left(=t / \cos \left(\theta_{\text {Bragg }}\right)\right), P_{d}$ is the absorbed power density, and $\mathrm{P}$ is the absorbed power.

\begin{tabular}{|c|c|c|c|c|}
\hline $\begin{array}{c}\mathrm{E}_{1} \\
(\mathrm{keV})\end{array}$ & $\begin{array}{c}\theta_{\mathrm{Bragg}} \\
(\mathrm{deg} .)\end{array}$ & $\begin{array}{c}\mathrm{t}_{\mathrm{eff}} \\
(\mathrm{mm})\end{array}$ & $\begin{array}{c}\mathrm{P}_{\mathrm{d}} \\
\left(\mathrm{W} / \mathrm{mm}^{2}\right)\end{array}$ & $\begin{array}{c}\mathrm{P} \\
\text { (watts) }\end{array}$ \\
\hline \hline 4.0000 & 48.826 & 0.15190 & 6.89 & 50.30 \\
\hline 5.0000 & 37.026 & 0.12526 & 7.34 & 41.70 \\
\hline 6.0000 & 30.120 & 0.11561 & 6.47 & 32.90 \\
\hline 7.0000 & 25.475 & 0.11077 & 5.35 & 25.20 \\
\hline 8.0000 & 22.108 & 0.10794 & 4.27 & 19.00 \\
\hline 9.0000 & 19.545 & 0.10611 & 3.30 & 14.10 \\
\hline 19.000 & 17.523 & 0.10487 & 2.46 & 10.20 \\
\hline 11.000 & 15.885 & 0.10397 & 1.69 & 6.80 \\
\hline 12.000 & 14.531 & 0.10330 & 1.10 & 4.30 \\
\hline \hline
\end{tabular}

Table C6. Absorbed power and power density for the third harmonic energies on the Laue geometry. E3 is the energy of the first harmonic, $t_{\text {eff }}$ is the effective thickness $\left(=t / \cos \left(\theta_{\mathrm{Bragg}}\right)\right), \mathrm{P}_{\mathrm{d}}$ is the absorbed power density, and $\mathrm{P}$ is the absorbed power.

\begin{tabular}{|c|c|c|c|c|}
\hline $\begin{array}{c}E_{3} \\
(\mathrm{keV})\end{array}$ & $\begin{array}{c}\theta_{\text {Bragg }} \\
(\mathrm{deg})\end{array}$ & $\begin{array}{c}\mathrm{t}_{\mathrm{eff}} \\
(\mathrm{mm})\end{array}$ & $\begin{array}{c}\mathrm{P}_{\mathrm{d}} \\
\left(\mathrm{W} / \mathrm{mm}^{2}\right)\end{array}$ & $\begin{array}{c}\mathrm{P} \\
(\text { watts })\end{array}$ \\
\hline \hline 12.000 & 14.531 & 0.10330 & 8.36 & 40.900 \\
\hline 13.000 & 13.392 & 0.10279 & 8.31 & 39.800 \\
\hline 14.000 & 12.419 & 0.10240 & 8.10 & 38.100 \\
\hline 15.000 & 11.579 & 0.10208 & 7.81 & 36.200 \\
\hline 16.000 & 10.847 & 0.10182 & 7.44 & 34.000 \\
\hline 17.000 & 10.201 & 0.10161 & 7.05 & 31.800 \\
\hline 18.000 & 9.6291 & 0.10143 & 6.65 & 29.600 \\
\hline 19.000 & 9.1179 & 0.10128 & 6.24 & 27.400 \\
\hline 20.000 & 8.6584 & 0.10115 & 5.83 & 25.300 \\
\hline \hline
\end{tabular}

